\title{
DEVELOPMENT AND APPLICATIONS OF NOVEL NANOSTRUCTURED MATERIALS IN WATER TREATMENT: ADSORPTION, FILTRATION, AND REACTION
}

\author{
A Dissertation \\ presented to \\ the Faculty of the Graduate School \\ at the University of Missouri-Columbia
}

In Partial Fulfillment

of the Requirements for the Degree

Doctor of Philosophy

By:

Mohammed M. Numaan

Dr. Maria M. Fidalgo, Dissertation Supervisor

MAY 2021 
The undersigned, appointed by the dean of the Graduate School, have examined the dissertation entitled

\author{
DEVELOPMENT AND APPLICATIONS OF NOVEL \\ NANOSTRUCTURED MATERIALS IN WATER TREATMENT: \\ ADSORPTION, FILTRATION, AND REACTION \\ presented by \\ Mohammed M. Numaan \\ a candidate for the degree of Doctor of Philosophy in Environmental Engineering and \\ hereby certify that, in their opinion, it is worthy of acceptance.
}

Dr. Maria M. Fidalgo

Dr. Baolin Deng

Dr. Inniss Enos

Dr. Chung-Ho Lin 


\section{DEDICATION}

This dissertation is dedicated to my father's soul, my mother, and my sisters.

For their endless love, support, and encouragement. 


\section{ACKNOWLEDGEMENTS}

I would like to sincerely thank my advisor, Dr. Fidalgo, for her continuous guidance and support, and, especially, for her confidence in me throughout this study. I also would like to express my appreciation and gratitude to all the members in my dissertation committee, Dr. Baolin Deng, Dr. Enos Innis, and Dr. Chung-Ho Lin, for providing their knowledge, experience, inspirations and encouragement.

To all my friends, thank you for your understanding and encouragement in my all moments. Your friendship makes my life a wonderful experience. I cannot list all the names here, but you are always on my mind. 


\section{Table of Contents}

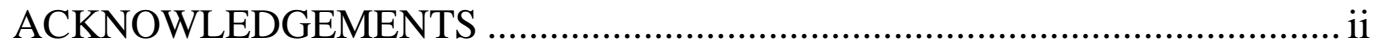

Table of Contents ......................................................................................... ii

Table of Figures...................................................................................... viii

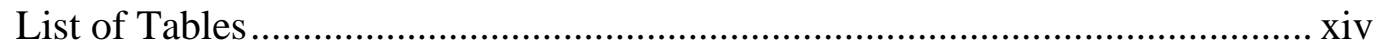

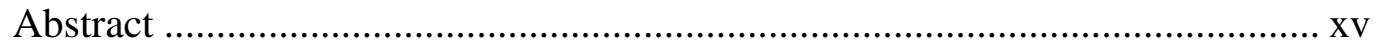

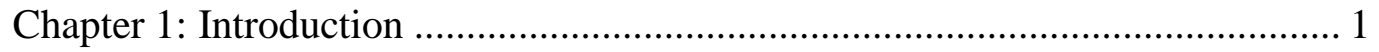

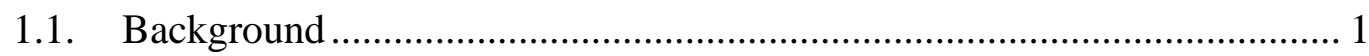

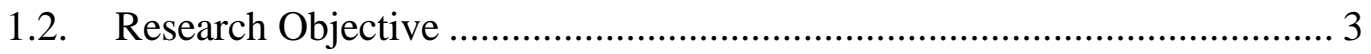

Chapter 2: Literature review.................................................................... 5

2.1. Introduction to Nanotechnology ...................................................... 5

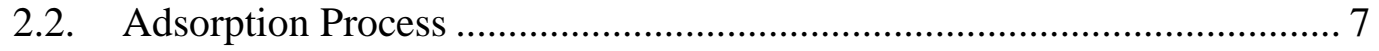

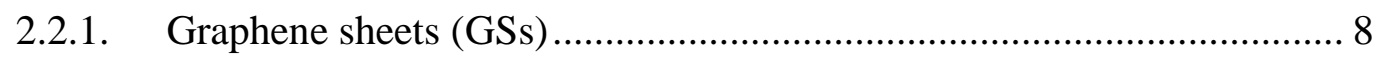

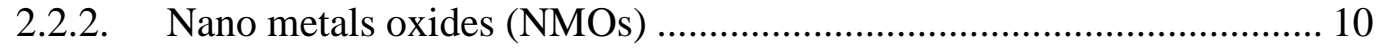

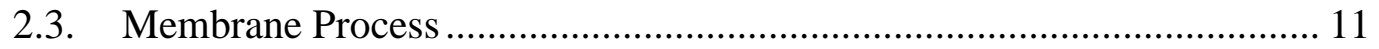

2.3.1. Nanocomposite membranes ......................................................... 13

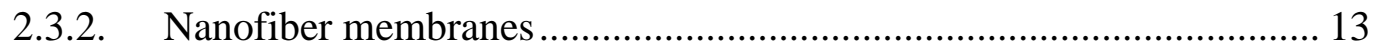

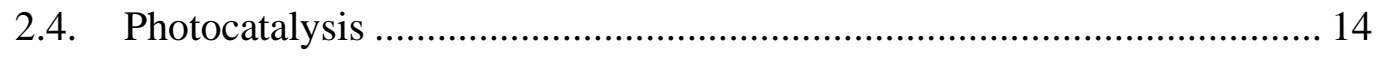


2.4.1. Titanium dioxide $\left(\mathrm{TiO}_{2}\right)$ nanoparticles photocatalyst for advanced oxidation technology: 15

2.5. Arsenic (As); characteristics and occurrences in aqueous solutions ....... 17

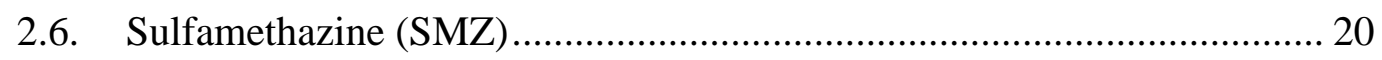

Chapter 3: Synthesis of Iron Oxide/Graphene Oxide Composite Materials as

Adsorbents for As(V) Removal. 23

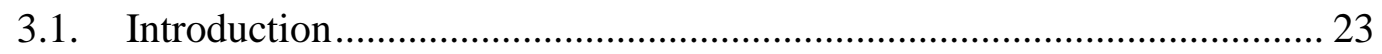

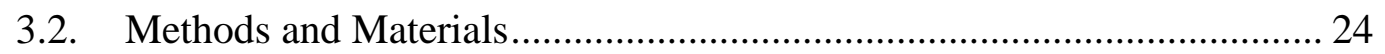

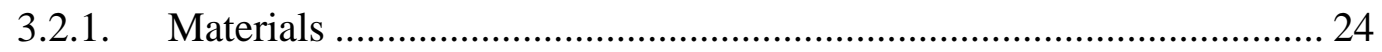

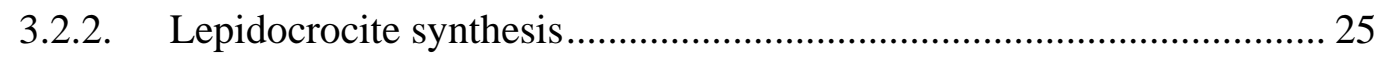

3.2.3. Graphene Oxide (GO) Synthesis ................................................ 25

3.2.4. Composite Material Production ....................................................... 26

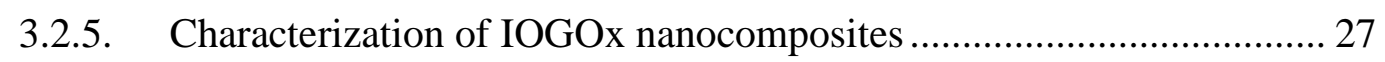

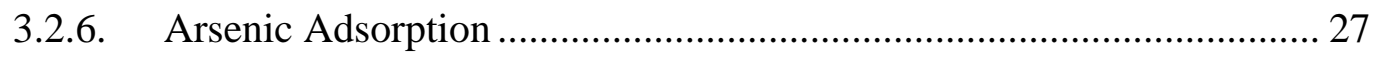

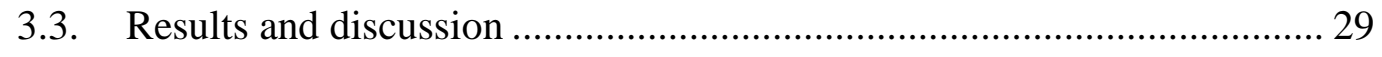

3.3.1. Characterization of iron oxide (IO), graphene oxide (GO), and IOGO(x)

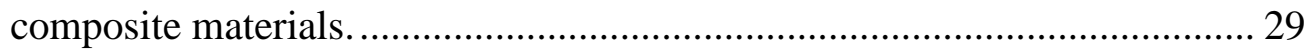

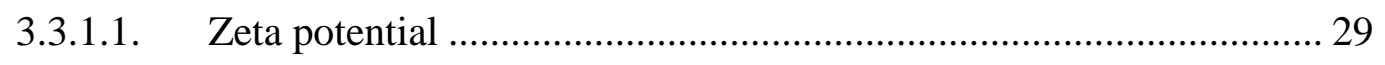

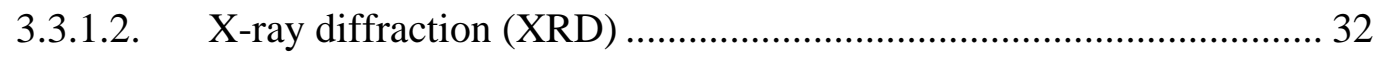

3.3.1.3. Scanning Electron Microscopy (SEM) images .............................. 33 


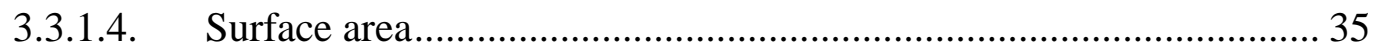

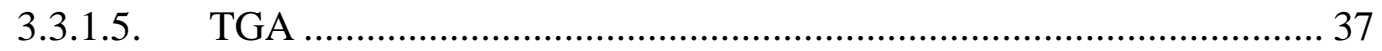

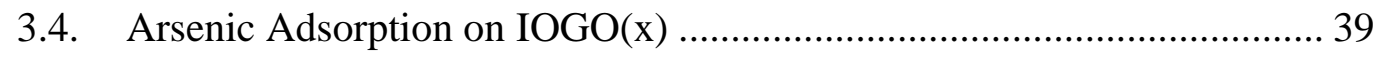

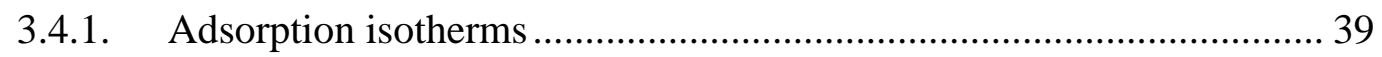

3.4.2. Adsorption kinetics of $\mathrm{As}(\mathrm{V})$ on the composite materials.................... 42

3.5. Adsorption mechanism of $\mathrm{As}(\mathrm{V})$ on IOGO composite adsorbent ............. 44

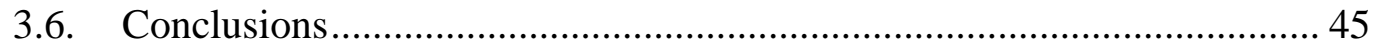

Chapter 4: Asymmetric Tubular Membranes coated by Multi-layers of

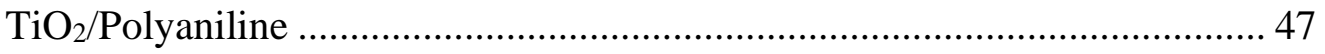

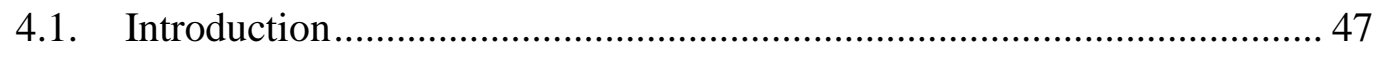

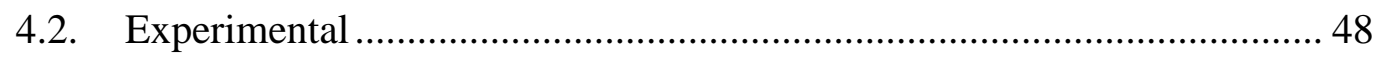

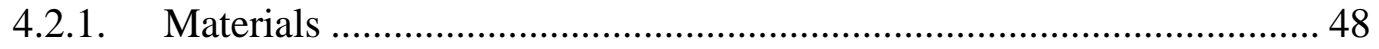

4.2.2. Preparation and coating of tubular microfiltration ceramic membrane 49

4.2.3. Experimental system setup …………………............................... 50

4.2.4. Structural characteristics of Membrane .................................................. 51

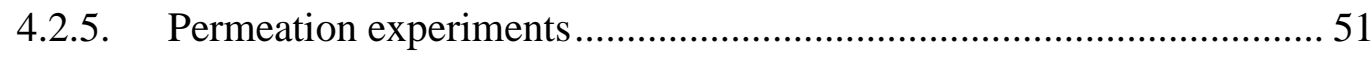

4.2.5.1. Clean Water Flux (CWF) and Membrane Permeability (Pm) .......... 51

4.2.5.2. PEG vs. TOC Calibration curve..................................................... 52

4.2.5.3. Membrane fouling ......................................................................... 52

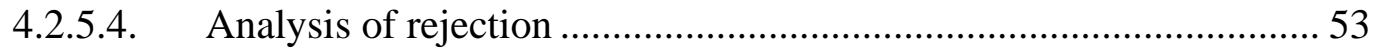


4.3. Results and Discussion

4.3.1. Membranes characterizations............................................................. 53

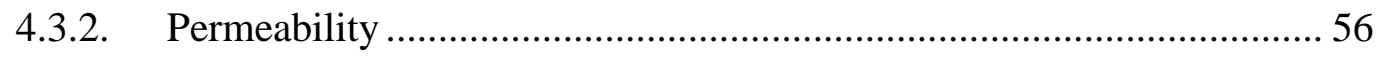

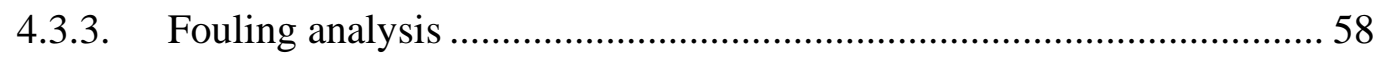

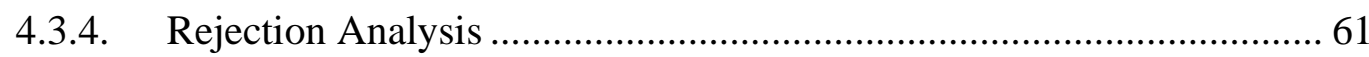

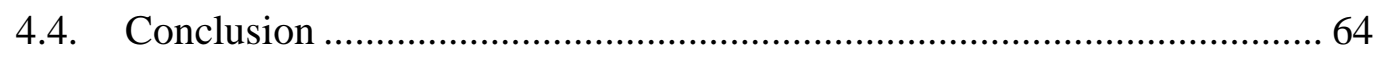

Chapter 5: Enhanced Degradation of Sulfamethazine by using Advance

Oxidation Processes (AOPs) Combined with Membrane Filtration. ............. 66

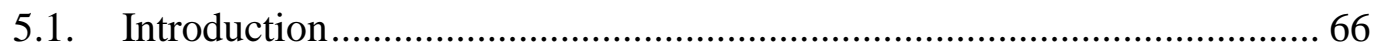

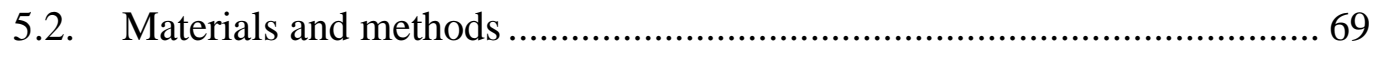

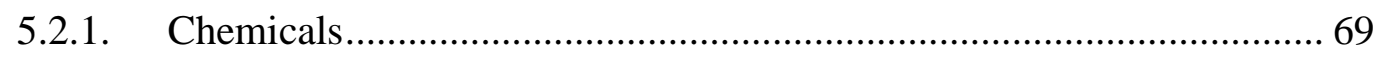

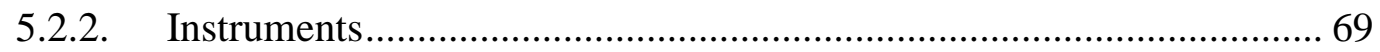

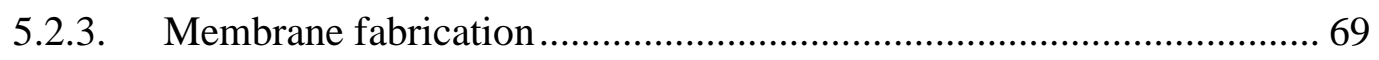

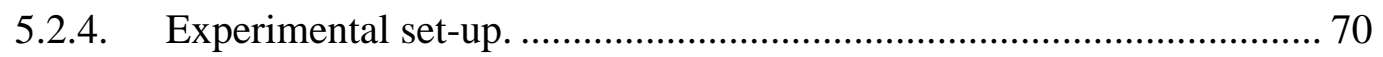

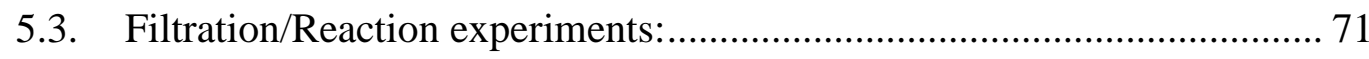

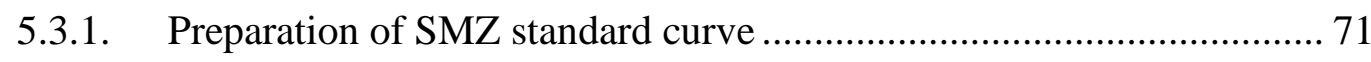

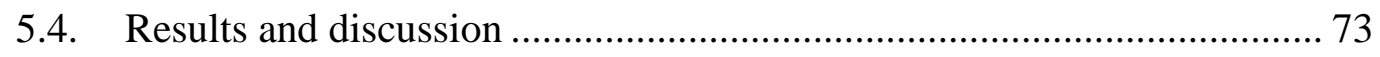

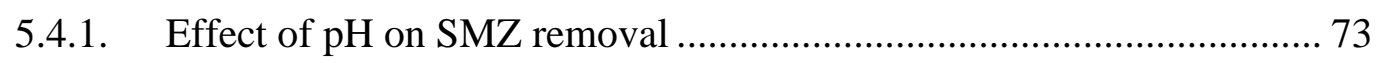

5.4.2. Effect of SMZ concentration .............................................................. 77

5.4.3. Effect of HA presence on SMZ degradation......................................... 79 
5.4.4. Effect of ionic strength on the SMZ degradation.............................. 82

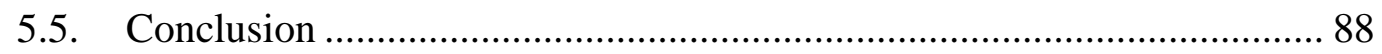

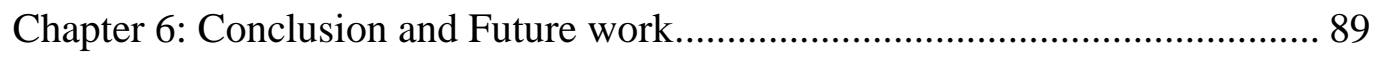

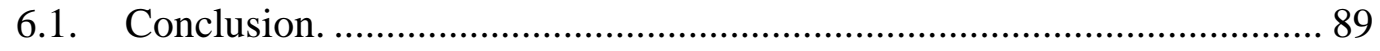

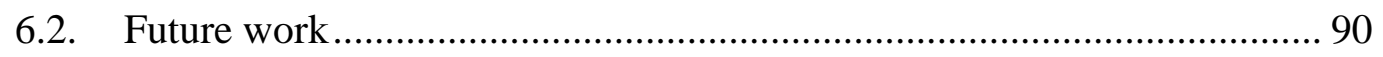

6.2.1. Investigating the performance of the coated tubular ceramic membranes by multilayers of $\mathrm{TiO}_{2}$ for removal a group of antibiotics contaminants. ...... 91

6.2.2. Degradation Mechanisms Analysis of Photocatalytic ........................ 91

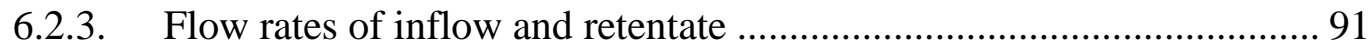

6.2.4. Time of illumination by UV-light.............................................. 91

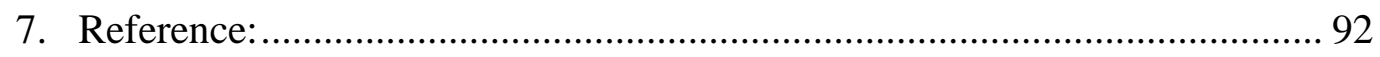

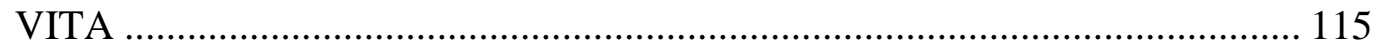




\section{Table of Figures}

Figure

$\underline{\text { Page }}$

2.1. Schematic of nanotechnology used in wastewater treatment

6

2.2. Schematic structure of graphene oxide ................ 9

2.3. Schematic of membrane filtration .................... 12

2.4. Pollutant degradation after irradiation $\mathrm{TiO}_{2}$ particle by

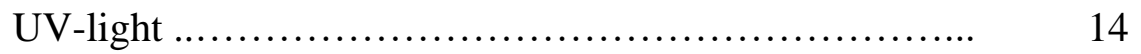

2.5. Removal pollutants by $\mathrm{TiO}_{2}$ particle surfaces ........... 16

2.6. Eh-pH diagram for aqueous As species in the system As$\mathrm{O}_{2}-\mathrm{H}_{2} \mathrm{O}$ at $25^{\circ} \mathrm{C}$ and 1 bar total pressure $\ldots \ldots \ldots \ldots \ldots \ldots . . . . . \quad 18$

$\begin{array}{ll}\text { 2.7. Distribution of arsenate and arsenite as a function of } \mathrm{pH} . . & 19\end{array}$

2.8. Chemical structure of sulfamethazine.................. 20

2.9. Distribution of cationic $\left(\mathrm{SMZ}^{+}\right)$, neutral and zwitterionic $\left(\mathrm{SMZ}^{0}\right)$, and anionic $\left(\mathrm{SMZ}^{-}\right)$species in aqueous solution

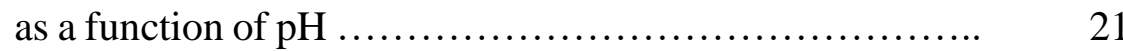

3.1. Schematic of the synthesis process of IOGO composites ... 27

3.2. Zeta potentials of lepidocrocite and GO before sintering and IO and IOGOx composites after sintering, suspended in ultrapure water at different values of $\mathrm{pH} \ldots \ldots \ldots \ldots \ldots . . . . . \quad 30$

3.3. Point of zero charges of hematite and IOGOx composites.. 32 
3.4. XRD-diagrams for the studied adsorbents (a) before and (b) after sintering

3.5. SEM images for: (a)IOGO5; (c)IOGO10; (e)IOGO15; (g)IOGO20; (i)IOGO25 before sintering, and (b)IOGO5; (d)IOGO10; (f)IOGO15; (h)IOGO20; (j)IOGO25 after sintering

3.6. The relationship between percentage of total pores and pore size for: (a)IOGO5; (b)IOGO10; (c)IOGO15; (e)IOGO20; (d)IOGO25 composites

3.7. Surface area and total pore volume of fabricated composites after sintering, as a function of graphene content

3.8. TGA curves Lepidocrocite, IOGOx, and GO in the air atmosphere

3.9. $\mathrm{As}(\mathrm{V})$ adsorption isotherms at $\mathrm{pH} 7$ and $\mathrm{IS}(1 \mathrm{mM})$ of the hematite control sample and $\mathrm{IOGO}(\mathrm{x})$ composites

3.10. $A s(V)$ adsorption kinetic curves of (a) hematite control sample and (b-f) IOGO(5-25) composite materials,

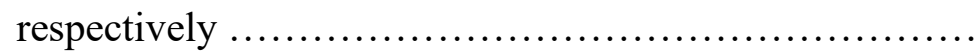

4.1. The dimensions of the used membrane (a) the length (b) the cross-section

4.2. Schematic of the experimental setup and the membrane module 
4.3. SEM images for the membranes surfaces of (a) uncoated and (b) 1-layer of $\mathrm{TiO} 2$ (c) 2-layers (d) 3-layers (e) 4 -layers ......................................... 54

4.4. SEM images for the membranes cross-sections of (a) uncoated (b) 1-layer of $\mathrm{TiO}_{2}$, and (c) 2-layers (d) 3-layers (e) 4-layers .............................. 55

4.5. The relationship between flux and the number of coating layers .................................................

4.6. The relationship between permeability and the number of

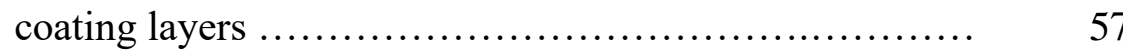

4.7. TMP evolution vs time using (a) PEG (MW $20 \mathrm{kDa}$ )

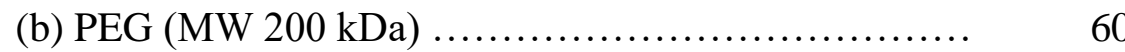

4.8. Comparison between the TMP of all the used membranes before and after using ................................. 61

4.9. Rejection evolution vs time using PEG (MW 20,000 Da)

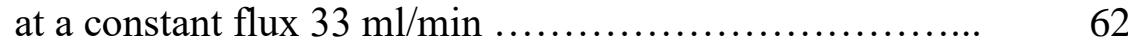

4.10. Rejection evolution vs time using PEG (MW 200,000 Da) at a constant flux $33 \mathrm{ml} / \mathrm{min}$

5.1. Tubular ceramic supports: (a) side view (b) cross-sectional view

5.2. Schematic of experimental setup for integrated direct contact membrane filtration-UV photolysis treatment ..... 
5.3. Influence of $\mathrm{pH}$ on the removal of SMZ, 5ppm initial [SMZ] in the absence of UV light: (a) permeate (b) feed ...

5.4. Percentage removal $\left(\mathrm{C} / \mathrm{C}_{0}\right)$ vs time in the absence of UV light (5ppm initial [SMZ]): (a) permeate (b) feed .......... 74

5.5. Influence of $\mathrm{pH}$ on the removal of SMZ, $10 \mathrm{ppm}$ initial [SMZ] in the absence of UV light: (a) permeate (b) feed ...

5.6. Percentage removal $\left(\mathrm{C} / \mathrm{C}_{\mathrm{o}}\right)$ vs time in the absence of $\mathrm{UV}$ light (10 ppm initial [SMZ]): (a) permeate (b) feed .........

5.7. Influence of $\mathrm{pH}$ on the removal of SMZ, 5ppm initial [SMZ] under UV light: (a) permeate (b) feed .............

5.8. Percentage removal $\left(\mathrm{C} / \mathrm{C}_{\mathrm{o}}\right)$ vs time in the absence of $\mathrm{UV}$ light (5 ppm initial [SMZ]): (a) permeate (b) feed .........

5.9. Influence of the $\mathrm{pH}$ on the removal of $\mathrm{SMZ}, 5 \mathrm{ppm}$ and 10ppm initial [SMZ] under of UV light: (a) permeate (b) feed

5.10. Percentage removal $\left(\mathrm{C} / \mathrm{C}_{\mathrm{o}}\right)$ vs time in the absence of $\mathrm{UV}$ light (5 ppm and $10 \mathrm{ppm}$ initial [SMZ]): (a) permeate (b) feed

5.11. Influence of $\mathrm{pH}$ on the removal of $\mathrm{SMZ}, 1 \mathrm{ppm} \mathrm{HA}$ and $5 \mathrm{ppm}[\mathrm{SMZ}]$ in the absence of UV light (a) permeate (b) feed

5.12. Percentage removal $\left(\mathrm{C} / \mathrm{C}_{0}\right)$ vs time in the absence of $\mathrm{UV}$ light (1ppm HA and 5ppm [SMZ]) (a) permeate (b) feed... 
5.13. The influence of the $\mathrm{pHs}$ solution on $1 \mathrm{ppm} \mathrm{HA}$ and $5 \mathrm{ppm}$ [SMZ] vs time under of UV light (a) permeate (b) feed .....

5.14. The normalized 1ppm HA and 5ppm [SMZ] plotted vs time under of UV light (a) permeate (b) feed...............

5.15. The influence of different levels of $\mathrm{NaNO}_{3} 1,10,100 \mathrm{mM}$ and $\mathrm{NaCl}^{-} 10 \mathrm{mM}$ on an initial 5ppm [SMZ] solution at pH5 vs time at the absence of UV light (a) permeate (b) feed........................................................

5.16. Percentage removal $\left(\mathrm{C} / \mathrm{C}_{0}\right)$ vs time in the absence of UV light (different levels of $\mathrm{NaNO}_{3}$ 1,10,100 $\mathrm{mM}$ and $\mathrm{NaCl}^{-} 10 \mathrm{mM}$ on an initial 5ppm [SMZ] solution at pH5).

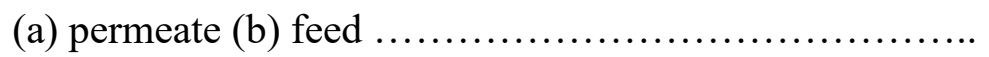

5.17. The influence of $\mathrm{NaNO}_{3} 1,10,100 \mathrm{mM}$ on an initial $5 \mathrm{ppm}$ [SMZ] solution at $\mathrm{pH} 5$ vs time under of UV-light (a) permeate (b) feed

5.18. The normalized of $\mathrm{NaNO}_{3} 1,10,100 \mathrm{mM}$ on an initial 5ppm [SMZ] solution at $\mathrm{pH} 5$ vs time under of UV-light (a) permeate $(\mathbf{b})$ feed..........................................

5.19. Normalized pressure-time profiles vs time at absence of UV light (a) 5ppm [SMZ] (b) 10ppm [SMZ] (c) 1ppm HA and 5ppm [SMZ] (d) 1,10,100 $\mathrm{mM} \mathrm{NaNO}_{3}$ at pH5 (e) 10 $\operatorname{ppm}\left[\mathrm{NaCl}^{-}\right]$and $5 \mathrm{ppm}[\mathrm{SMZ}]$ at $\mathrm{pH} 5 \ldots \ldots \ldots \ldots \ldots \ldots \ldots$ 
5.20. Normalized pressure-time profiles vs time under UV light

(a) 5ppm [SMZ] (b) 10ppm [SMZ] (c) 1ppm HA and 5ppm

[SMZ] (d) $1,10,100 \mathrm{mM} \mathrm{NaNO} 3$ at pH5 (e) $10 \mathrm{ppm}$

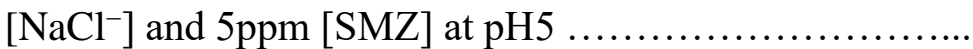




\section{List of Tables}

$\underline{\text { Table }}$

$\underline{\text { Page }}$

2.1. Physical properties of arsenic ...................... 17

2.2. Physicochemical characteristics of SMZ ............... 21

3.1. The surface area of graphene oxide, hematite, lepidocrocite, and IOGOx composites before and after sintering

3.2. The initial concentrations of $\mathrm{As}(\mathrm{V})$ in adsorption isotherm experiments

3.3. Comparison of maximum $\mathrm{As}(\mathrm{V})$ adsorption capacity ......

3.4. Summary of model parameters and correlation coefficients for Langmuir and Freundlich isotherms removal of As(v) by hematite and IOGOx

3.5. Adsorption capacity normalized by specific surface area ..

3.6. Fitting parameters of $\mathrm{As}(\mathrm{v})$ adsorption kinetics on $\operatorname{IOGO}(\mathrm{x})$ and hematite

4.1. Shows the flux decreasing ratios of all membranes ........

5.1. Uses and disadvantages of some water and wastewater technologies

5.2. The gradient conditions for HPLC method 


\begin{abstract}
Nanomaterial-based adsorbents and photocatalysts have gained increasing attention in the applications of water and wastewaters treatment due to their attractive properties and strong adsorption capabilities for a wide range of contaminants. The objective of this study is to fabricate, characterize, and apply a group of nanomaterials to adsorb, remove, and degrade contaminants in water. An iron oxide/graphene oxide (IOGOx) composite was evaluated for the effective As(V) removal from the aqueous solutions. Adsorption on hematite and $\operatorname{IOGO}(25 \%)$ at $25^{\circ} \mathrm{C}$, $\mathrm{pH} 7$, and $1 \mathrm{mM} \mathrm{NaNO}_{3}$ showed $76 \%$ of $\mathrm{As}(\mathrm{V})$ removal within the first 5 minutes and $95 \%$ at 40 minutes. As(V) adsorption efficiency increased with increase GO loading; while, this efficiency decreased at high IO loading. Kinetic data was a well fitted to pseudo-second-order, so those results suggested that the surface complexation is the main mechanism for $\mathrm{As}(\mathrm{V})$ adsorption on the surface of adsorbents. All composites were able to reduce the $\mathrm{As}(\mathrm{V})$ concentration below $10 \mu \mathrm{gL}^{-1}$ that is the recommended maximum permissible concentration of $\mathrm{As}(\mathrm{V})$ in drinking water by World Health Organization (WHO).

A novel technique for coating a group of tubular ceramic membranes by multilayers of $\mathrm{TiO}_{2}$ was used to reduce the pore size of the support membranes and to improve their performances. Polyethylene glycol was used as a model molecule to compare and examine the coated membranes in the evolution of fouling and rejection over time. The SEM images showed that $\mathrm{TiO}_{2}$ covered the surface and the active layer; therefore, the permeable path sizes decreased gradually. The results of flux and permeability of membranes confirmed the success of the coating. The transmembrane pressure (TMP)
\end{abstract}


increased with each coating layer, while the rejection of the membrane was improved. After cleaning the membranes with ultrapure water, TMP of all the membranes decreased until reaching to the clean material values. In this study, 4-layers coated membrane showed its ability to be used many times after cleaning with ultrapure water.

The coated membranes were tested for a novel technique that combines filtration and advanced oxidation processes for sulfamethazine (SMZ) removal and degradation using a continues flow reactor and under different conditions. The system included a a membrane module with UV-light. In the absence of UV-light, the results showed no significant removal of $5 \mathrm{ppm}$ and $10 \mathrm{ppm}$ of SMZ during the experiment. Under UV-light, the system was able to significantly degrade $5 \mathrm{ppm}$ and $10 \mathrm{ppm}$ of SMZ from the solution, particularly, at $\mathrm{pH} 2$. In the presence of humic acid (HA), there was a significant increase in the SMZ degradation with all $\mathrm{pH}$ values by decreasing the required time to degrade SMZ in clean water. When $\mathrm{NO}_{3}{ }^{-}$or $\mathrm{Cl}^{-}$ions were added, an increase in the degradation rate of SMZ was observed in the presence of $\mathrm{NO}_{3}{ }^{-}$in comparison with clean water, but $\mathrm{Cl}^{-}$led to a decrease in the SMZ degradation under UV light. The process could be applied for SMZ removal from the water in water treatment plants. 


\section{Chapter 1: Introduction}

\subsection{Background}

Water is considered an abundant natural resource either as groundwater, deep and shallow, or as surface water, lakes, rivers, oceans, etc. Moreover, water is one of the most important and integral aspects of daily life for every human being, such as clothing, food, etc. On the other hand, the population around the world is expected to reach approximately 9.7 billion by 2050 and 11.2 billion by 2100 ; therefore, the water scarcity will become a critical for environmental agencies and governments in the next few decades [1].

Because of the enormous growth of the human population nowadays, the demands for vital resources has been increasing day by day. have been increasing day by day. This increasing demand will threaten the availability and quality of water resources by discharging a wide range of toxic contaminants into surrounding environments. Among all the activities that have attracted the attention of environmental experts is industrialization. Most of the industrial wastewater includes toxic and exotic pollutants to the environment, such as dyes, pharmaceutical wastes, etc. [2]. As a result, those hazardous contaminants will accumulate with time on the sediments in water bodies or stay dissolved. Therefore, they will threaten human health by the direct contact between them and human bodies by drinking polluted water, swimming, etc.[3]. The World Health Organization (WHO) recently announced that one person out of three people around the world does not have access to safe drinking water [4], and 10-20 million people were every year estimated to die due to waterborne diseases [5]. As a result, the demand for supplying clean water has 
become an urgent necessity around the world. Thus, strict environmental laws had been issued to enforce the industries to achieve the allowable concentrations of pollutants for discharging by using efficient treatment technologies [6].

To achieve this goal, many water and wastewater treatment technologies have been used to overcome the levels of the harmful contaminants in wastewater effluent, such as antibiotics, heavy metal ions, pesticides, etc. Most of the recent traditional water and wastewater technologies need to develop to be economical, effective, and more stable for this purpose [7]. Therefore, all the environmental researchers nowadays have been modifying or developing some materials and methods to be cost-effective, efficient, and reliable to achieve significant results for producing safe drinking water and reusing the wastewater.

One of these techniques is conventional technologies such as bio-reduction, chemical precipitation, and sorption, which are widely used to remove the heavy metals from groundwater [8]. However, those methods have several drawbacks and disadvantages, such as adding reagents requirements, producing high quantities of toxic sludge, and achieving low sorption capacity. As a result, Therefore, those disadvantages will result in secondary contamination and require unusual conditions, such as anaerobic and carbonate-free [9]. On the other hand, physicochemical treatment processes such as coagulation and flocculation are considered ineffective in removing the endocrinedisrupting chemicals (EDCs) and pharmaceutical compounds [10].

Nowadays, scientists around the world are interested in and adapting the advanced nanotechnologies more than the traditional methods because they provide a chance to develop and invent economically feasible and environmentally stable treatment 
technologies. Because of their unique properties such as fast diffusion, high reactivity, high specific surface area, and strong sorption, nano-metal oxides (NMOs) such as iron oxide, graphene oxide, titanium dioxide, etc. have been recently used to develop novel materials for water and wastewater treatment processes such as adsorption materials, membranes, nano-catalysts, etc. [11].

\subsection{Research Objective}

The overall objective of this work is to apply for advances in nanotechnology and nanoparticle manipulation to fabricate better porous and high surface area materials for water treatment. The research effort is focused on inorganic (metal oxide) nanoparticles to create adsorbents, filters, and catalysts. For example, an iron oxide/graphene oxide composite material was created with different weight ratios of iron oxide (IO) and graphene oxide (GO). Those composites will be used as adsorbents for $\mathrm{As}(\mathrm{V})$ removal. Subsequently, a novel nano-coating method was used to obtain titanium dioxide $\left(\mathrm{TiO}_{2}\right) /$ polyaniline asymmetric ceramic membranes: the rejection characteristics of the membrane's layers were investigated as well as its application as a catalyst for the degradation of organic compounds.

This document includes five chapters; chapter two presents a comprehensive literature review about nanotechnology and its uses. Then, a general introduction about their types and their recent applications in water and wastewater treatment processes, such as adsorption, membrane, and photocatalysis treatment technologies.

Chapter three describes the synthesis of iron oxide/graphene oxide (IOGO) composite materials, using different GO content $(5,10,15,20,25 \mathrm{wt} \%)$. The surface area, surface charge, surface morphology characteristics of the composite adsorbents were 
studied to explore their morphological structure and to interpret the adsorption mechanism for adsorbing arsenic(V) and removing it from the aqueous solution. In this objective, novel hematite nanoparticles will be fabricated through using eco-friendly rout and applied to assess for As(V) removal.

In chapter four, a group of tubular ceramic membranes was coated by multi-layers of $\mathrm{TiO}_{2} /$ Polyaniline by the sol-gel method. Their permeability was studied by calculating the means of permeation experiments at a constant inflow of $33 \mathrm{ml} / \mathrm{min}$ and outflow 22.5 $\mathrm{ml} / \mathrm{min}$. Fouling and rejection experiments were also carried out to investigate the membrane antifouling by using different molecular weight (20 and $200 \mathrm{kDa})$ of polyethylene glycol (PEG) as a model. This chapter shows a novel method to coat the tubular membrane by multiple layers of $\mathrm{TiO}_{2}$ to assess this approach for decreasing the fouling and rejection by using different molecular weights of PEG as a feed solution.

Finally, chapter five presents the development of an advanced oxidation process (AOP) coupled with a membrane technology to apply it for sulfamethazine (SMZ) degradation. A LED UV strip was used to achieve this task and fixed inside a tubular membrane reactor, used in chapter four, on a distance. This research will assess the efficiency of the coated tubular membrane by $\mathrm{TiO}_{2} / \mathrm{PANI}$ for sulfamethazine degradation. 


\section{Chapter 2: Literature review}

\subsection{Introduction to Nanotechnology}

In ancient times, the history of civilizations have always been named depending on the kinds of materials used during the age such as, Bronze Age, Iron Age, Stone Age, etc. while the current age is the age of Nanomaterials [12]. The nano-dimensions materials were first invented by Nario Tanisguchi in 1974 when he described the instrument with a tolerance of less than a micron [13]. Recently, nanotechnology played a key role in addressing the fundamental issues of energy, health, and water [14], but the most emphasis has been currently placed on the remediation and treatment of water and wastewater [15].

Nanotechnology has been developed by scientific researchers for providing a way to create new structures that work at an atomic level [16]. This technology aims to use nanosized particles $(1-100 \mathrm{~nm})$ and their unique characteristics in numerous applications, such as engineering, medicine, and sciences [17]. Nanotechnologies have shown incredible potential due to their unique properties for wastewater remediation [18]. Nanotechnologies include wide ranges of nanomaterials such as colloids, films, nanotubes, particles, etc. At this scale, the materials show different physical, chemical, and biological characteristics comparing with their bulky counterparts [19]. Because of their high ratios of surface area to volume, nanomaterials have been used as excellent adsorbents for removal various kinds of contaminants. Also, the high ratios of surface area to volume enable catalyzation of the surfaces of nanomaterials to degrade, oxidize, and reduce the pollutants. As a result, the large surface to volume ratio is considered the most significant feature that makes 
nanomaterials suitable for applicaton in water and wastewater treatment i.e., adsorption, membrane, photocatalysis processes, as shown in figure 2.1. [20]. Thus, nanostructures have completely different electrical, magnetic, and optical properties, greater reactivity with contaminants faster chemical processes [21]. All these characteristics of nanomaterials make nanotechnology attractive in terms of eliminating pollutants and contaminants and making it as a proper technology for water and wastewater treatment [22].

Nanotechnological water and wastewater treatment processes can be classified to three major groups (a) pollution prevention (b) sensing and detection (c) treatment and remediation [23]. The benefits of using nanotechnology has been observed in environmental and industrial area, but this technology might be useful in future by bringing helpful innovations to solve specific issues [24]. Therefore, the multiple benefits of large infrastructure of nanotechnology have made nanotechnology more reliable for solving the emerging issues in the world [20].

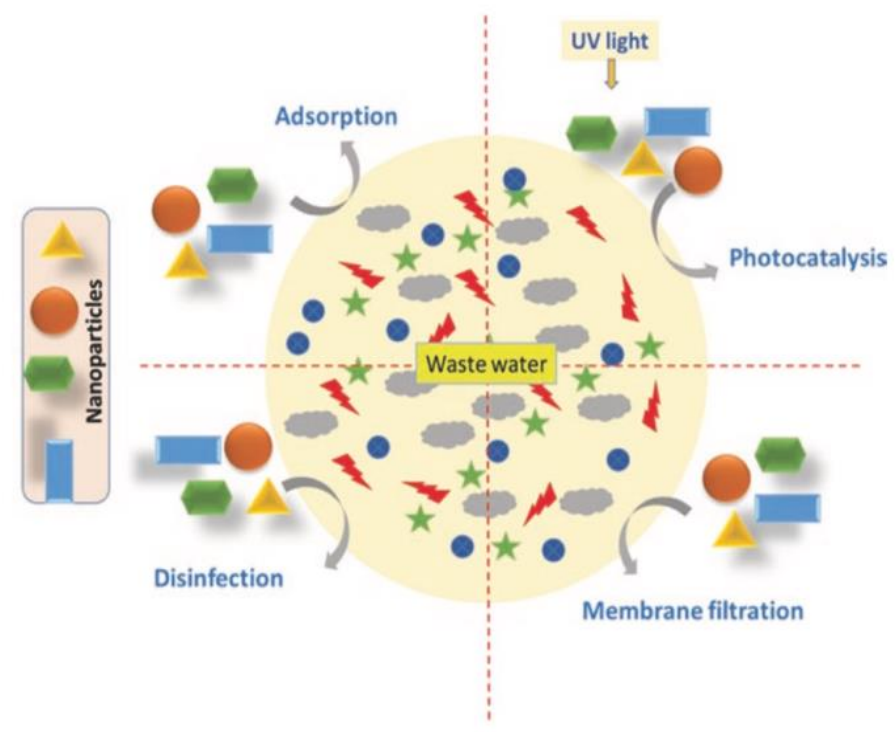

Figure 2. 1. Schematic of nanotechnology used wastewater treatment [25]. 


\subsection{Adsorption Process}

In both natural aquatic and engineered systems, adsorption plays a critical role in transport and fate the contaminants. Also, adsorption is responsible for accumulating the contaminants in the silt which settles down in a river delta, in soil, or in the sludge of a treatment plant, instead of remaining in the aqueous solution that passes through such systems. Adsorption often reduces the high concentrations of dissolved contaminants to significant low levels by providing cost effective means [26].

Adsorption process is known as the ability of substances, either solid or liquid, to absorb the ions and the molecules of contaminants, either as gaseous or dissolved, on their surfaces. The solid or liquid substances on which adsorption occurs are called "adsorbent". While the ions and molecules of gas or liquid which are adsorbed on the surface of the adsorbent are called "adsorbate" [11]. There are two broad classifications of adsorption depending on the nature of forces that exists between adsorbate and adsorbent molecules; Chemical adsorption (chemisorption) and physical adsorption (physisorption). Chemical adsorption: It happens when the attraction forces between the adsorbed molecules and the active sites of adsorbents have same strength as chemical bonds. As a result, the desorption process will be not easy because of the strong attraction forces [27]. Therefore, chemisorption is used primarily to estimate quantitatively the number of active sites that contribute in promoting (catalyze) chemical reaction [28].

Physical adsorption happens when the attraction forces between the adsorbate and adsorbent are Vander Waal's forces or long range of electrostatic interactions. This kind of adsorption is usually weak; therefore, its desorption will be easy by changing the ionic system, decreasing the pressure, and heating. The adsorption process range depends on 
factors such as activation of the adsorbents and experimental conditions, such as ionic strength of the solution, pressure, temperature, etc. [9].

The adsorption process is considered one of the most popular and broadly utilized techniques for inorganic and organic contaminants removal from water and wastewater [29]. Using adsorption technology has many advantages, such as economically viable, simplicity of operation, and neutrality to toxic pollutants and harmful compounds [30][31]. Nowadays, the researchers have been trying to discover and develop reliable adsorbents that can be extensively applied in the commercialized and industries. Some of these adsorbents such as alumina silicates [32], clay [33], zeolites [34], graphene oxide (GO) [35], iron oxide (IO), etc. are well known for targeting the heavy metals removal [36]. All these adsorbents are porous inorganic or organic materials, and they have a high affinity to adsorb the heavy metals on their surface [28][29]. To enhance their performances in the adsorbing of heavy metals, NMOs will be functionalized by other promising materials such as GO.

\subsubsection{Graphene sheets (GSs)}

In the past few years, Graphene oxide (GO) and reduced graphene oxide (rGO), oxidized forms of graphene, have risen as one of the popular materials studied because of their unique characteristics. Those characteristics are higher adsorption capacity, larger surface area, various synthesis methods, abundant oxygen-containing functional groups (i.e., carboxyl groups, epoxy groups, and hydroxyl groups), as shown in Figure 2.2, [37]. Therefore, those forms have been attracting significant attention from the researchers to use them for adsorption applications. 
$\mathrm{GO}$ is defined as one layer of $\mathrm{sp}^{2}$ allotropic carbon atoms, which arrange in a twodimensional hexagonal honeycomb lattice structure [38]. GO is known for its highly oxygenated monolayer graphite oxide because of the exfoliation and oxidation processes of graphene [39]. Therefore, $\mathrm{GO}$ and $\mathrm{rGO}$ nanoparticles render reactive sites and provide a negatively charged surface to graft other functional groups to improve the capacity of adsorption and to increase the surface area [40]. However, GO and rGO nanoparticles usually tend to agglomerate because of their robust Van der Waals interactions and hydrophilic surface, which leads to lower adsorption capacity and reduce surface area [41].

To overcome this deficiency, many researchers have been investigating some nanocomposites by combining GO or rGO with magnetic metal oxides [36], metal-organic frameworks [42][43][44], polymers [45]. As a result, GO and rGO will be as excellent candidates for loading nanomagnetic particles such as iron oxides nanoparticles. This process will combine the high sorption capacity of GO and $\mathrm{rGO}$ and the separation convenience of magnetic materials [46].

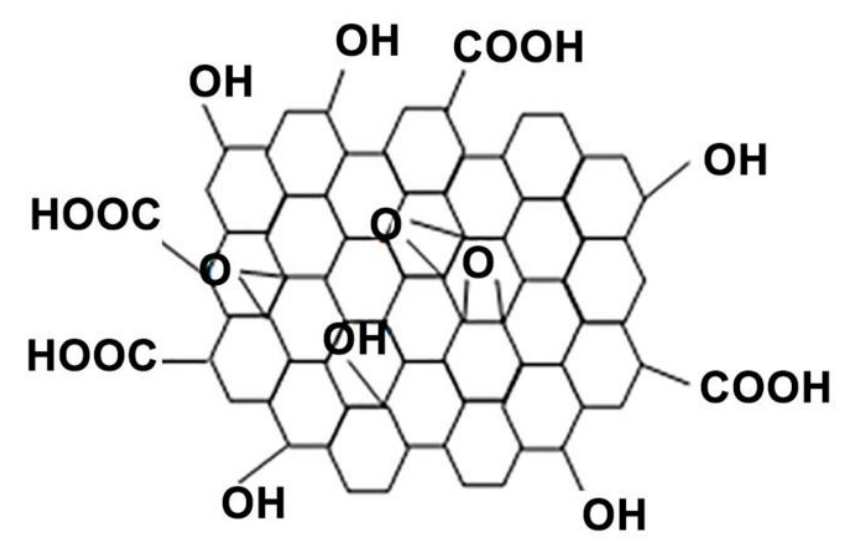

Figure 2. 2. Schematic structure of graphene oxide [24].

GO sheets have been extensively used since it was used for the first time in 2004 as an adsorbent [47] for the removal of antibiotics [48], organic pollutants [49], oil [50], 
pesticide [51], pharmaceuticals [52], heavy metals [53], etc. Particularly, GO has gotten much attention for heavy metal adsorption due to its proper characteristics mentioned previously.

\subsubsection{Nano metals oxides (NMOs)}

NMOs have shown impressive potential as a low-cost, environmentally friendly, and sustainable in water and wastewater treatment technology. Moreover, NMOs have significant characteristics, such as its easy reusability, high specific surface area, short intraparticle diffusion distance, small size of their particles that ranged between 1 to 100 $\mathrm{nm}$ [54], and significant sites for adsorption [55]. Furthermore, NMOs can be reused and regenerated easily through changing $\mathrm{pH}$ solution. Because of all these characteristics, NMOs have been used widely in adsorption technology as adsorbents for contaminates removal such as heavy metals from water and wastewater [56]. The mechanism of adsorption is mainly carried out by the complexation between molecules of oxygen in metal oxide groups and dissolved metals. Therefore, the efficient adsorption of heavy metals on the outer surfaces of NMOs is activated along the walls by limiting the rate of diffusion [57].

A wide range of metal oxides such as alumina, iron, titanium, zirconium, etc., have enormous potential in water and wastewater treatment as an environmentally friendly, low cost, and sustainable technology. As well as having all of these properties, some kinds of NMOs (e.g., nanomaghemite and nanomagnetite) are superparamagnetic that are easy to be removed and separated from the solution by applying a low magnetic field [25]. Therefore, they can be employed as an adsorptive media for filters and slurry reactors [19]. 
Iron materials, hydroxide and oxide, have been studied and used for many years in water and wastewater treatment technologies. Scientific and engineering researchers have been interested in using the unique physical and chemical properties of nanoparticles. Recently, scientific researches have shown that iron oxide nanoparticles enhance abilities to adsorb metals from aqueous solutions in comparison with conventional adsorbents of iron oxides [58][9]. Adsorption of $(\mathrm{Cd}(\mathrm{II}), \mathrm{Cu}(\mathrm{II}), \mathrm{Pb}(\mathrm{II}), \mathrm{Zn}(\mathrm{II}))$ metal ions and heavy metals $(\mathrm{As}(\mathrm{III})$ and $\mathrm{As}(\mathrm{V})$ onto iron oxide such as hematite was examined as a function of adsorbent concentration, exhaustion, $\mathrm{pH}$, and temperature [59]. Hematite nanoparticles showed capability to adsorb metal oxide ions with adsorption increasing when the concentration of nanoparticles increase.

Ghosh et al. [60] synthesized Goethite $(\alpha-\mathrm{FeOOH})$ nanoparticles by using hydrazine sulfate as a modifying agent for removal $\mathrm{As}(\mathrm{V})$ from solution. They achieved adsorption capacity $76 \mathrm{mg} \mathrm{g}^{-1}$ at $\mathrm{pH} 3$. Park et al. [61] prepared maghemite $\left(\gamma-\mathrm{Fe}_{2} \mathrm{O}_{3}\right)$ nanoparticles to remediate $\mathrm{As}(\mathrm{V})$ from solution, and it achieved adsorption capacity was $2.9 \mathrm{mg} \mathrm{g}^{-1}$ in the $\mathrm{pH}$ range 2-9. Their adsorbent was appropriate for remediating $\mathrm{As}(\mathrm{V})$ to the recommended concentration by the World Health Organization (WHO). Kalhori et al. [62] synthesized superparamagnetic permanently confined micelle array (Mag-PCMAs) nanoparticle as adsorbents for removal metronidazole antibiotic at different values of $\mathrm{pH}$ 3-11. The study shows that the adsorption capacity was $84.55 \mathrm{mg} \mathrm{g}^{-1}$.

\subsection{Membrane Process}

In membrane technology, porous materials play an essential role in capturing and trapping pollutants. The membranes will allow one component to transport through them more than others, depending on the physical and chemical properties of the membrane and 
the permeate components [63][64]. Recently, the membranes have numerous forms with various pore sizes involving microfiltration, nanofiltration, reverse osmosis, and ultrafiltration. All these forms depend on their materials which would be clean out through each process, as shown in Figure 2.3. [65].

Nowadays, the membrane technology has been facing many challenges in water purification, such as exchange link between permeability and selectivity in addition to low resistance to fouling. Therefore, the recent novel researches have been focusing on improving flux efficiency and selectivity by developing antifouling layers to overcome these challenges [11]. Nanotechnology have offered recently growing new generation of membranes for water purification [66].

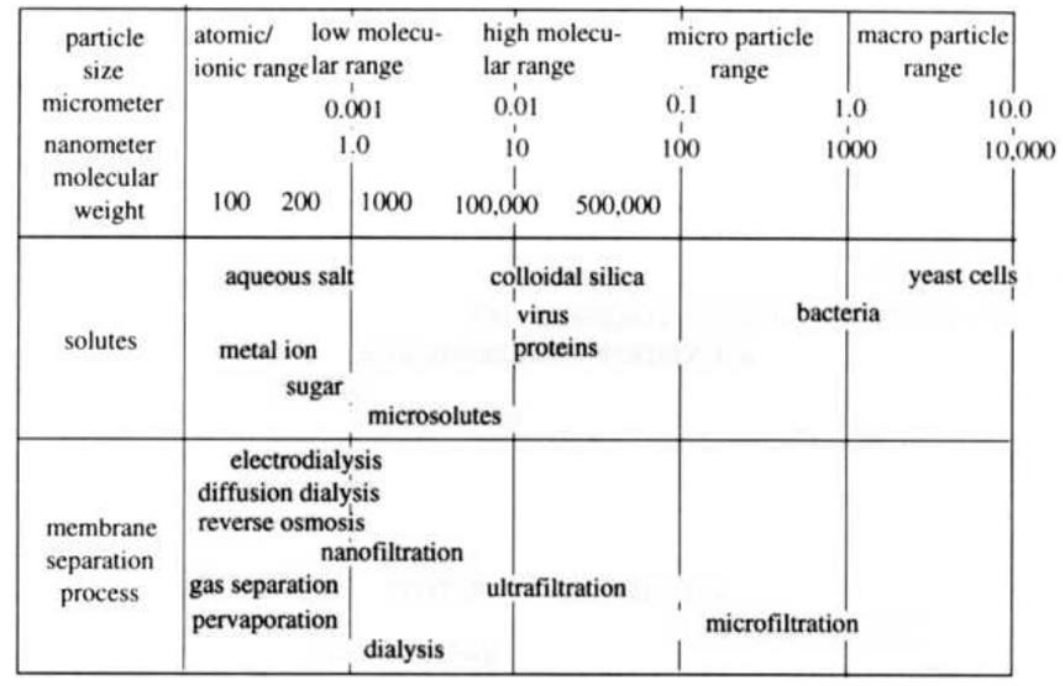

Figure 2. 3. Schematic of membrane filtration [57].

Recently, different manufacturing techniques have been used for membranes fabrication such as aerosol deposition, dip coating, film casting, ion exchange, layer-bylayer deposition, spray coating, surface adsorption, etc. [67]. These techniques depend on the membranes' materials more than the pore size of the membrane itself. 


\subsubsection{Nanocomposite membranes}

Nanocomposite membranes are considered as a new group of filtration materials which includes a mixed matrix of nanofillers embedded either by inorganic oxide matrix or polymeric. In most cases, nanofillers are characterized by their high ratio of surface area to mass and surface-functionalized [68]. Using NMOs such as $\mathrm{Al}_{2} \mathrm{O}_{3}, \mathrm{Fe}_{3} \mathrm{O}_{4}, \mathrm{SiO}_{2}, \mathrm{TiO}_{2}$, $\mathrm{ZnO}$ help to develop some of the characteristics of membranes like mechanical and thermal stabilities in addition to permeate flux of polymeric membranes. For instance, Ping and Guohua [69] designed a compact electro-microfiltration to treat humid acid (HA) by using a moditf67fied $\mathrm{Ti}_{4} \mathrm{O}_{7} / \mathrm{Al}_{2} \mathrm{O}_{3}$ tubular membrane. They achieved the removal of $91-96.5 \%$ HA and $86.7-88.3 \%$ TOC.

\subsubsection{Nanofiber membranes}

One of the techniques used to produces fibers is called nanofiber, which used in filtration and separation processes. This technique draws very fine special materials such as ceramics or polymers by using an electric field [11]. Nanofiber technique has many benefits, such as ensuring a high specific surface area to mass ratio. Also, it will increase the capacity to be tailored to details like interconnected open pore structure and membrane thickness [70]. Suriyaraj et al. [71] synthesized crystalline $\mathrm{TiO}_{2}$ nanoparticles using Bacillus licheniformis bacteria modified it by using $\mathrm{Al}_{2} \mathrm{O}_{3}$ precursor to fabricate $\mathrm{TiO}_{2} / \mathrm{Al}_{2} \mathrm{O}_{3}$ nanocomposite. This nanocomposite was carried out using electro-spun thermoplastic polyurethane (TPU) nanofibers. This study showed the size and diameter of the nanocomposite and nanofiber particles were $50 \pm 6 \mathrm{~nm}$ and $239 \pm 33 \mathrm{~nm}$, respectively. Moreover, the nanofibrous membrane was tested for fluoride removal from the solution, and it achieved an adsorption capacity of $1.9 \mathrm{mg} / \mathrm{g}$. 


\subsection{Photocatalysis}

Photocatalysis, known as advanced oxidation processes (AOPs), is a treatment technique that used to degrade organic contaminants in water and wastewater such as estrogens, crude oil, dyes, inorganic molecules (NOx), pesticides, etc. by using UV-light [72]. The main principles of this method lie in generating highly reactive species such as $\mathrm{OH}^{\mathrm{o}}, \mathrm{O}_{2}, \mathrm{O}_{3}$ to degrade the organics into biodegradable compounds and convert them finally to $\mathrm{CO}_{2}$ and water. NMOs semiconductors have obtained significant attention by the experts in the field of developing wastewater treatment techniques because of the excellent properties of their bandgap, which upon irradiation of UV-light produces electron-hole $\left(\mathrm{e}^{-} / \mathrm{h}^{+}\right)$pairs for waste degradation [73]. On the other hand, the size and geometry of NMOs semiconductors such as $\mathrm{TiO}_{2}$ and $\mathrm{ZnO}$ play an important role in their $\left(\mathrm{e}^{-} / \mathrm{h}^{+}\right)$dynamics, solid-phase transformation, and sorption. For instance, the efficiency of $\mathrm{TiO}_{2}$ will be low when the recombination process of $\mathrm{e}^{-}$and $\mathrm{h}^{+}$is fast; therefore, this recombination can be lowered by decreasing the size of $\mathrm{TiO}_{2}$ particles, which leads to improving interfacial charge carrier transfer [74]. Figure 2.4 shows the oxidative, and reductive reactions occurred on the surface of $\mathrm{TiO}_{2}$.

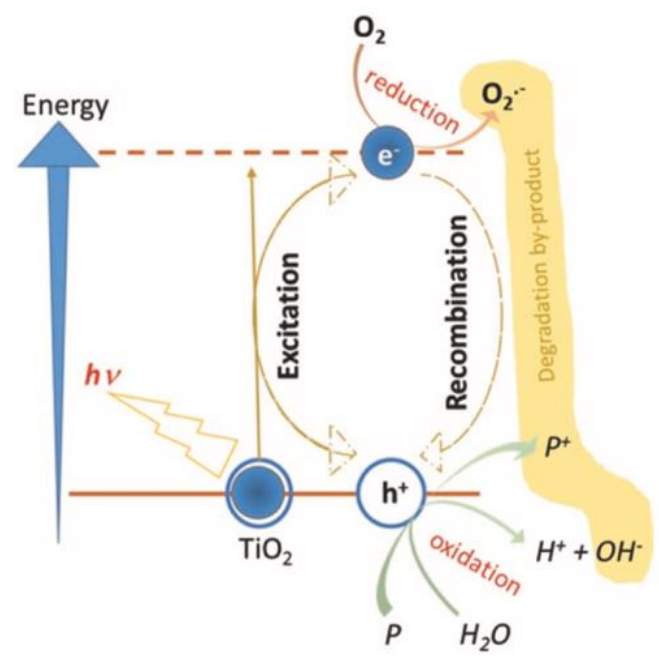

Figure 2. 4. Pollutant degradation after irradiation $\mathrm{TiO}_{2}$ particle by UV-light. 
$\mathrm{TiO}_{2}$ is widely used as a photocatalyst because of its significant properties, such as cost efficiency, high availability, and low toxicity. Recently, many researchers around the world have been investigating the combination between the catalytic and separation processes through using the ceramic membrane filtration and photocatalysis together to purify the water with keeping the particles of catalytic [75]. Most of the nanofiltration processes that use highly efficient nanoparticles must be applied to a proper filtration system to reject the harmful nanoparticles completely. Therefore, it is necessary to use extensive and costly installation technologies, including high-pressure pumps [11].

\subsubsection{Titanium dioxide ( $\left.\mathrm{TiO}_{2}\right)$ nanoparticles photocatalyst for advanced oxidation technology:}

Titanium dioxide $\left(\mathrm{TiO}_{2}\right)$ nanoparticles have been studied enormously because of their unique characteristics, such as high specific surface area, abundant, non-toxicity, wide bandgap semiconductors, and high chemical and thermal stability [76]. Therefore,

Titanium dioxide has broad applications with different fields, such as environmental cleaning, and photocatalysis. To apply the photocatalysts for water treatment, the following needs to be achieved; the process has to be fulfilled at room temperature, mineralization has to be completed without producing by products, low costs for operations and repetitious cycles. Titanium dioxide $\left(\mathrm{TiO}_{2}\right)$ photocatalysis is considered as a photo-induced charge separation phenomenon which happens on the surface of $\mathrm{TiO}_{2}$. Also, $\mathrm{TiO}_{2}$ has a high reactive oxygen species which can cause organic mineralization without producing by products. The decomposition reaction, mostly oxidative reaction, depends on the photocatalyst's valence band to degrade the contaminants in the water. Thus, the oxidative reaction will improve when the photocatalyst's valence band holes has higher oxidative 
power. Figure 2.5 shows how pollutants will be removed by the photo-induced charge $(\mathrm{e} / \mathrm{h}+)$ by semiconductor $\mathrm{TiO}_{2}$ particles surface [77].

When the surface of $\mathrm{TiO}_{2}$ catalysts are irradiated by UV light Equation 2.1., the conductive band will take part in the reduction processes by the photo-induced electrons that will usually react with dissolved oxygen to generate superoxide radical anions $\mathrm{O}_{2}^{-}$. On the other hand, the photo-induced holes will diffuse on the surface of $\mathrm{TiO}_{2}$ in the valence band, and they will form $\mathrm{OH}^{*}$ which reacts with molecules of adsorbed water. Specifically, the $\mathrm{OH}^{*}$ is a major active specie in the photocatalytic oxidation reactions [78].

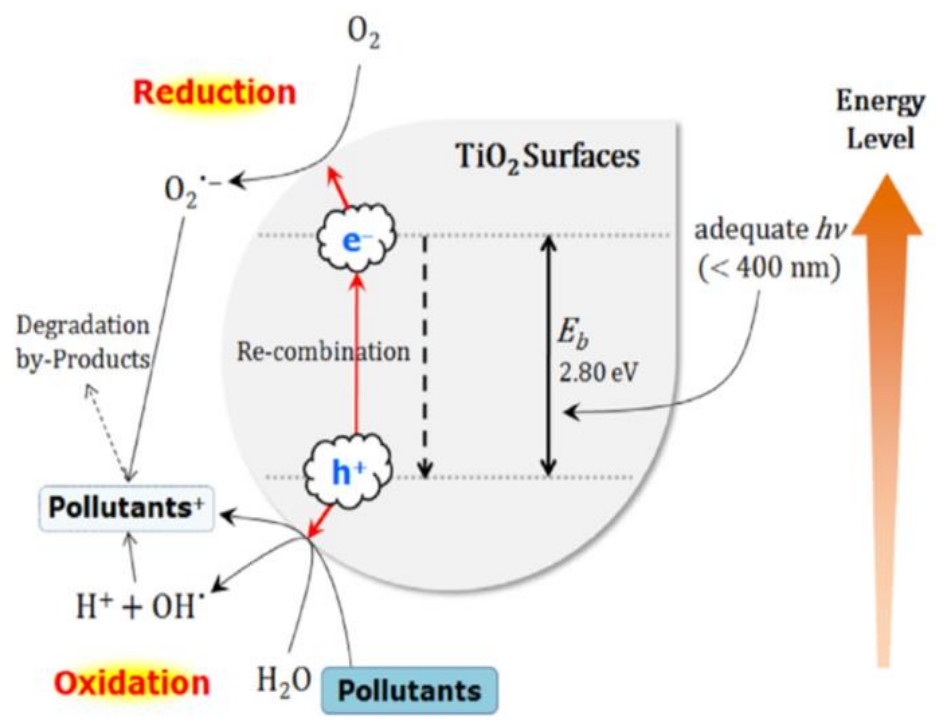

Figure 2. 5 Removal pollutants by $\mathrm{TiO}_{2}$ particle surfaces [77].

The formation mechanism of the electron-hole pair are shown below:

$$
\begin{aligned}
& \mathrm{TiO}_{2}+h v \rightarrow e^{-}+h^{+} \\
& e^{-} \mathrm{CB} \rightarrow e^{-} \mathrm{TR} \\
& h^{+} \mathrm{CB} \rightarrow h^{+} \mathrm{TR} \\
& e^{-} \mathrm{TR}+h^{+} \mathrm{TR} \rightarrow e^{-} \mathrm{CB}+\text { heat }
\end{aligned}
$$




$$
\begin{aligned}
& \left(\mathrm{O}_{2}\right)_{\text {adsorbed }}+e^{-} \rightarrow \mathrm{O}_{2}^{\bullet^{-}} \\
& \mathrm{OH}^{-}+h^{+} \rightarrow \mathrm{OH}^{\cdot} \\
& \mathrm{R}-\mathrm{H}+\mathrm{OH}^{\cdot} \rightarrow \mathrm{R}^{+\bullet} \rightarrow \text { Intermediate(s)/final degradation products } \\
& \mathrm{O}_{2}^{{ }^{-}}+\mathrm{OH}^{\cdot} \rightarrow \mathrm{HOO}^{\cdot} \\
& \mathrm{HOO}^{-}+e^{-} \rightarrow \mathrm{HO}_{2}^{-} \\
& \mathrm{HO}_{2}^{-}+\mathrm{H}^{+} \rightarrow \mathrm{H}_{2} \mathrm{O}_{2}
\end{aligned}
$$

Where:

$e^{-} \mathrm{TR}:$ the surface trapped VB electron.

$h^{+}$TR : the surface trapped CB hole.

\subsection{Arsenic (As); characteristics and occurrences in aqueous solutions}

Arsenic (As), often referred to as the king of poisons [79], is a common trace element in the earth's crust and widely spread in all the environments. Elemental Arsenic is metallic gray or yellow in color, not soluble in water, and very brittle, and arsenic structure is a semi-metallic crystalline. Arsenic oxidizes on heating to arsenous oxide, and its smell in air as a garlic [80]. Arsenic physical properties are illustrated in Table 2.1.

Table 2.1. Physical properties of arsenic [81].

\begin{tabular}{|l|c|}
\hline Atomic symbol & As \\
\hline Classification & Metalloid \\
\hline Color & Gray \\
\hline Crystal structure & Rhombohedral \\
\hline Density @ 293 K & $5.72 \mathrm{~g} / \mathrm{cm}^{3}$ \\
\hline Atomic mass & 74.9216 \\
\hline Atomic number & 33 \\
\hline Electronic configuration & {$[\mathrm{As}] 4 \mathrm{~s}^{2} 3 \mathrm{~d}^{10} 4 \mathrm{p}^{3}$} \\
\hline Oxidation states & $5,3,0,-3$ \\
\hline Atomic radius & $125 \mathrm{pm}$ \\
\hline Melting point & $\sim 817^{\circ} \mathrm{C}$ \\
\hline Boiling point & $603^{\circ} \mathrm{C}($ sublimation $)$ \\
\hline
\end{tabular}


There are many applications that arsenic is used in such as bronzing, making agricultural insecticides and pesticides, etc. [82]. Arsenic has two forms; organic and inorganic. Organic arsenic compounds includes many forms such as arseno-sugars, dimethyl arsenic acid (DMAA), and monomethyl arsenic acid (MMAA). On the other hand, inorganic form, known as high toxicity, exists in four main oxidation states, and the most common are As(III) and $\mathrm{As}(\mathrm{V})$.

The oxidation states of arsenic in the hydrosphere depend on different environmental factors such as $\mathrm{pH}$ conditions, ionic distribution states, reduction-oxidation reactions, general hydrochemistry, microbial activity [83]. On the other hand, the concentration of arsenic species depends mainly on $\mathrm{pH}$ and redox potential (Eh) [82]. The distribution of arsenic species as a function of $\mathrm{pH}$ and redox potential (Eh) are depicted in Figures 2.6 and 2.7, respectively [84].

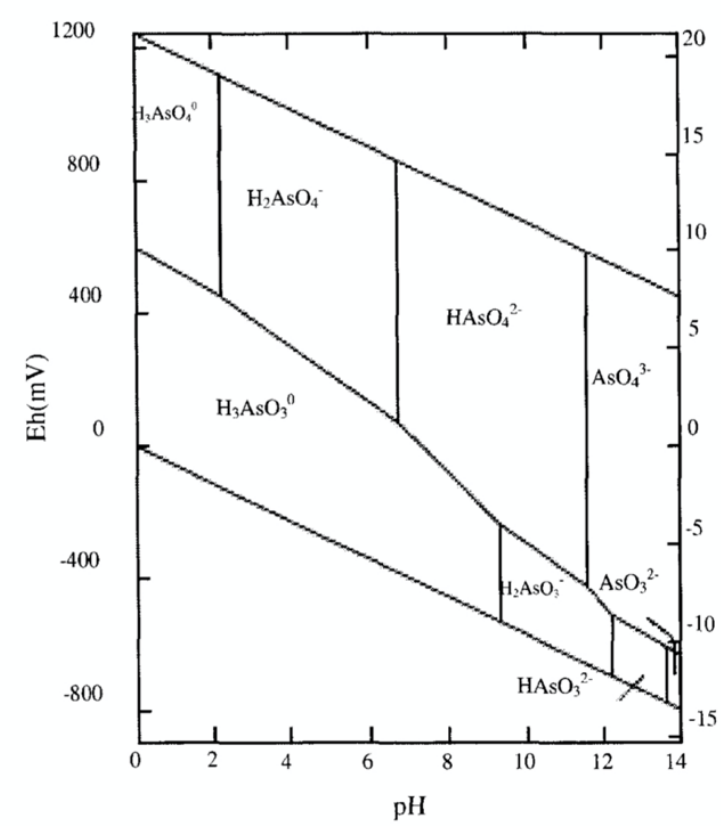

Figure 2.6. Eh-pH diagram for aqueous As speciesin the system $\mathrm{As}-\mathrm{O}_{2}-\mathrm{H}_{2} \mathrm{O}$ at $25^{\circ} \mathrm{C}$ and 1 bar total pressure [85]. 
Arsenite $\mathrm{As}(\mathrm{III})$ is a dominant form under reducing conditions, as shown in Figures 2.6 and 2.7. while arsenate As(V) is generally more stable form thermodynamically in well oxygenated environments. Arsenate $\left(\mathrm{H}_{2} \mathrm{AsO}_{4}{ }^{-}\right)$is the major species at pKa equal to 6.9, and $\mathrm{HAsO}_{4}{ }^{2-}$ is dominant species at higher $\mathrm{pH}$. However, these species of As will appear when the values of $\mathrm{pH}$ range between 6 to 8 . When $\mathrm{pH}$ is equal to 9.3 the species of As(III) will be the dominant as an arsenious acid $\left(\mathrm{H}_{3} \mathrm{AsO}_{3}\right)$.
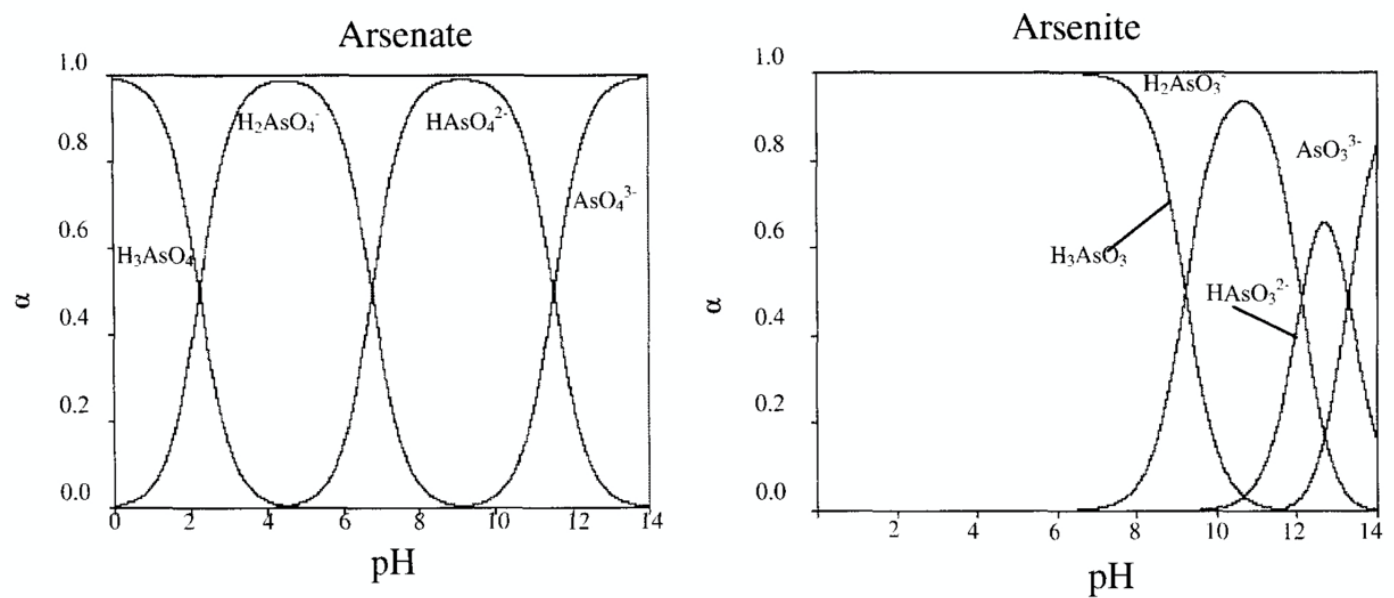

Figure 2.7. Distribution of arsenate and arsenite as a function of $\mathrm{pH}$ [81].

Every day, a lot of people around the world such as Bangladesh, Ghana, India, USA, etc., have been drinking contaminated water by arsenic; therefore, they are exposed to it [86]. As a result, it is important to study the occurrence, toxicity, and mobility of arsenic to develop and improve the treatment technologies for arsenic removal from drinking water and wastewater. There are more than 320 minerals containing arsenic in their structures such as arsenopyrite (FeAsS), orpiment $\left(\mathrm{As}_{2} \mathrm{~S}_{3}\right)$, realgar $\left(\mathrm{As}_{2} \mathrm{~S}_{2}\right)$, etc. [87].

Some of these minerals can be found in nature as sedimentary or volcanic rocks because of adsorbing As by $\mathrm{Fe}(\mathrm{III})$ and $\mathrm{Mn}(\mathrm{IV})$ after weathering sulfide minerals [88]. These minerals are also produced by discharging the effluents of some industrial activities 
such as agricultural chemicals, pharmaceuticals, applications in mining, etc. [89]. In the United States, some of the states are depending on the groundwater as a source for drinking water, so those states have been suffering from the high As concentrations ( $\geq 50 \mu \mathrm{g} / \mathrm{L}$ ) [90]. Some environmental and health agencies, such as United States Environment Protection Agency (EPA) and World Health Organization (WHO), established a standard for the allowable recommended $10 \mu \mathrm{g} / \mathrm{L}$ as a maximum As concentration allowable in drinking water. Therefore, the world have adapted this standard to protect the consumers from the chronic exposure to As in drinking water for the long-term [91].

\subsection{Sulfamethazine (SMZ)}

To protect animals' health prophylactically and treat their diseases, veterinary antibiotics (VPs) have been universally. For instance, in the united states alone there are around 7.5-8.6 billion chickens, 104-110 million cattle, 275-292 million turkeys, and 6092 million swine which are fed with food containing varieties of veterinary pharmaceuticals [92]. Sulfamethazine (SMZ), as a typical sulfonamide-class antibiotic, is a one kind of antibiotics that are known as Pharmaceutical and Personal Care Products (PPCPs), shown in Figure 2.8. SMZ is used in human and veterinary drugs as antibacterial medicines and growth promoters [93].

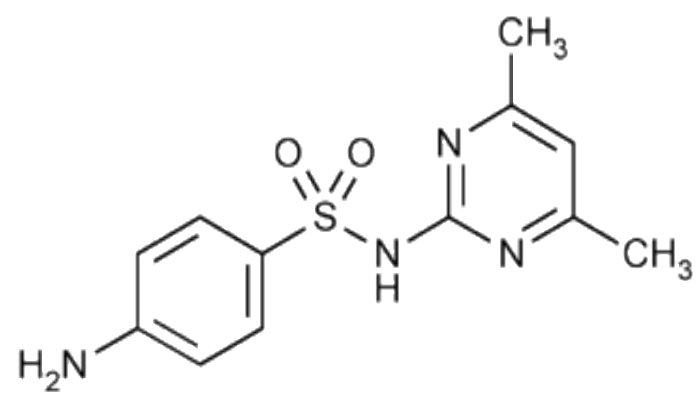

Figure 2.8. Chemical structure of sulfamethazine [93]. 
SMZ enters in the aqueous environment by some predominant pathways. SMZ exists in three different forms: cationic, neutral, and anionic, depending on $\mathrm{pH}$ values, as shown in Figure 2.9 and Table 2.2.

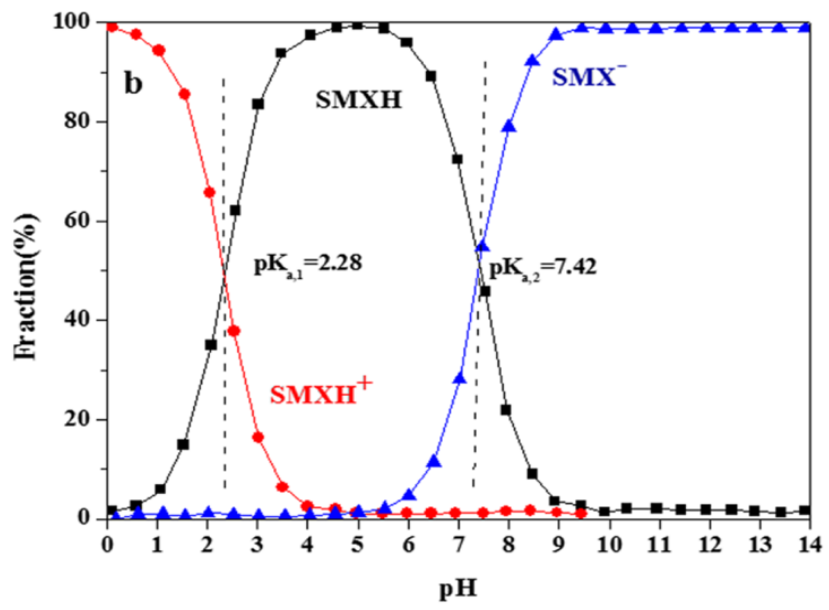

Fig. 2.9 Distribution of cationic $\left(\mathrm{SMZ}^{+}\right)$, neutral and zwitterionic $\left(\mathrm{SMZ}^{0}\right)$, and anionic $\left(\mathrm{SMZ}^{-}\right)$species in aqueous solution as a function of $\mathrm{pH}[93]$.

Table 2. 2 Physicochemical characteristics of SMZ [93].

\begin{tabular}{|c|c|}
\hline Molecular Formula: & $\mathrm{C}_{12} \mathrm{H}_{14} \mathrm{~N}_{4} \mathrm{O}_{2} \mathrm{~S}$ \\
\hline Molecular weight (MW) & 278.33 \\
\hline $\boldsymbol{L o g} \boldsymbol{K}_{\mathbf{o w}}$ & 0.89 \\
\hline Solubility & $1500 \mathrm{mg} / \mathrm{L}$ \\
\hline $\mathbf{p} \boldsymbol{K} \boldsymbol{a}_{\boldsymbol{I}}$ & $2.65 \pm 0.2$ \\
\hline $\mathbf{p} \boldsymbol{K} \boldsymbol{a}_{2}$ & $7.42 \pm 0.2$ \\
\hline
\end{tabular}

Those form are adsorbed by the bodies of animals by food that is excreted from organism with the feces or urine. In many countries, those antibiotics are widely applied to economic values, harmless property, and the land for toxic-free, and they could be abundantly discharged from animals bodies as a waste [94]. Moreover, antibiotics have few pathways for entering human body, including dairy and meat products derived from dairy cattle and beef lactating being feed with food containing antibiotics.

As a result, SMZ has received a great concern by environmental scientists because of its potential effects on the normal ecosystems functionalities [95]. Because of its ability 
to treat a wide range of bacteria and its low cost, SMZ is commonly used to treat infections by microbes [96]. On the other hand, SMZ can form antibiotic resistance bacteria at low concentration $(\leq 1 \mathrm{ppm})$ [97] which make the conventional biological treatment processes unable to remove it effectively because of their toxic nature and persistence [98]. Therefore, develop alternative treatment processes became necessary to deal with and degrade these bio-recalcitrant contaminants effectively.

Therefore, SMZ has become a global contaminant because it is difficult removed effectively by conventional water and wastewater treatment processes. There are many technologies used to remove SMZ such as adsorption [99], membrane filtration [100], and advanced oxidation processes [101]. 


\section{Chapter 3: Synthesis of Iron Oxide/Graphene Oxide Composite Materials as Adsorbents for As(V) Removal.}

\subsection{Introduction}

Arsenic, with two inorganic forms; arsenite $\mathrm{As}(\mathrm{III})$ and arsenate $\mathrm{As}(\mathrm{V})$, exhibits both acute and carcinogenic toxicity. It can be found in nature as part of geological formations and volcanic deposits, etc. or due to anthropogenic activities such the application of herbicides and pesticides in agriculture, or industry, such as electronic components, pharmaceuticals, pigments, landfills, and mining wastes [102][103]. Because of its high toxicity and analytical and removal difficulties [104], both the US Environmental Protection Agency (EPA) and European Union adopted $0.010 \mathrm{mg} / \mathrm{L}$ as maximum the allowable concentration of As in drinking water, in agreement with World Health Organization (WHO) guidelines. WHO defined this concentration as analytical achievability and treatment performance [105].

Nowadays, many technologies such as biological remediation, coagulation/filtration, ion exchange, adsorption, membrane, and reverse osmosis have been used to eliminate arsenic from water and wastewater [106][107]. Among those technologies, adsorption is generally considered the most efficient and economical option, especially at low concentrations [3][4]. A wide range of adsorbents are available for arsenic removal: for example, activated carbon, metal oxides, and natural minerals [104]. Recently, graphene oxide (GO) has received significant attention for adsorption processes because of relevant properties such as a high surface area to mass ratio, good dispersion in water, and abundant surface functional groups [110]. On the other hand, GO sheets suffer from 
some challenges respecting with its application in water treatment. For instance, interactions among adjacent sheets of GO may lead to agglomeration and loss the promising high surface area, so the expected adsorption capacity will be limited [111]. Moreover, GO sheets need extra steps for separation them from the water after treatment processes. To achieve those goals, GO sheets have been recently used to fabricate various kinds of composite materials that would facilitate dispersion and stability [9][10]. One of the materials that is loaded to GO is iron oxide which have been used in water treatment by taking advantage of their magnetic property to assist in the separation processes between the treated water and adsorbents. Iron with its varied forms; oxides, oxyhydroxides, and hydroxides [3][9], has been extensively studied because of its attractive capacity performance for arsenic adsorption, large abundance, low toxicity, and low cost [7][10]. Therefore, this work proposed fabricating iron/GO composites to be used as arsenic adsorbents from the solution. The composites were fabricated at different iron oxide (IO) to GO weight ratios. Subsequently, their compositional, structural, and textural properties were characterized. Finally, the ability of all composites to adsorb As(V) from the solution was investigated.

\subsection{Methods and Materials}

\subsubsection{Materials}

All the reagents used were of analytical grade. Graphite nanoplatelet (5um, xGnP graphite nanoplatelet XG Sciences), sodium nitrate $\mathrm{NaNO}_{3}$ (Sigma-Aldrich, St. Louis, $\mathrm{MO}$, USA), sulfuric acid $\mathrm{H}_{2} \mathrm{SO}_{4} 98 \%$ (w/w) (Fisher Scientific, Pittsburgh, PA, USA), hydrogen peroxide $30 \%$ (w/w) in $\mathrm{H}_{2} \mathrm{O}$ (Fisher Scientific, Pittsburgh, PA, USA), potassium permanganate $\mathrm{KMnO}_{4}$ (Flinn Scientific, Batavia, IL, USA), sodium hydroxide pellets 99\%, 
(ACROS Organics, Flinn Scientific, Batavia, IL, USA), sodium arsenate $\geq 98 \%$ (SigmaAldrich, St. Louis, MO, USA) were purchased and used as received without any additional purification. Ultrapure water was used in all experiments from Type I $(18 \mathrm{M} \Omega * \mathrm{~cm})$ and obtained from a Barnstead E-pure ultrapure Water Purification System (Thermo Scientific, Waltham, MA, USA).

\subsubsection{Lepidocrocite synthesis}

Lepidocrocite was synthesized from industrial grade $\mathrm{FeCl}_{2}(28-32 \%$ w/w; PPE Argentina S.A., Buenos Aires, Argentina). Briefly, lepidocrocite $\gamma-\mathrm{FeO}(\mathrm{OH})$ was prepared by oxidizing $\mathrm{FeCl}_{2}$ under controlled $\mathrm{pH}(6.7-6.8)$ [116]. A $0.2 \mathrm{M}$ solution of iron (II) chloride tetrahydrate $\left(\mathrm{FeCl}_{2} \bullet 4 \mathrm{H}_{2} \mathrm{O}\right)$ was prepared in ultrapure water. During this reaction, a diffuser was installed to provide air for the reaction. The $\mathrm{pH}$ was monitored and controlled by adding $1 \mathrm{M}$ solution of $\mathrm{NaOH}$ as needed to maintain the $\mathrm{pH}$ value between 6.7 and 6.8 . Agitation and aeration were kept for 3 hours, leading to an orange precipitate. Later, the suspension was centrifuged at 3,500 rpm for 8 minutes, and the supernatant was discarded. This step was repeated three times to remove the remaining $\mathrm{NaCl}$. Finally, the produced precipitate was dried in a crystallization dish at $50^{\circ} \mathrm{C}[9,10]$.

\subsubsection{Graphene Oxide (GO) Synthesis}

Graphene oxide was synthesized by a modified Hummer's method from graphite nanoplatelets [118]. In brief, $1 \mathrm{~g}$ of graphite and $1 \mathrm{~g}$ of $\mathrm{NaNO}_{3}$ were mixed in an ice-bath followed by the addition of $46 \mathrm{ml}$ of $98 \%(\mathrm{w} / \mathrm{w}) \mathrm{H}_{2} \mathrm{SO}_{4}$. Then, $6 \mathrm{~g}$ of $\mathrm{KMnO}_{4}$ was carefully added to the mixture. After stirring for $1 \mathrm{~h}$ at $35^{\circ} \mathrm{C}, 80 \mathrm{~mL}$ of ultrapure water $(18 \mathrm{~m} \Omega * \mathrm{~cm})$ was added, and the temperature increased to $90^{\circ} \mathrm{C}$ for $30 \mathrm{~min}$. Then, $200 \mathrm{ml}$ of ultrapure 
water and $6 \mathrm{ml}$ of $30 \%(w / w) \mathrm{H}_{2} \mathrm{O}_{2}$ were added to the reaction and stirred for 10 minutes to eliminate the excess of $\mathrm{KMnO}_{4}$. Then, the product was washed several times by centrifuged at 3,500 rpm (Eppendorf Centrifuge, model 5810 R, Hamburg, Germany) for 8 minutes. The supernatant was discarded, and the centrifuge tube was filled with ultrapure water in each cycle until the $\mathrm{pH}$ of liquid equal to 5 .

\subsubsection{Composite Material Production}

Five different composite materials with a content of 5, 10, 15, 20, and 25\% w/w of GO were fabricated by a co-precipitation method. The materials were designated IOGOx, where $\mathrm{x}$ is the $\%$ weight of GO added in the precipitation step. The general procedure for composite material fabrication is illustrated in Figure 3.1. For example, to prepare IOGO5, $237.5 \mathrm{mg}$ of lepidocrocite and $12.5 \mathrm{mg}$ of graphene oxide were weighted. Then, they were suspended separately in ultrapure water using ultrasonication (Branson 2510 Sonicator, 42 $\mathrm{kHz}$, Danbury, CT, USA) for $1 \mathrm{hr}$.

Both solutions were adjusted their $\mathrm{pH}$ to be equal to 4 by adding $1 \mathrm{M}$ solutions of $\mathrm{NaOH}$ or $\mathrm{H}_{2} \mathrm{SO}_{4}$ and leaving for 6 hours to aggregate and settle together with checking the solution $\mathrm{pH}$. The sludge produced was dried in an oven at $80{ }^{\circ} \mathrm{C}$ and then sintered in a furnace (Vulcan 3-550, Neytech, USA) with the following program: 1) the temperature was raised to $100{ }^{\circ} \mathrm{C}$ at a constant rate of $1{ }^{\circ} \mathrm{C} / \mathrm{min}$ and held for 2 hours. 2) the temperature was raised to $280{ }^{\circ} \mathrm{C}$ at a constant rate of $1{ }^{\circ} \mathrm{C} / \mathrm{min}$ and held for 3 hours. 3) finally, the temperature was raised to $410{ }^{\circ} \mathrm{C}$ at a constant rate of $1{ }^{\circ} \mathrm{C} / \mathrm{min}$ and held for 4 hours. IOGO10, IOGO15, IOGO20, and IOGO25 were fabricated, following the same procedure, but a different starting mass of each component. 


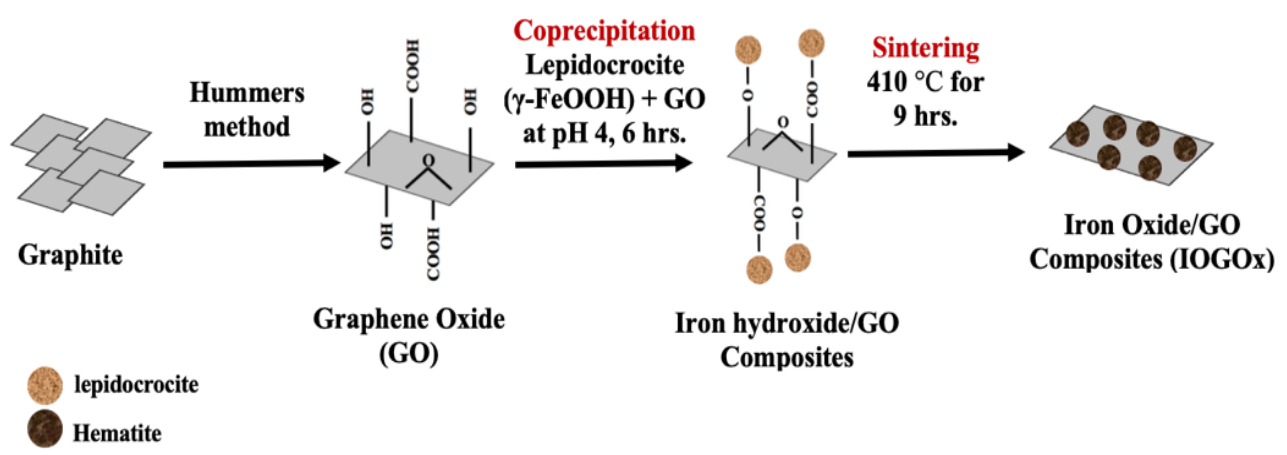

Figure 3. 1 Schematic of the synthesis process of IOGO composites.

\subsubsection{Characterization of IOGOx nanocomposites}

The crystalline structure of lepidocrocite, GO, and all composites were characterized by X-ray powder diffraction (XRD) using a Rigaku Ultima IV X-ray diffractometer (Japan) using $\mathrm{Cu} \mathrm{K} \alpha$ radiation (tension $=40 \mathrm{kV}$, current $=20 \mathrm{~mA}$ ). Scanning Electron Microscopy (SEM) (Quanta 650 FEG-FEI, USA) was used to investigate the surface morphology of the fabricated composites before and after sintering, and their elemental composition. Zeta potential was measured by a Zetasizer Nano ZS (ZEN3600Malvern, UK). Specific surface area and total pore volume were measured by the Braunauer-Emmett-Teller (BET) method, using nitrogen adsorption at $77 \mathrm{~K}$ (Coulter SA3100-Beckman Coulter, USA). Thermogravimetric analysis (TGA) was conducted in a Q500-TA instrument in an air atmosphere.

\subsubsection{Arsenic Adsorption}

Batch adsorption experiments were carried out to study the adsorption process of IOGO5, IOGO10, IOGO15, IOGO20, IOGO25, and hematite (IO) as control. A 10 ppm $\mathrm{As}(\mathrm{V})$ stock solution, $1 \mathrm{mM}$ ionic strength $\left(\mathrm{NaNO}_{3}\right)$ and $\mathrm{pH} 7$, was used to prepare working solutions of variable $\mathrm{As}(\mathrm{V})$ concentrations between $0.5 \mathrm{ppm}$ and $10 \mathrm{ppm}$. Then, $50 \mathrm{ml}$ of 
each solution was poured into a $125 \mathrm{~mL}$ flask, and $20 \mathrm{mg}$ of each adsorbent was added. The flasks were sealed and shaken at $200 \mathrm{rev} / \mathrm{min}$ at room temperature $\left(23^{\circ} \mathrm{C}\right)$ for 48 hours. Then, samples were taken from the solutions in each flask and filtered with a syringe filter (0.22 $\mu \mathrm{m}$ PES, Bonna-Agela Tech. Inc., CA, USA) to separate the suspended adsorbent. After that, residual concentrations of $\mathrm{As}(\mathrm{V})$ were measured by Atomic Absorption Spectroscopy (BUCK Scientific, Model 210 VGP, with graphite furnace, at wavelength $193.7 \mathrm{~nm}$, Lamp current $7 \mathrm{~mA}$, slit width $0.7 \mathrm{~nm}$, detection limits $200 \mathrm{ppb}$ ). All samples were measured three times. Finally, the amount of $\mathrm{As}(\mathrm{V})$ adsorbed to the solid $q(\mathrm{mg} / \mathrm{g})$ was calculated by Equation 3.1:

$$
\mathrm{q}_{\mathrm{t}}=\left(\mathrm{C}_{0}-\mathrm{C}_{\mathrm{t}}\right) * \mathrm{~V} / \mathrm{W}
$$

where $C_{0}$ and $C_{t}$ are the concentrations of $\mathrm{As}(\mathrm{V})$ at time 0 and $t$, respectively. Whereas, $w$ is the weight of added adsorbent, and $V$ is the solution volume.

The adsorption isotherms were fitted using two models; Langmuir and Freundlich isotherm models. The Langmuir model is presented in Equation 3.2.

$$
\mathrm{q}_{\mathrm{e}}=\left(\mathrm{a} * \mathrm{~b} * \mathrm{C}_{\mathrm{e}}\right) /\left(1+\mathrm{b} * \mathrm{C}_{\mathrm{e}}\right)
$$

where $q_{e}$ is the amount of $\mathrm{As}(\mathrm{V})$ adsorbed per unit weight of adsorbent, $a$ is the maximum adsorption capacity, $b$ is a constant, and $C_{e}$ is the equilibrium liquid concentration of $\operatorname{As}(\mathrm{V})$. The Freundlich isotherm model is represented in Equation 3.3 [119].

$$
\mathrm{q}_{\mathrm{e}}=\mathrm{K}\left(\mathrm{C}_{\mathrm{e}}\right)^{1 / \mathrm{n}}
$$

where $K$ is the Freundlich constant, and 1/n is the adsorption intensity. 
The adsorption kinetic of IO as a control sample, IOGO5, IOGO10, IOGO15, IOGO20, and IOGO25, was investigated by following a similar approach used with isotherm experiments. The initial $\mathrm{As}(\mathrm{V})$ concentration was $0.5 \mathrm{ppm}$, and the samples were taken at time $0,5,10,20,40$, and $60 \mathrm{~min}$, filtered and analyzed.

Two models were used to fit the kinetic adsorption data of $\mathrm{As}(\mathrm{V})$ : pseudo firstorder and pseudo second-order reactions, shown in Equations (3.4) and (3.5).

$$
\begin{aligned}
& \operatorname{Ln}\left(\mathrm{q}_{\mathrm{e}}-\mathrm{q}_{\mathrm{t}}\right)=\operatorname{Ln}\left(\mathrm{q}_{\mathrm{e}}\right)-\left(\mathrm{k}_{1} * \mathrm{t}\right) \\
& \left(\mathrm{t} / \mathrm{q}_{\mathrm{t}}\right)=\left(\mathrm{k}_{2} * \mathrm{qe}^{2}\right)^{-1}+\left(\mathrm{t} / \mathrm{q}_{\mathrm{e}}\right)
\end{aligned}
$$

where $q_{e}$ and $q_{t}$ are the solid concentration at equilibrium and time $t$, respectively, $\mathrm{k}_{1}$ is the first-order rate constant, and $\mathrm{k}_{2}$ is the second-order rate constant.

\subsection{Results and discussion}

\subsubsection{Characterization of iron oxide (IO), graphene oxide (GO), and IOGO(x) composite materials.}

\subsubsection{Zeta potential}

Lepidocrocite and GO zeta potential was investigated in a $\mathrm{pH}$ range from 2.2 to 9.8 . The zeta potential values of both materials provide an indicator for the nature of surface charge existing on the surface of both particles. At $\mathrm{pH} 4$, lepidocrocite and graphene oxide had zeta potential values with a similar magnitude but opposite signs, which suggests attractive electrostatic forces may induce the formation of homogeneously mixed composite materials. The zeta potential of lepidocrocite varied between $46.7 \mathrm{mV}$ at $\mathrm{pH} 4.5$ 
to $-22.3 \mathrm{mV}$ at $\mathrm{pH}$ 9.1, as shown in Figure 3.2, and its point of zero charge (PZC) was determined to be 8.5 .

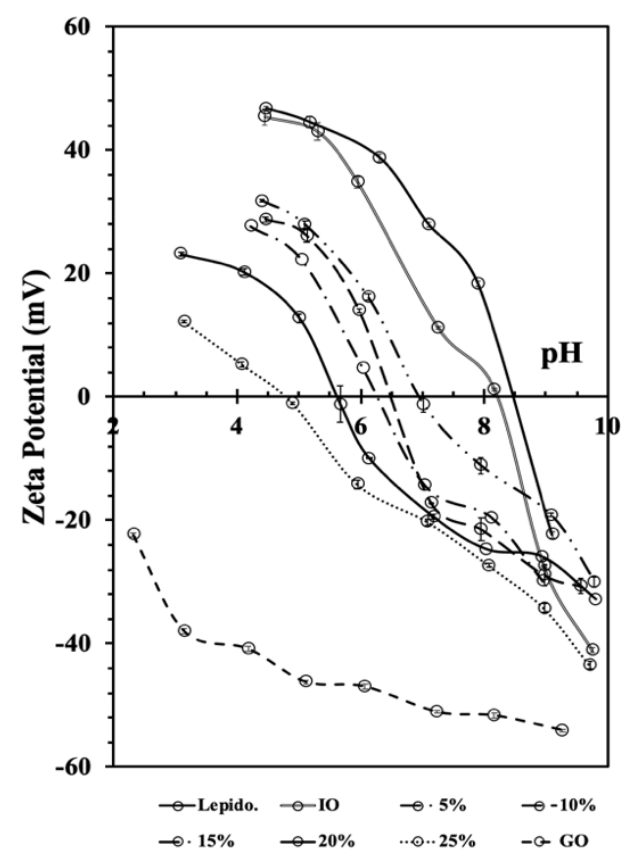

Figure 3. 2 Zeta potentials of lepidocrocite and GO before sintering and IO and IOGOx composites after sintering, suspended in ultrapure water at different values of $\mathrm{pH}$.

The values of GO zeta potential were between $-22.4 \mathrm{mV}$ at $\mathrm{pH} 2.2$ and $-54.1 \mathrm{mV}$ at $\mathrm{pH}$ 9.3. All the values of GO zeta potential sheets recorded were negative, indicating the presence of deprotonated surface groups, mostly hydroxyl and carboxyl groups, at the $\mathrm{pH}$ range studied [120]. In summary, lepidocrocite particles showed strongly positive charged at $\mathrm{pH}$ below 8.5, while the graphene oxide nanoparticles maintained its negative surface charge at all the measured values of $\mathrm{pH}$.

Electrostatic attraction plays a major role in the heteroaggregation of the two particles. Lepidocrocite and graphene oxide showed negatively charged at $\mathrm{pH}>9$; therefore, no aggregation was expected under this condition due to the electrostatic repulsive forces. At $\mathrm{pH} \mathrm{4,} \mathrm{both} \mathrm{materials} \mathrm{showed} \mathrm{an} \mathrm{opposite} \mathrm{surface} \mathrm{charge} \mathrm{which} \mathrm{is} \mathrm{a}$ 
good condition for the mixture of lepidocrocite and GO to produce the new composites. Those differences in the values of zeta potential lead to an increase in the electrostatic attraction between them.

With increasing the weight ratios of $\mathrm{GO}$, the zeta potential of all composite materials showed decreasing in their values and became close gradually to the values of GO zeta potential. Those results reveal that weight ratios of GO added to lepidocrocite has a significant effect through observing the continuous changes in the surface charges of all composites progressively. In this context, the zeta potential values of all sintered composites decreased with continuous increase of GO weight ratios leading to shift the PZC of IOGO5-25 to be $(6.9,6.5,6.2,5.6,4.8)$, respectively. All their surface charges are positive at $\mathrm{pH}<\mathrm{PZC}$. $\mathrm{As}(\mathrm{V})$ is present under most of the $\mathrm{pH}$ conditions as a negative ionic form $\left(\mathrm{H}_{2} \mathrm{AsO}_{4}{ }^{-}\right.$at $\mathrm{pH}$ 2.2-6.5, and $\mathrm{HAsO}_{4}{ }^{-2}$ at 6.5-11.5) [85]. The strong adsorption between IOGOx and $\mathrm{As}(\mathrm{V})$ species will be at $\mathrm{pH}$ lower than PZC because of the electrostatic interactions that happened between negatively charged $\mathrm{As}(\mathrm{V})$ species and positively charged IOGOx. On the other hand, when the $\mathrm{pH}$ of the solution is greater than PZC of IOGOx, the surface charge of all composites will be negatively charged, which leads to an increase in the repulsion between IOGOx and $\mathrm{As}(\mathrm{V})$. As a result, the adsorption capacity will decrease continuously for $\mathrm{As}(\mathrm{V})$.

PZC of all sintered composites showed decreasing values with decreasing IO content, as presented in Figure 3.3. The obtained results revealed that the different weight ratios of GO added to lepidocrocite have a significant effect on shifting PZC's values of the composites to be more acidic pHs because of the contribution of the negative charges of surface functional groups. 


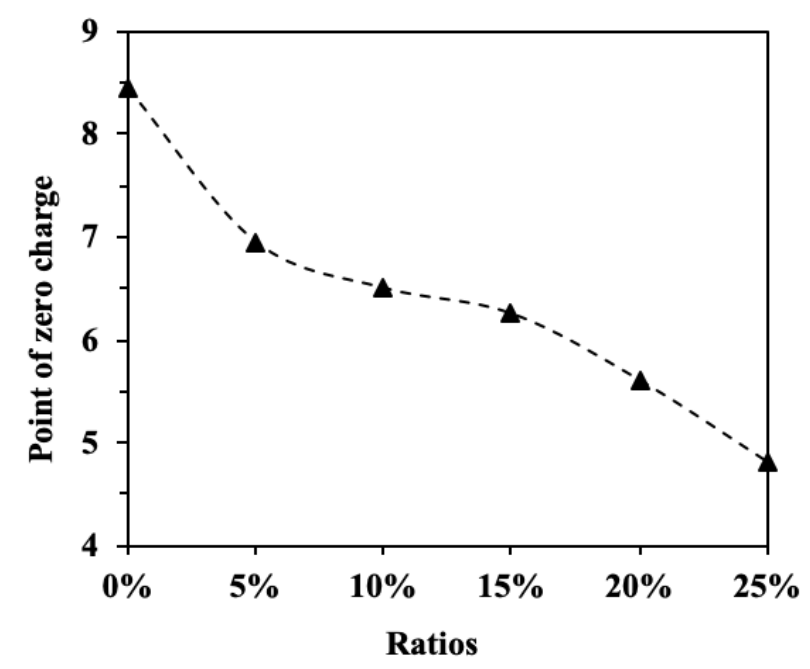

Figure 3. 3 Point of zero charges of hematite and IOGOx composites.

\subsubsection{X-ray diffraction (XRD)}

The crystallinity and composition of the IOGOx before and after sintering were studied by XRD. The X-ray diffraction patterns are presented in Figure 3.4 (a and b). All diffractograms before sintering showed peaks attributable to lepidocrocite and to GO. A strong peak of $\mathrm{GO}$ appeared at $2 \Theta=11^{\circ}$ as a result of the interlayer spacing among the sheets of graphene oxide that contains functional groups on both sides [120]. This peak was not present in the IOGOx diffractograms, which suggests that the lepidocrocite produced the complete exfoliation of graphene sheets and promoted the stability of individual sheets [113]. Also, a weak peak was observed at $43^{\circ}$ due to the graphite powder $[24,25]$. On the other hand, peaks associated with lepidocrocite were observed at $2 \Theta=14^{\circ}$, $27^{\circ}, 36^{\circ}$, and $47^{\circ}$, in agreement with the previous published results [117]. After sintering at $410^{\circ} \mathrm{C}$, the peak of GO shifted from $2 \Theta=12^{\circ}$ to $2 \Theta=23^{\circ}$ and $42^{\circ}$ due to reducing the oxygen functional groups [123]. 

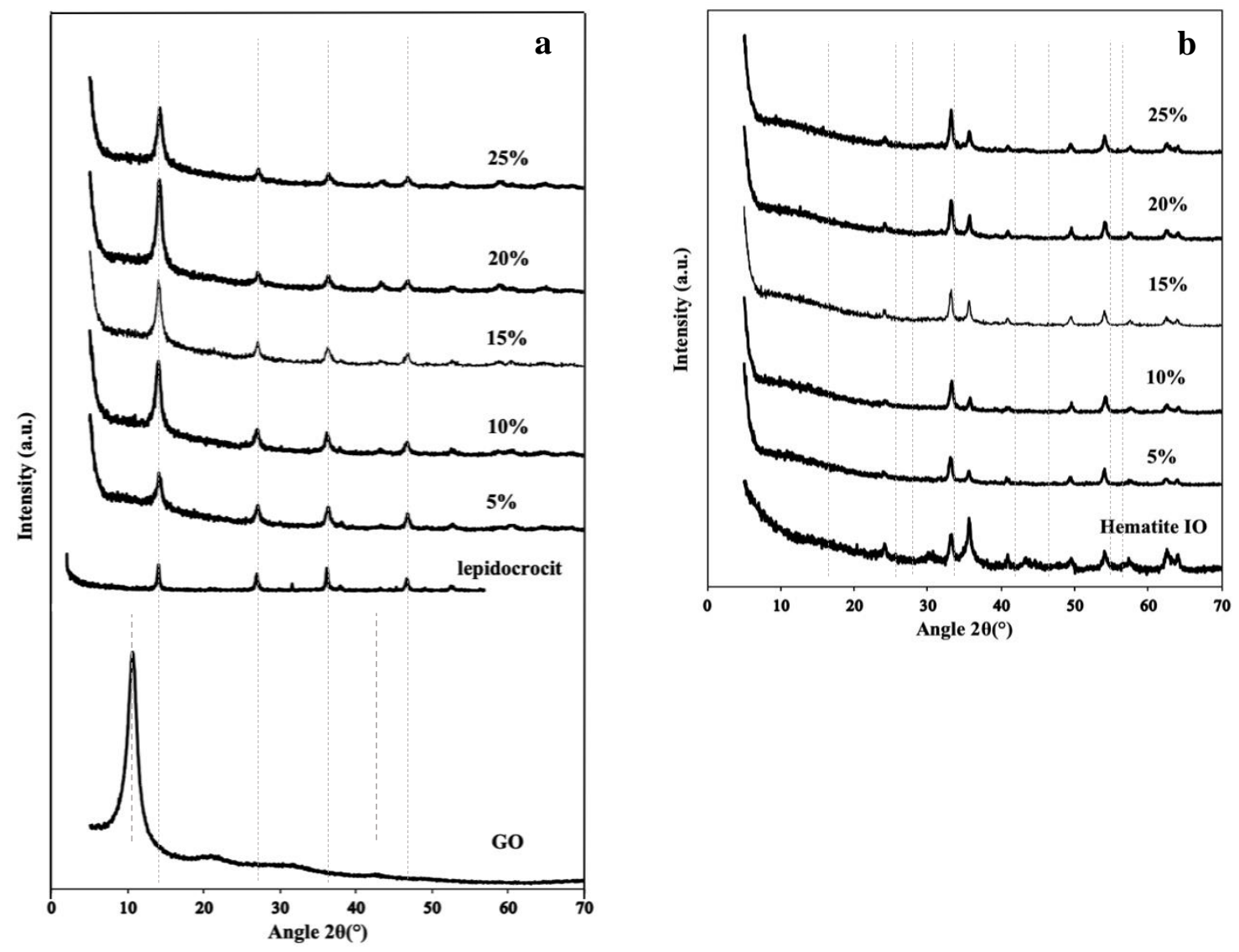

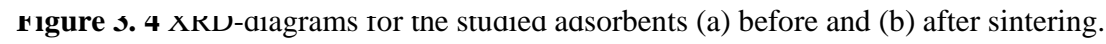

Many distributed peaks appeared at $2 \Theta=24.2^{\circ}, 33.2^{\circ}, 35.7^{\circ}, 40.8^{\circ}, 49.2^{\circ}, 54.1^{\circ}$, $62.6^{\circ}$, and $64.2^{\circ}$ which all belong to hematite. Those peaks confirm that lepidocrocite was converted to hematite due to the thermal conversion process at $410{ }^{\circ} \mathrm{C}$ [124].

\subsubsection{Scanning Electron Microscopy (SEM) images}

SEM images of IOGOx composites before and after sintering are shown in Figure 3.5. The SEM images of all composites before sintering showed irregular surface morphology with several wrinkles on their surfaces [125]. On the other hand, the SEM images of IOGOx show that iron oxide was covered the GO sheets completely and 
irregularly. While after the thermal treatment, the SEM images of IOGOx surfaces confirm that the GO sheets were reduced, and the iron oxide particles grew on their surfaces uniformly. Therefore, it is expected that the number of active sites to adsorb As(V) increased.
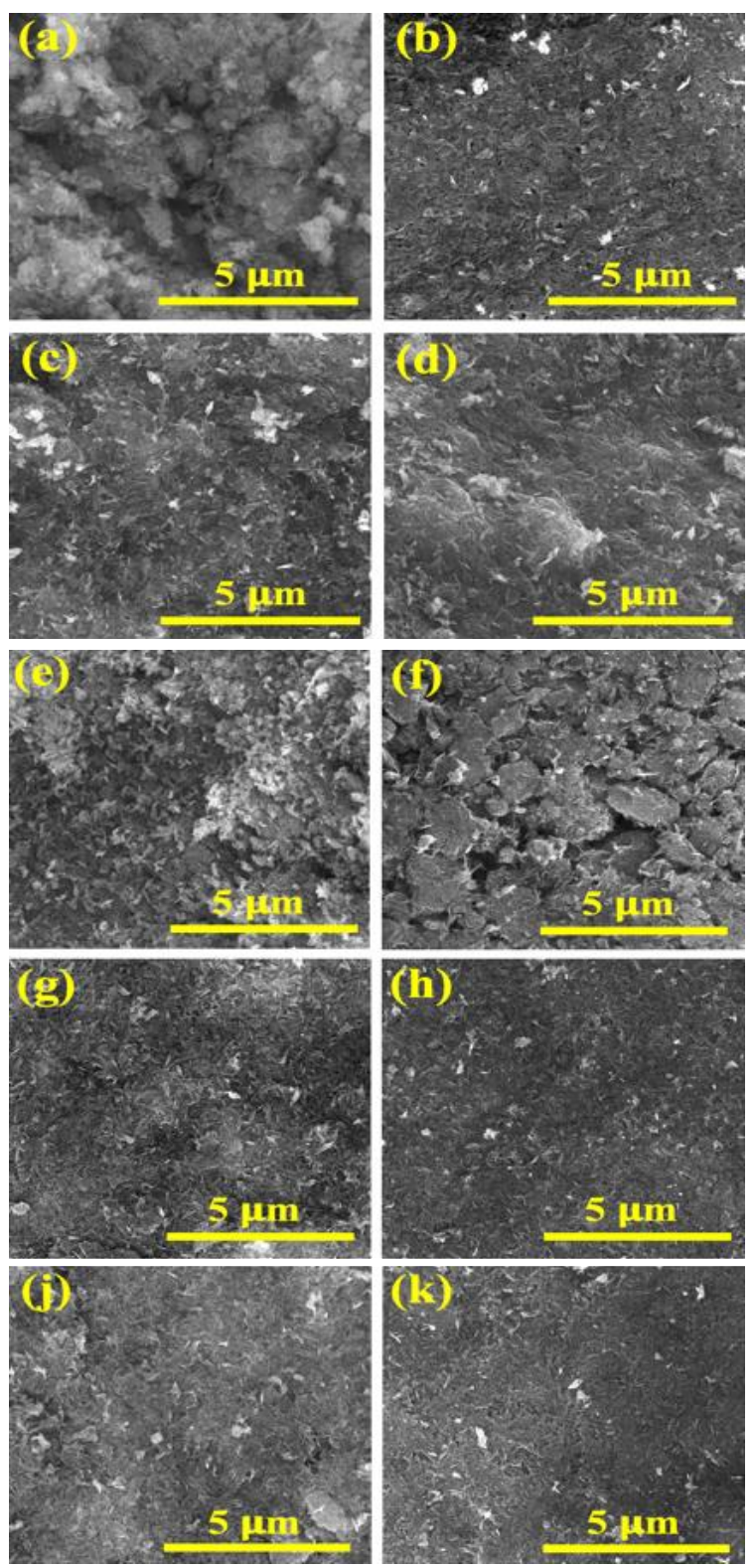

Figure 3. 5 SEM images for: (a)IOGO5; (c)IOGO10; (e)IOGO15; (g)IOGO20; (i)IOGO25 before sintering, and (b)IOGO5; (d)IOGO10; (f)IOGO15; (h)IOGO20; (j)IOGO25 after sintering. 


\subsubsection{Surface area}

The specific surface area of the IO, GO, and IOGOx composites before and after sintering were measured. The GO added to the iron oxide led to an increase in the surface area values of all composites before sintering concerning the control sample, lepidocrocite, as mentioned in Table 3.1. A probable reason for this increase is that the GO sheets attracted the lepidocrocite particles to settle down on their surface. As a result, iron oxide particles will distribute uniformly on the GO surface. However, the surface area of composites showed a slight decrease with increasing the weight ratio of GO. This decrease may be interpreted that the single sheets of GO may form in the form of stacks, which reduces the total available area to interact with the iron oxide.

Table 3. 1 The surface area of graphene oxide, hematite, lepidocrocite, and IOGOx composites before and after sintering.

\begin{tabular}{|c|c|c|c|c|c|c|c|c|}
\hline & \multirow{2}{*}{$\begin{array}{c}\text { Lepidocrocite } \\
\left(\mathbf{m}^{2} / \mathbf{g}\right)\end{array}$} & \multirow{2}{*}{$\begin{array}{c}\text { Hematite } \\
\left(\mathbf{m}^{2} / \mathbf{g}\right)\end{array}$} & $\begin{array}{c}\text { Graphene } \\
\text { oxide }\end{array}$ & \multicolumn{5}{|c|}{ IOGOx Composites $\left(\mathbf{m}^{\mathbf{2}} / \mathbf{g}\right)$} \\
\cline { 7 - 9 } & & --- & $135.2 \pm 0.8$ & $96.9 \pm 0.5$ & $95.1 \pm 0.4$ & $94.5 \pm 0.4$ & $90.3 \pm 0.3$ & $87.2 \pm 0.5$ \\
\hline $\begin{array}{c}\text { Before } \\
\text { sintering }\end{array}$ & $77.8 \pm 0.7$ & --- & $72.9 \pm 0.3$ & $71.1 \pm 0.2$ & $67.1 \pm 0.1$ & $65.3 \pm 0.1$ & $61.9 \pm 0.2$ \\
\hline $\begin{array}{c}\text { After } \\
\text { sintering }\end{array}$ & --- & $30.4 \pm 0.4$ & -- & $\mathbf{1 0 \%}$ & $\mathbf{1 5 \%}$ & $\mathbf{2 0 \%}$ & $\mathbf{2 5 \%}$ \\
\hline
\end{tabular}

After sintering, the IO surface area showed decreasing in its value because of the densification caused by the thermal treatment [117][126]. The surface area of IOGOx after sintering at $410{ }^{\circ} \mathrm{C}$ additionally decreased because of the reduction of GO by iron oxide particles, which enhanced the contact between the surface of GO with air for combustion [104]. 

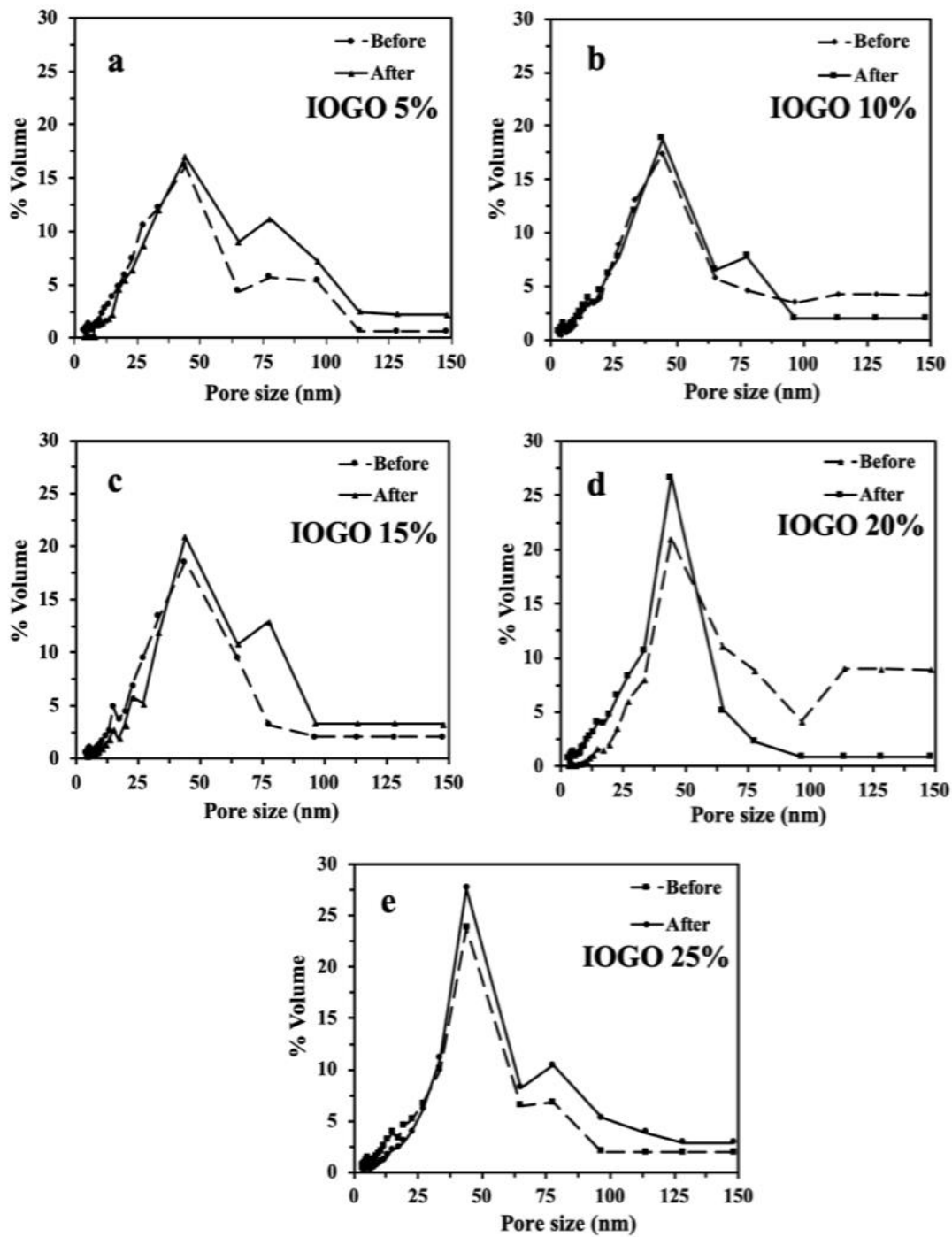

Figure 3. 6 The relationship between percentage of total pores and pore size for: (a)IOGO5; (b)IOGO10; (c)IOGO15; (e)IOGO20; (d)IOGO25 composites.

The relationship between the percentage of pore volume and the pore size is depicted in Figure 3.6. The results showed that the sintering process led to a slight increase in the percentage of mesopore volume (pores $\leq 50 \mathrm{~nm}$ ) in all composites resulting from aggregation/packing of the crystalline of hematite nanoparticles [104]. Figure 3.7 shows clearly that the surface area and the total pore volume of composite materials decreased 
together after sintering because of burning GO that led to blocking the pores in composite materials.

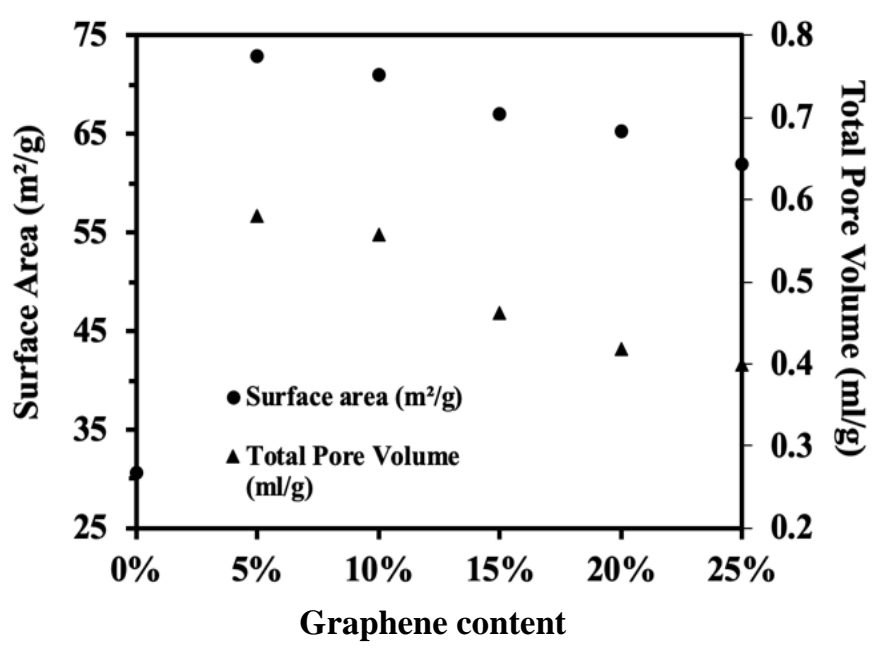

Figure 3. 7 Surface area and total pore volume of fabricated composites after sintering, as a function of graphene content.

\subsubsection{TGA}

The TGA curves for lepidocrocite, GO, and IOGOx samples are shown in Figure 3.8. The mass loss for the GO particles happened in two stages: first, the loss of $40 \%$ of GO mass occurred between 25 and $230{ }^{\circ} \mathrm{C}$, due to the evaporation of adsorbed water on the surface and some labile oxygen functional groups [127]. Second, 55\% of the remaining mass was lost between 230 and $550{ }^{\circ} \mathrm{C}$, as a result of the combustion of GO framework and the decomposition of more stable oxygen functionalities $[18,19]$. After $550{ }^{\circ} \mathrm{C}$, the mass loss of GO became negligible.

The TGA curve of iron oxide shows three stages of mass loss; first, lepidocrocite lost $2.5 \%$ of its weight within $25{ }^{\circ} \mathrm{C}$ to $100{ }^{\circ} \mathrm{C}$ corresponding to the adsorbed water molecules on its surface. In the second stage, between $200{ }^{\circ} \mathrm{C}$ and $275^{\circ} \mathrm{C}$, the iron oxide lost $7 \%$ of its weight, which belongs to the evaporation of molecules of water in the 
structure of lepidocrocite, and conversion from hydroxide to oxide [109]. During this step, the lepidocrocite was transformed into maghemite $\left(\gamma-\mathrm{Fe}_{2} \mathrm{O}_{3}\right)$. Finally, the weight loss in the third stage, between $300{ }^{\circ} \mathrm{C}$ and $800{ }^{\circ} \mathrm{C}$, was negligible, and the maghemite was transformed to hematite $\left(\alpha-\mathrm{Fe}_{2} \mathrm{O}_{3}\right)$ in this step [130].

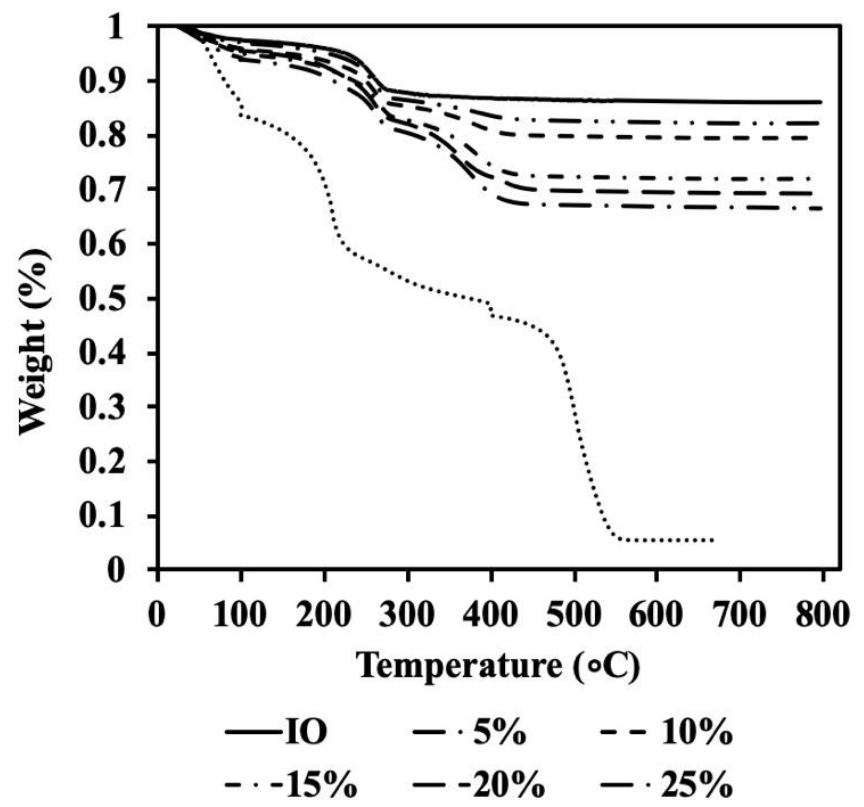

Figure 3.8 TGA curves Lepidocrocite, IOGOx, and GO in the air atmosphere.

Three steps can be observed for weight loss of the composite materials. The first occurred within $25^{\circ} \mathrm{C}$ and $100{ }^{\circ} \mathrm{C}$ because of evaporating the adsorbed water molecules. The second step happened between $200{ }^{\circ} \mathrm{C}$ and $280^{\circ} \mathrm{C}$ because of decomposition of oxygen that exists in functional groups of graphene. The last weight loss occurs between $300{ }^{\circ} \mathrm{C}$ and $380{ }^{\circ} \mathrm{C}$, and it may be related to the decomposition of the carbon skeleton of the composite materials [21][22]. With increasing content of iron oxide, the temperature of weight loss gradually decreased from $380{ }^{\circ} \mathrm{C}$ with IOGO25 to $350{ }^{\circ} \mathrm{C}$ with IOGO20 to 320 ${ }^{\circ} \mathrm{C}$ with IOGO15 to $270{ }^{\circ} \mathrm{C}$ IOGO10, and to $250{ }^{\circ} \mathrm{C}$ IOGO5. Those results could be interpreted that the existence of iron oxide particles on the surface of GO acts as a catalyst 
for the carbon combustion since their exothermic oxidation takes place at lower temperatures [133].

\subsection{Arsenic Adsorption on IOGO(x)}

\subsubsection{Adsorption isotherms}

The performance of hematite and IOGOx as adsorbent of $\mathrm{As}(\mathrm{V})$ was systematically examined in batch reactors at room temperature $\left(23^{\circ} \mathrm{C}\right)$. The initial concentrations of $\mathrm{As}(\mathrm{V})$ in the adsorption experiments of hematite and IOGOx were varied, and the mass of adsorbent added was kept constant at 0.2 grams. The experimental conditions tested are summarized in Table 3.2.

Table 3. 2 The initial concentrations of $\mathrm{As}(\mathrm{V})$ in adsorption isotherm experiments.

\begin{tabular}{c|c}
\hline Adsorbents & Initial As(V) concentrations (ppm) \\
\hline $\begin{array}{c}\text { Hematite } \\
\text { IOGO5 } \\
\text { IOGO10 }\end{array}$ & $0.5,1,2,3,5,6,8,10$ \\
\hline IOGO15 & $0.5,1,2,3,5,6,8,10,15$ \\
\hline IOGO20 & $0.5,1,2,3,5,6,8,10,15,20,25$ \\
IOGO25 &
\end{tabular}

All experiments were conducted at $\mathrm{pH}$ 7. For each composite material, experiments were conducted with increasing initial concentrations of $\mathrm{As}(\mathrm{V})$ until no changes in the final (equilibrium) solid concentration $\left(q_{e}\right)$ between two experiments was observed, i.e., the solid reached saturation.

The results showed that hematite had the lowest adsorption capacity of the materials tested, with a $q_{\max }$ of $12.6 \mathrm{mg} \mathrm{g}^{-1}$. At the same time, IOGO25 recorded the highest adsorption capacity, at $40.3 \mathrm{mg} \mathrm{g}^{-1}$, as shown in Figure 8. Isotherm curves of hematite, IOGO5, and IOGO10 reached a plateau sooner, i.e., at lower initial As(V) concentrations 
than other adsorbents, as shown in Figure 3.9. Therefore, experiments with a higher initial concentration of $\mathrm{As}(\mathrm{V})$ were conducted with the remaining adsorbents to investigate their saturation. The results showed adsorption capacity of IOGO15, IOGO20, and IOGO25 were $21.11 \mathrm{mg} \mathrm{g}^{-1}, 38.4 \mathrm{mg} \mathrm{g}^{-1}$, and $40.3 \mathrm{mg} \mathrm{g}^{-1}$, respectively, and they reached an apparent plateau. Table 3.3. presents a comparison among $\mathrm{As}(\mathrm{V})$ adsorption capacities with some studied that used various adsorbents as nanoparticles or composite materials by using IO, GO, rGO.

The addition of GO to the iron oxide led to gradual improvements in the As(V) adsorption capacity of the composite material, as shown in Figure 3.9. This increment could be interpreted as an enhancing effect of the GO sheets, which led to a uniform distribution of iron oxide particles on their surface and therefore develop and enhanced accessibility to the adsorption sites.

Table 3. 3 Comparison of maximum As(V) adsorption capacity.

\begin{tabular}{|c|c|c|c|c|c|}
\hline Adsorbent & $\begin{array}{c}\text { Surface } \\
\operatorname{area}\left(\mathrm{m}^{2}\right. \\
\left.\mathrm{g}^{-1}\right)\end{array}$ & $\begin{array}{c}\text { Adsorbents weight } \\
\text { (mg)/ volume of } \\
\text { solution }(\mathrm{ml})\end{array}$ & $\begin{array}{l}\text { Initial } \\
\operatorname{As}(\mathbf{V}) \\
(\mathbf{p p m}) \\
\end{array}$ & $\begin{array}{c}\mathbf{q}_{\max }\left(\mathbf{m g ~ g ^ { - 1 }}\right) \\
\text { for } \operatorname{As}(V)\end{array}$ & Ref. \\
\hline $\begin{array}{c}\alpha-\mathrm{Fe}_{2} \mathrm{O}_{3}-\mathrm{Fe}_{3} \mathrm{O}_{4}- \\
\mathrm{GO} \text { composite }\end{array}$ & 70.2 & $9 / 50$ & $1-30$ & 54.18 & [134] \\
\hline $\begin{array}{l}\text { Iron-doped } \\
\text { activated micro/ } \\
\text { nanocarbon } \\
\text { particles }\end{array}$ & 231 & $100 / 20$ & $0.5-20$ & 5 & [135] \\
\hline $\begin{array}{c}\alpha-\mathrm{Fe}_{2} \mathrm{O}_{3} \\
\text { nanoparticles }\end{array}$ & 162 & $80 / 100$ & 100 & 47 & [136] \\
\hline $\begin{array}{c}\gamma-\mathrm{Fe}_{2} \mathrm{O}_{3} \\
\text { nanoparticles }\end{array}$ & 168.73 & $0.005,7,10,20$ & 0.095 & 95.37 & [137] \\
\hline $\begin{array}{c}\gamma-\mathrm{Fe}_{2} \mathrm{O}_{3}-\mathrm{GO} \\
\text { composite }\end{array}$ & 341 & $0.1-1$ & $350-1200$ & 113 & [104] \\
\hline
\end{tabular}

This is further facilitated by the increase in the ratio of mesoporosity to microporosity after sintering, which means $\mathrm{As}(\mathrm{V})$ ions will reach the active sites faster. 
This study showed the efficacy of the adsorption treatment because hematite and all composites were able to reduce the concentration of $\mathrm{As}(\mathrm{V})$ from $0.5 \mathrm{mg} / \mathrm{L}$ to below 10 $\mu \mathrm{g} / \mathrm{L}$ which is the recommended maximum permissible concentration of arsenic in drinking water by World Health Organization (WHO) [105].

Langmuir and Freundlich adsorption isotherm models were applied to interpret the experimental isotherm data. Table 3.4 shows the calculated parameters and correlation coefficients $\left(\mathrm{R}^{2}\right)$ for the two isotherm models. Although both models presented acceptable $\mathrm{R}^{2}$ values, the results showed that Langmuir isotherm model was overall a better fit with isotherm data of hematite and IOGO5, IOGO10, IOGO15, IOGO20, IOGO25, and their correlation coefficients $\left(\mathrm{R}^{2}\right)$ were above 0.9 , which means the adsorption of $\mathrm{As}(\mathrm{V})$ on these materials can be well described by the Langmuir expression [24].

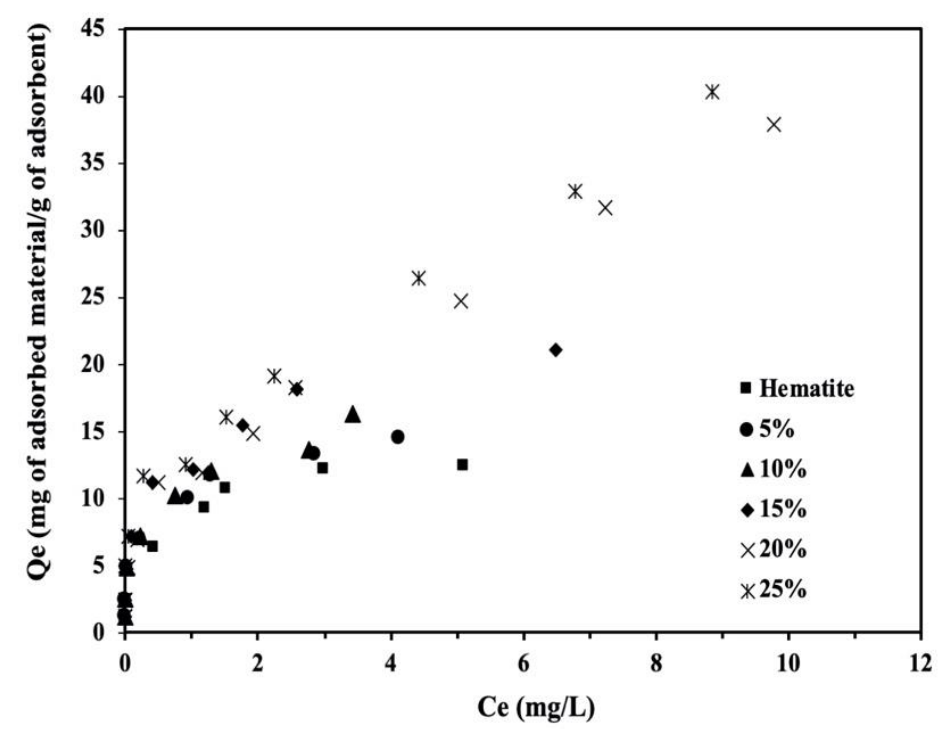

Figure 3.9 $\mathrm{As}(\mathrm{V})$ adsorption isotherms at $\mathrm{pH} 7$ and IS $(1 \mathrm{mM})$ of the hematite control sample and IOGO(x) composites. 
Table 3. 4 Summary of model parameters and correlation coefficients for Langmuir and Freundlich isotherms removal of As(v) by hematite and IOGOx.

\begin{tabular}{c|cccccc} 
& \multicolumn{3}{c}{ Langmuir model } & \multicolumn{3}{c}{ Freundlich model } \\
\cline { 2 - 7 } Adsorbents & $\mathbf{R}^{\mathbf{2}}$ & $\begin{array}{c}\boldsymbol{b} \\
(\mathbf{L} / \mathbf{m g})\end{array}$ & $\begin{array}{c}\mathbf{q} \text { max } \\
\left(\mathbf{m g ~ g}^{-1}\right)\end{array}$ & $\boldsymbol{k}_{f}$ & $\boldsymbol{n}$ & $\mathbf{R}^{\mathbf{2}}$ \\
\hline Hematite (IO) & 0.99 & 4.9 & 12.6 & 9.4 & 1.7 & 0.94 \\
IOGO5 & 0.99 & 5.6 & 14.5 & 11.0 & 1.8 & 0.97 \\
IOGO10 & 0.98 & 5.1 & 16.3 & 11.7 & 1.9 & 0.94 \\
IOGO15 & 0.98 & 2.1 & 19.3 & 14.3 & 2.8 & 0.97 \\
IOGO20 & 0.90 & 0.7 & 38.4 & 17.9 & 3.9 & 0.78 \\
IOGO25 & 0.93 & 1.1 & 40.3 & 20.4 & 4.3 & 0.83
\end{tabular}

Table 3.5 shows the adsorption capacity normalized by the surface area of hematite and the composite adsorbents. As(V) adsorption capacity of all composites increased with GO wt \%, which suggests an enhancement of the surface area utilization, as the presence of the graphene sheets may facilitate the access to the active sites of the iron oxide particles.

Table 3. 5 Adsorption capacity normalized by specific surface area.

\begin{tabular}{|c|c|c|c|c|c|c|}
\hline & \multicolumn{6}{|c|}{ After sintering } \\
\hline & \multirow{2}{*}{ Hematite } & \multicolumn{5}{|c|}{ IOGO Composites } \\
\hline & & 5 & 10 & 15 & 20 & 25 \\
\hline $\begin{array}{c}\text { Adsorption Capacity }(\mathrm{mg} / \mathrm{g}) \\
\text { Surface } \text { area }\left(\mathrm{m}^{2} / \mathrm{g}\right)\end{array}$ & $0.41 \pm 0.01$ & $0.2 \pm 0.01$ & $0.23 \pm 0.01$ & $0.29 \pm 0.01$ & $0.59 \pm 0.01$ & $0.65 \pm 0.01$ \\
\hline
\end{tabular}

\subsubsection{Adsorption kinetics of $\operatorname{As}(V)$ on the composite materials}

The adsorption kinetic curves of hematite and IOGOx adsorbents at the initial $\mathrm{As}(\mathrm{V})$ concentration of $0.5 \mathrm{ppm}$ are shown in Figure 3.10a-f. The adsorption process can be divided into two distinct stages depending on the values of $\mathrm{As}(\mathrm{V})$ uptake rate. The first stage showed that a fast adsorption rate on hematite $1.9 \mathrm{mg}$ As(V)/L.hr and IOGO5 $2.3 \mathrm{mg}$ As(V)/L.hr, respectively, happened within the first 10 minutes of adsorption kinetic experiment. The second stage started at 10 mins until 40 min., and the uptake rates of As(V) 
became slower 0.29 and $0.22 \mathrm{mg} \mathrm{As}(\mathrm{V}) / \mathrm{L} . \mathrm{hr}$, respectively. On the other hand, the first stage of IOGO10, IOGO15, IOGO20 and IOGO25 occurred during the first 5 minutes, and it can be observed the fast decrease in $\mathrm{As}(\mathrm{V})$ concentration during this period at rates of 4.4, 4.5, 4.6, $4.7 \mathrm{mg} \mathrm{As}(\mathrm{V}) / \mathrm{L} . h r$, respectively. While their second stages began after 5 minutes until 40 minutes, and their $\mathrm{As}(\mathrm{V})$ uptake rates were $0.19,0.18,0.17,0.16 \mathrm{mg}$ $\operatorname{As}(\mathrm{V}) / \mathrm{L} . h r$, respectively.
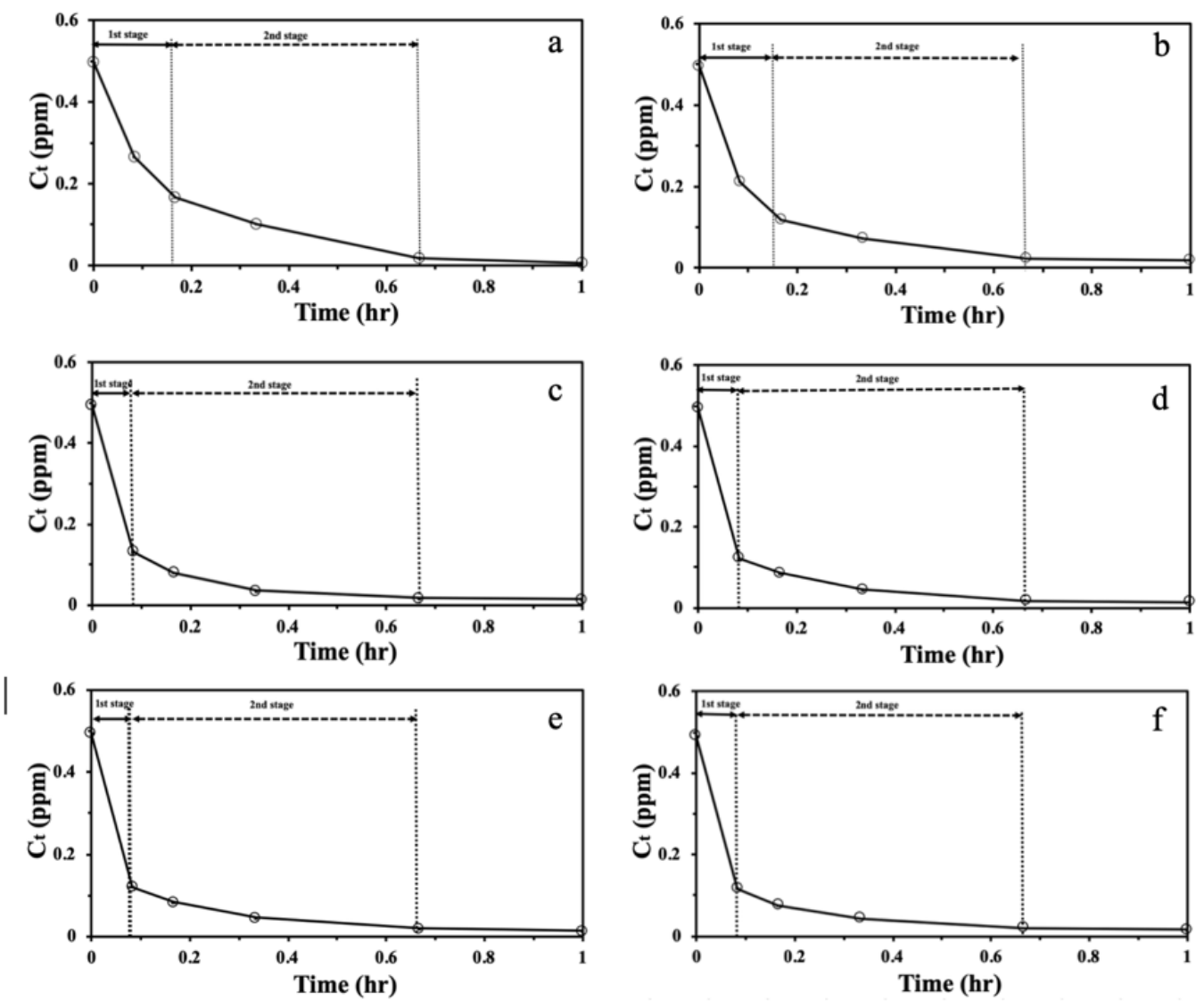

Figure 3. $10 \mathrm{As}(\mathrm{V})$ adsorption kinetic curves of (a) hematite control sample and (b-f) IOGO(5-25) composite materials, respectively.

Adsorption rate of IOGO25 was recorded as a faster one among the others because it achieved 76\% $\mathrm{As}(\mathrm{V})$ removal during the first 5 minutes and $95 \% \mathrm{As}(\mathrm{V})$ removal after 40 minutes from the beginning. After 40 minutes, all the uptake rates of all the adsorbents were negligible. All the adsorbents used in this study were able to reduce the concentration 
of $\mathrm{As}(\mathrm{V})$ in the solution to below $10 \mu \mathrm{g} / \mathrm{L}$ with fast adsorption rates, which gives a good indication about the benefits of loading GO on iron oxide through reducing the required adsorption time for removal $\mathrm{As}(\mathrm{V})$ and increasing the adsorption capacity of adsorbents.

The pseudo first and second-order kinetic models were applied to understand the adsorption behavior of the materials. Table 3.6 presents the parameters and regression coefficients of the two kinetics models. Based on the $\mathrm{R}^{2}$ values, pseudo second-order rate showed a better fit than the pseudo first-order rate to simulate the adsorption kinetic of As(V) with all adsorbents used in this study. Therefore, the pseudo second-order model suggests that chemical sorption should be the rate limiting step for As(V) adsorption by composite materials [139].

\subsection{Adsorption mechanism of $\mathrm{As}(\mathrm{V})$ on IOGO composite adsorbent}

Several major and minor forms of $\mathrm{As}(\mathrm{V})$ undergo acid-base equilibrium, so the predominant form of $\mathrm{As}(\mathrm{V})$ species present in water depends on $\mathrm{pH}$ value. Therefore, the dissociation process of $\mathrm{As}(\mathrm{V})$ in water will follow those steps:

$$
\begin{array}{ll}
\mathrm{H}_{3} \mathrm{AsO}_{4} \leftrightarrow \mathrm{H}^{+}+\mathrm{H}_{2} \mathrm{AsO}_{4}^{-} & \mathrm{pK}_{\mathrm{al}}=2.1 \\
\mathrm{H}_{2} \mathrm{AsO}_{4}^{-} \leftrightarrow \mathrm{H}^{+}+\mathrm{HAsO}_{4} 4^{2-} & \mathrm{pK}_{\mathrm{a} 2}=6.7 \\
\mathrm{HAsO}_{4}{ }^{2-} \leftrightarrow \mathrm{H}^{+}+\mathrm{AsO}_{4}^{3-} & \mathrm{pK}_{\mathrm{a} 3}=11.2
\end{array}
$$

The governing forms of $\mathrm{As}(\mathrm{V})$ in this study were $\mathrm{H}_{2} \mathrm{AsO}_{4}{ }^{-}\left(\mathrm{pH} \mathrm{2-7}\right.$ ) and $\mathrm{HAsO}_{4}{ }^{{ }^{-}}$ ( $\mathrm{pH} 7-11)$ since all the experiments were conducted at $\mathrm{pH} 7$ [140]. Two major mechanisms have been proposed as responsible for the adsorption of $\mathrm{As}(\mathrm{V})$ ions on the surface of IOGO(x) composites. The first mechanism is surface complexation which involves the adsorption of $\mathrm{H}_{2} \mathrm{AsO}_{4}{ }^{-}$and $\mathrm{HAsO}_{4}{ }^{2^{-}}$ions on the surface of composites by forming inner sphere complex between the surface of the iron oxide and As(V) acid through As-O-Fe 
linkage; As- $\mathrm{O}(\mathrm{H})$ species can additionally undergo ligand exchange reactions with hydroxide groups from the surface of $\mathrm{Fe}_{2} \mathrm{O}_{3}$ to form inner sphere complex. The second mechanism comprises electrostatic interactions between $\mathrm{As}(\mathrm{V})$ ions and the functional groups of graphene oxide, such as carboxyl and hydroxyl [138]. We suggested in this study that surface complexation is the main mechanism for $\mathrm{As}(\mathrm{V})$ adsorption on the surface of adsorbents because GO lost more than $50 \%$ of its weight after sintering it at high temperature $\left(410^{\circ} \mathrm{C}\right)$ and, as a result, missed most of its functional groups on the surface. Therefore, electrostatic interactions are expected to be a minor mechanism of adsorption. The role of the GO is important in allowing iron oxide particles to distribute uniformly on the GO surface, and to provide easy access to the active sites of iron oxide, as was observed by the increased adsorption capacity of As(V) shown in Table 6.

Table 3. 6 Fitting parameters of $\mathrm{As}(\mathrm{v})$ adsorption kinetics on $\mathrm{IOGO}(\mathrm{x})$ and hematite.

\begin{tabular}{|c|c|c|c|c|c|c|c|}
\hline \multirow[b]{2}{*}{ Adsorbents } & \multirow[b]{2}{*}{$\begin{array}{r}\text { qeq (exp.) } \\
\left(\mathbf{m g ~ g}^{-1}\right)\end{array}$} & \multicolumn{3}{|c|}{ Pseudo second order } & \multicolumn{3}{|c|}{ Pseudo first order } \\
\hline & & $\mathbf{R}^{2}$ & $\begin{array}{c}k_{2} \\
\left(\text { g.mg }{ }^{-1} \cdot h^{-1}\right)\end{array}$ & $\begin{array}{c}\text { qeq (Cal.) } \\
\left(\mathrm{mg} \mathrm{g} \mathrm{g-1)}^{-1}\right)\end{array}$ & $\mathbf{R}^{2}$ & $\begin{array}{c}k_{1} \\
\left(h^{-1}\right)\end{array}$ & $\begin{array}{l}\text { qeq (Cal.) } \\
\left(\mathbf{m g ~ g ~}^{-1}\right)\end{array}$ \\
\hline Hematite & 1.24 & 1 & 24.9 & 1.24 & 0.57 & 0.34 & 0.043 \\
\hline IOGO5 & 1.23 & 1 & 0.345 & 1.23 & 0.66 & 0.38 & 0.092 \\
\hline IOGO10 & 1.23 & 1 & 0.384 & 1.23 & 0.55 & 0.32 & 0.079 \\
\hline IOG015 & 1.22 & 1 & 0.472 & 1.22 & 0.69 & 0.36 & 0.062 \\
\hline IOGO20 & 1.22 & 1 & 0.497 & 1.22 & 0.73 & 0.49 & 0.065 \\
\hline IOGO25 & 1.21 & 1 & 0.577 & 1.21 & 0.59 & 0.56 & 0.056 \\
\hline
\end{tabular}

\subsection{Conclusions}

In this project, new composite materials of iron/graphene oxides (IOGO) were fabricated using different weight ratios of graphene oxide $(5,10,15,20,25 \%)$. The produced composites were first dried in an oven at $80{ }^{\circ} \mathrm{C}$ then sintered in a furnace at $410^{\circ} \mathrm{C}$. Zeta potential, X-ray diffraction (XRD), Scanning electronic microscopy (SEM), Surface area (BET), and Thermogravimetric analysis (TGA) were investigated to study the composites 
morphologies and characteristics before and after sintering. The results of XRD confirmed that graphite and lepidocrocite in the composites were transformed to graphene oxide and hematite after sintering. The amounts of graphene oxide added to iron oxide led to increase the surface area of all the composites as confirmed by BET. The results shows that As(V) adsorption capacities increased significantly when the weight ratios of graphene oxide increased. The higher As(V) adsorption capacity was noticed with IOGO25 composite, and its reaction rate was faster than hematite control sample and other composites. Pseudosecond order kinetic model was a well fit to describe the As(V) adsorption kinetics. This study suggested that the surface complexation is the main mechanism for $\mathrm{As}(\mathrm{V})$ adsorption on the surface of adsorbents. Because of their availability and their low cost, this research highlights on using lepidocrocite and graphite to fabricating adsorbents that have a good ability to remove $\mathrm{As}(\mathrm{V})$ from water. 


\section{Chapter 4: Asymmetric Tubular Membranes coated by Multi- layers of $\mathrm{TiO}_{2} /$ Polyaniline}

\subsection{Introduction}

Freshwater availability plays an important role in developing economies, industries, communities, etc. [141]. Recently, the fast growth of communities around the world has led the industries and farms to increase their productivities to provide the demands of communities. Therefore, the water consumption by industries has been increasing day by day, and, as a result, the released toxic contaminants will increase [2,3[144]. Experts and protection agencies in the environment field have been trying to find proper technologies that make the treatment easier, more efficient, and cost-effective. Membrane Separation Processes (MSPs) have been rapidly progressing in the field of water and wastewater treatment because of minimizing the risk related with contaminants and their sources, high-efficiency rate for removal low MW of organic pollutants, and their ability and modularity to combine with other techniques [145][146]. Therefore, developing cost-effective and stable materials and treatments has become an urgent necessity to deal with the modern challenges for providing freshwater in a sufficient amount.

Recently, many new treatment technologies and methods have been invented, but they need to be developed to be more economical, effective, and stable in comparison with the used techniques nowadays. Thus, this is an important step to achieve significant saving of potable water by reusing wastewater and treating the worsening drinking water quality day by day [7]. 
Nowadays, nanocomposite membranes have been attracting researchers for sustainable water purification by using different techniques such as electrospinning [147], layer-by-layer assembly [148], physical coating [149], and self-assembly [150]. Consequently, incorporation nanoparticles consisting of metal oxides such as $\mathrm{Al}_{2} \mathrm{O}_{3}$, $\mathrm{Fe}_{2} \mathrm{O}_{3}, \mathrm{SiO}_{2}$, and $\mathrm{TiO}_{2}[151]$ in polymer matrices will enhance the physicochemical properties and functionalities to membranes [152]. This study suggests to coat a group of the tubular ceramic membrane by multilayers of $\mathrm{TiO}_{2} /$ Polyaniline through using the condensed layer deposition, then investigate their characteristics such as surface and crosssectional morphology, flux, permeability, fouling, and rejection. Therefore, two different molecular weights of polyethylene glycol (PEG) (20 and $200 \mathrm{kDa}$ ) will be used as a model to study the evolution of fouling and rejection over time.

\subsection{Experimental}

\subsubsection{Materials}

All reagents were analytical grade and used as purchased without additional purification. Polyethylene glycol (PEG) $\mathrm{C}_{2 n} \mathrm{H}_{4 n+2} \mathrm{O}_{\mathrm{n}+1}(\mathrm{MW} 20000$ and 200000 Da), potassium hydrogen phthalate $(\geq 99.95 \%)$, ammonium persulfate $(\geq 98 \%)$, and titanium isopropoxide (99.9\%) were purchased from Sigma-Aldrich (St Louis, MO, USA). Hydrochloric acid (38\% analytical grade) and heptane ( $\geq 99 \%)$ were acquired from Alfa Aesar (Tewksbury, MA, USA). Aniline liquid ( $\geq 99 \%$ ) was purchased from Fisher Scientific (Pittsburgh, PA, USA). Ultrapure water $(18.2 \mathrm{M} \Omega . \mathrm{cm})$ was used in all the experiments and provided by Thermo Scientifi $^{\mathrm{c}}$ Barnstead $^{\mathrm{TM}}$ E-pure ${ }^{\mathrm{TM}}$ ultrapure Water Purification System, (Waltham, MA, USA). Ultrapure water was used in all experiments 
from Type I $(18 \mathrm{M} \Omega * \mathrm{~cm})$ and obtained from a Barnstead E-pure ultrapure Water Purification System (Thermo Scientific, Waltham, MA, USA).

\subsubsection{Preparation and coating of tubular microfiltration ceramic membrane}

Alumina porous ceramic tubes that were used in this study as support material were provided by Instituto Tecnológico de Buenos Aires. The dimensions of tubular ceramic membranes were $15 \mathrm{~cm}$ long with an outer diameter of $9.5 \mathrm{~mm}$ and an inner diameter of $3.2 \mathrm{~mm}$, as shown in Figure 4.1(a,b). Membranes were cut to 3 pieces, each $4 \mathrm{~cm}$ long. Samples were subjected to 1,2,3,4 coating layers. The coating procedure was carried out in a consecutive pattern, and it can be described as follow: to create the first layer, the tubular membranes were placed in $200 \mathrm{ml}$ heptane under gentle stirring for 10 minutes. Then 0.5 $\mathrm{ml}$ of $0.5 \mathrm{M}$ of titanium isopropoxide was added to the solution.
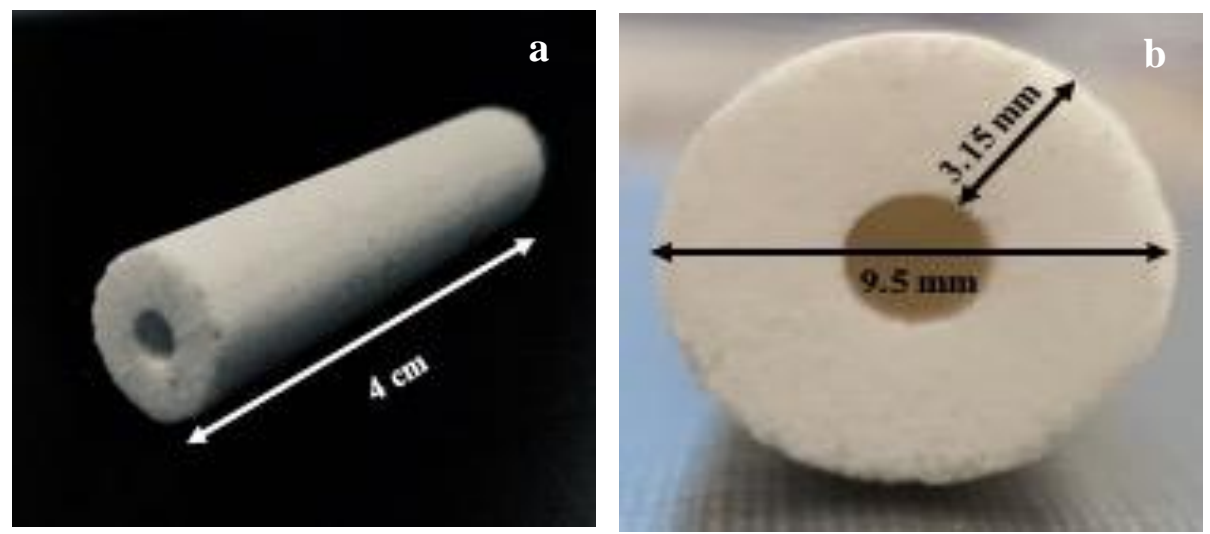

Fig. 4. 1 The dimensions of the used membrane (a) the length (b) the cross-section.

The membrane was left for 30 minutes to form a titania layer on its surface. The process conducted under ultrapure nitrogen gas flow is used to prevent any loss of the precursor due to the air moisture. The second coating agent is the polyaniline (PANI), which was proposed to enhance the bonding between the first and second layers of the $\mathrm{TiO}_{2}$ layer in addition to reduce the size of the micron level of the pores. The PANI- $\mathrm{TiO}_{2} /$ rods 
composite was prepared by an oxidation polymerization process, as reported elsewhere [153]. In a typical approach, $500 \mu \mathrm{L}$ of aniline solution was first dissolved into $2 \mathrm{ml}$ of 0.5 $\mathrm{M} \mathrm{HCl}$ solution, and then the $\mathrm{TiO}_{2} /$ rods were added under stirring for 30 minutes. After the above mixture was confirmed to be homogenous, $5 \mathrm{ml}$ of $0.5 \mathrm{M}$ ammonium persulfate (as an oxidizer) solution was added dropwise with vigorous stirring. The above suspension was stirred overnight, filtered, washed with DI-water, and finally dried at $80^{\circ} \mathrm{C}$ overnight. To make the third layer of $\mathrm{TiO}_{2}$, the first step was repeated to create a $\mathrm{TiO}_{2}-\mathrm{PANI}-\mathrm{TiO}_{2} / \mathrm{rod}$ composite.

\subsubsection{Experimental system setup}

The experimental set up for the filtration studies and its membrane module with tubular configuration, which was used to house the filters are shown in Figure 4.2. An $8 \mathrm{~L}$ tank was used for the feed. Peristaltic Pump, flowmeters with flow control valves to measure and control the values of inflow and outflow rates, and pressure gauge for monitoring the pressure changes inside the system were purchased from (Cole-Parmer, Vernon Hill, IL, USA).

The feed solution was pumped into the system at a constant inflow rate of 33 $\mathrm{ml} / \mathrm{min}$, and the retentate flow rate was $22.5 \mathrm{ml} / \mathrm{min}$. The retentate flow was discarded and not recirculated again to the feed tank. The operating flow rates were manually adjusted using the flow control valves installed in the flowmeters and the valve in the permeate flow line. The permeate samples were collected using four plastic tubes $(25 \mathrm{ml})$ at open atmosphere conditions, and the time was recorded since the start of the experiment. 


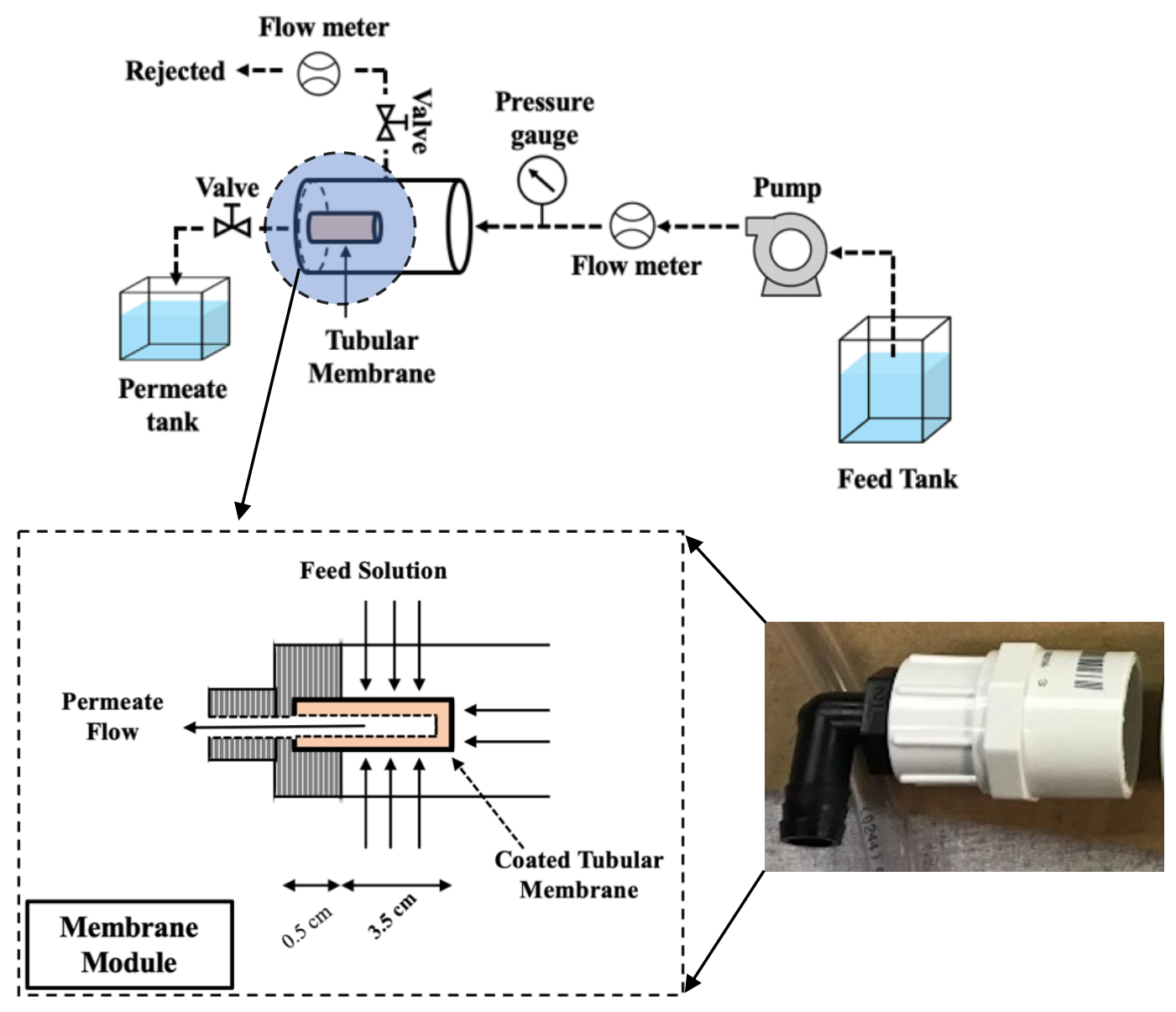

Fig. 4. 2 Schematic of the experimental setup and the membrane module.

\subsubsection{Structural characteristics of Membrane}

Scanning electron microscopy (SEM) (Quanta 650 FEG-FEI, USA) was used to analyze the visual information of the surface and cross-sectional morphologies of coated tubular membranes.

\subsubsection{Permeation experiments}

\subsubsection{Clean Water Flux (CWF) and Membrane Permeability (Pm)}

Ultrapure water was used to measure the clean water flux $\left(\mathrm{J}_{\mathrm{w}}\right)$. The permeated water was collected by using a graduated cylinder at atmospheric pressure $(101.325 \mathrm{kPa})$ and at 
room temperature $\left(25^{\circ} \mathrm{C}\right)$ and volume recorded as a function of time. The water flux $\left(\mathrm{J}_{\mathrm{w}}\right)$ was calculated by applying Equation 1:

$$
\mathrm{J}_{\mathrm{w}}=\mathrm{V} /(\mathrm{A} * \mathrm{t})
$$

where, $\mathrm{J}_{\mathrm{w}}$ is the water flux; $V$ is permeated water volume; $A$ is the effective filtration area of the membrane, and $t$ is the measured time. By the relationship between transmembrane pressure $\mathrm{P}$ and water flux $\left(\mathrm{J}_{\mathrm{w}}\right)$, membrane permeability $\left(\mathrm{P}_{\mathrm{m}}\right)$ of all membranes was calculated by using Equation 2 .

$$
\mathrm{P}_{\mathrm{m}}=\mathrm{J}_{\mathrm{w}} / \mathrm{P}
$$

where $\mathrm{P}_{\mathrm{m}}$ is the membrane permeability, $\mathrm{P}$ is the transmembrane pressure.

\subsubsection{PEG vs. TOC Calibration curve}

To convert the obtained TOC values to PEG concentrations (ppm), we first have to establish a calibration curve of (MW 20,000 and 200,000 Da) PEG concentrations and their TOC values. Therefore, different concentrations $(0,5,10,15,20,25,50 \mathrm{ppm})$ of PEG were prepared and send them to PC-Controlled Total Organic Carbon Analyzer (Shimadzu Corporation Analytical \& Measuring Instruments Division, Kyoto, Japan) to measure their TOC values. Then, the Microsoft Excel program was used to draw the relationship between PEG concentrations and TOC contents.

\subsubsection{Membrane fouling}

The membrane fouling was studied by observing the evolution of transmembrane pressure (TMP) at constant inflow $33 \mathrm{ml} / \mathrm{L}$ and retentate flow $22.5 \mathrm{ml} / \mathrm{L}$ and temperature $\left(25^{\circ} \mathrm{C}\right.$ ) by using two different feed solutions 25 ppm of PEG (MW 20,000 and 200,000 Da). The purpose of using different molecular weights of PEG in this study is to compare 
and study the effect of MWs on the fouling and rejection growth with increasing the number of $\mathrm{TiO}_{2}$ layers and time.

\subsubsection{Analysis of rejection}

The rejection of PEG was investigated in this work by using uncoated membrane and coated membranes. Before starting the experiment, one sample was taken from the feed solution to measure the initial PEG concentration; subsequently, four samples (25 ml) from permeate flow were taken when the experimental system started. The percentage of PEG rejection was calculated by using Equation 2.3:

$$
\mathrm{R}(\%)=\left(1-\mathrm{C}_{f} / \mathrm{C}_{i}\right) * 100
$$

Where $C_{f}$ and $C i$ are the concentration of PEG in the permeate flow and feed tank, respectively.

\subsection{Results and Discussion}

\subsubsection{Membranes characterizations}

Figure 4.3 shows the SEM images of the surface morphology and the crosssectional of the active layers of the coated and uncoated tubular membranes in this study. As the number of $\mathrm{TiO}_{2} /$ Polyaniline coating layers increased, the surface coverage increased, and, as a result, the diameters of the pores on their surfaces decreased. In this study, we used Image J $1.52 \mathrm{n}$ software to measure the diameters of pores approximately on the surface of membranes. The pores diameters of the uncoated tubular membrane ranged between $117.18 \mu \mathrm{m}$ and $331.43 \mu \mathrm{m}$. 

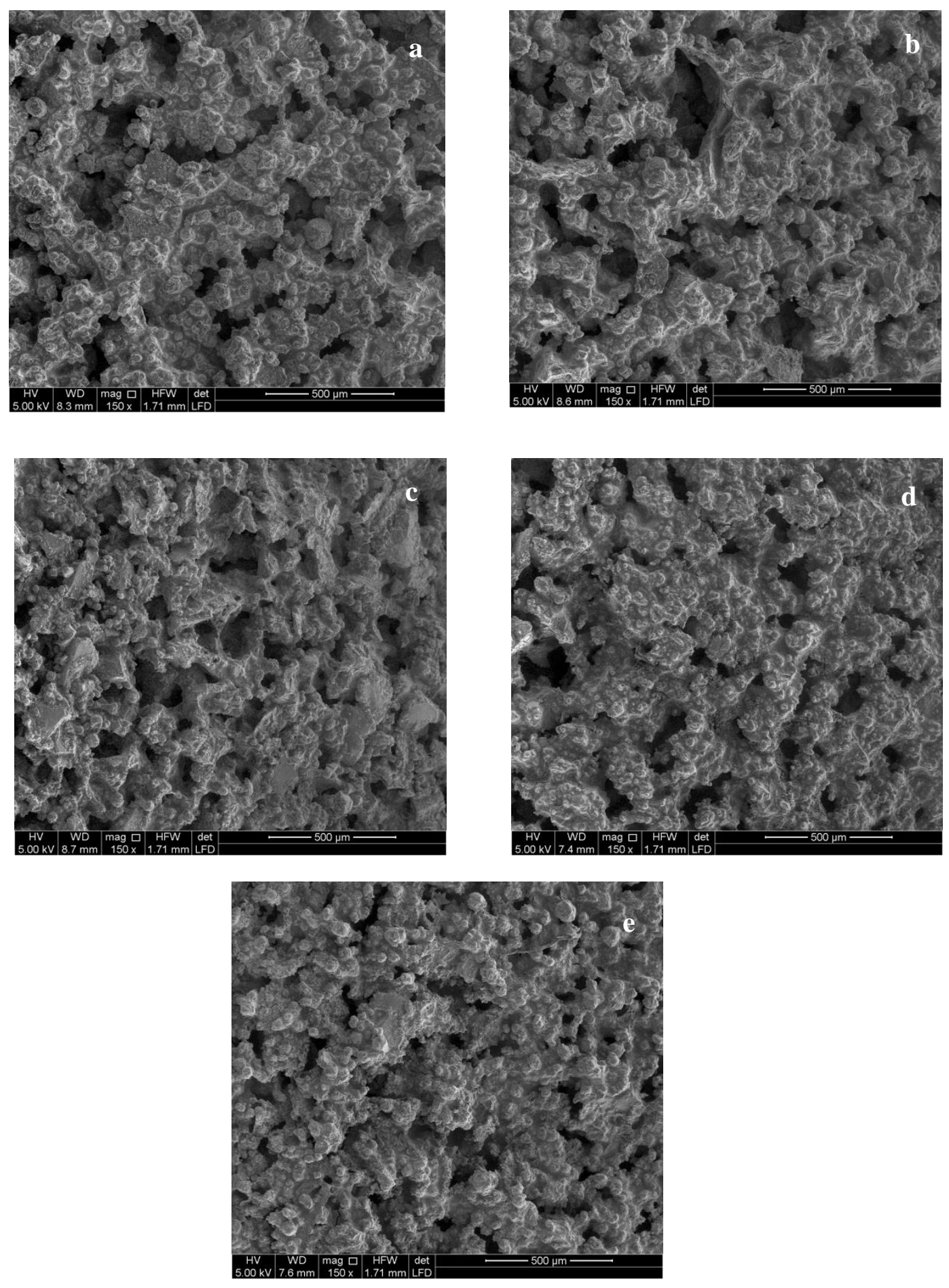

Fig. 4. 3 SEM images for the membranes surfaces of (a) uncoated and (b) 1-layer of $\mathrm{TiO} 2$ (c) 2-layers (d) 3-layers (e) 4-layers. 

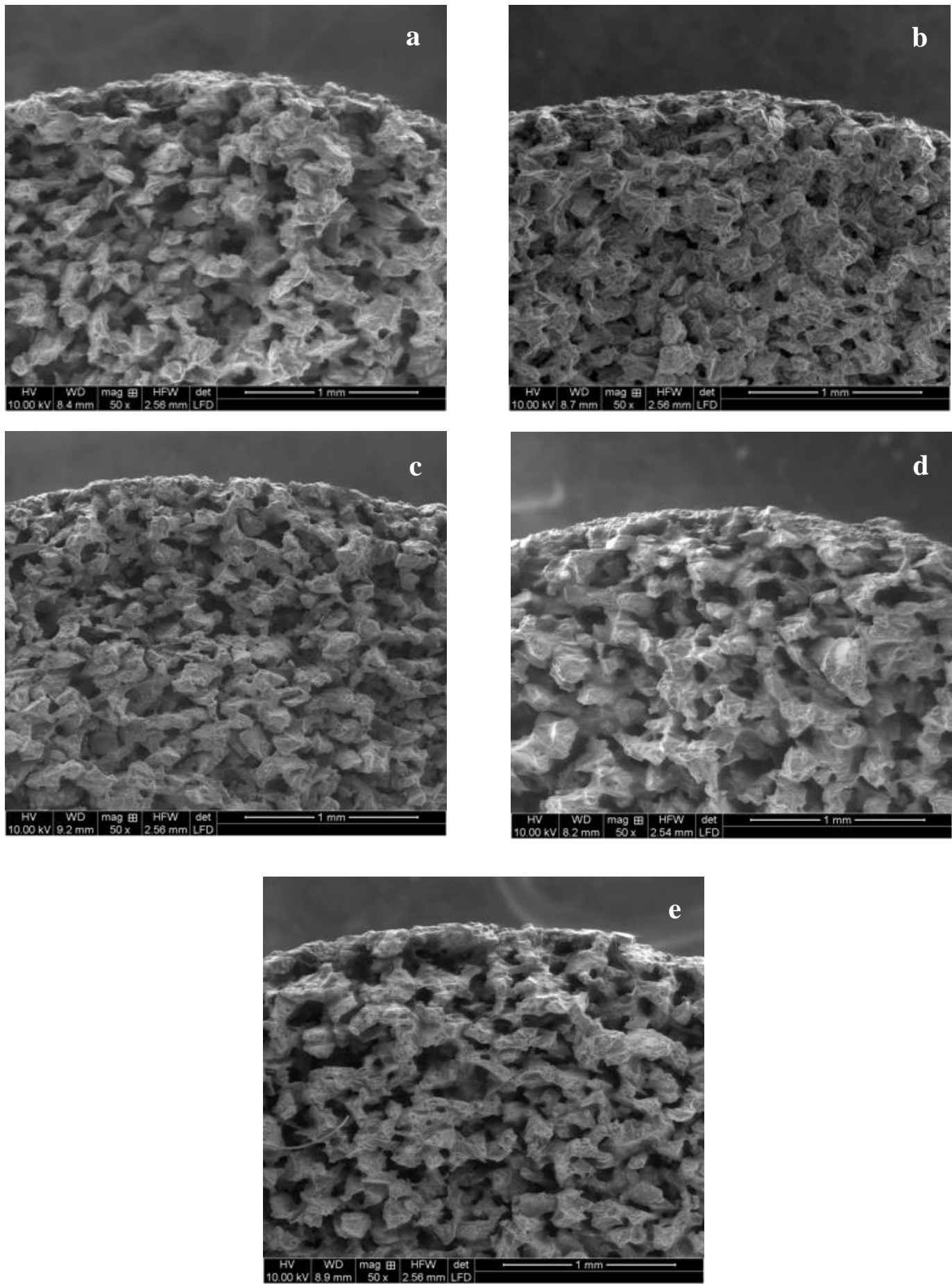

Fig. 4. 4 SEM images for the membranes cross-sections of (a) uncoated (b) 1-layer of $\mathrm{TiO}_{2}$, and (c) 2-layers (d) 3layers (e) 4-layers. 
With increasing the number of coating layers, the diameters of the pores decreased gradually in 2,3,4 layers to be (74.5-166.8) (41.31-103.26) (19.95-67.43) $\mu \mathrm{m}$, respectively, because of filling the pores by $\mathrm{TiO}_{2} / \mathrm{Polyaniline}$ layers that grow progressively on the surfaces of membranes resulting decrease in the diameter of the pores of gradually.

Figure 4.4(a-e) presents the cross-sectional images of all the membranes used in this study. The SEM images showed that there are abundant microporous with different sizes formed on and in the active layer of membranes. Therefore, the porous structures were formed and developed successfully in the active layer with increasing the number of coating layers.

\subsubsection{Permeability}

The relationships between the flux and the permeability values of all membranes with 1 to 4 coatings $\mathrm{TiO}_{2}$ layers are shown in Figures 4.5 and 4.6, respectively. All the values were measured before coating, after coating, and after using them with various molecular weights of PEG (MW 20,000 and 200,000 Da) after washing by ultrapure water (18.2 M $\Omega . c m)$.

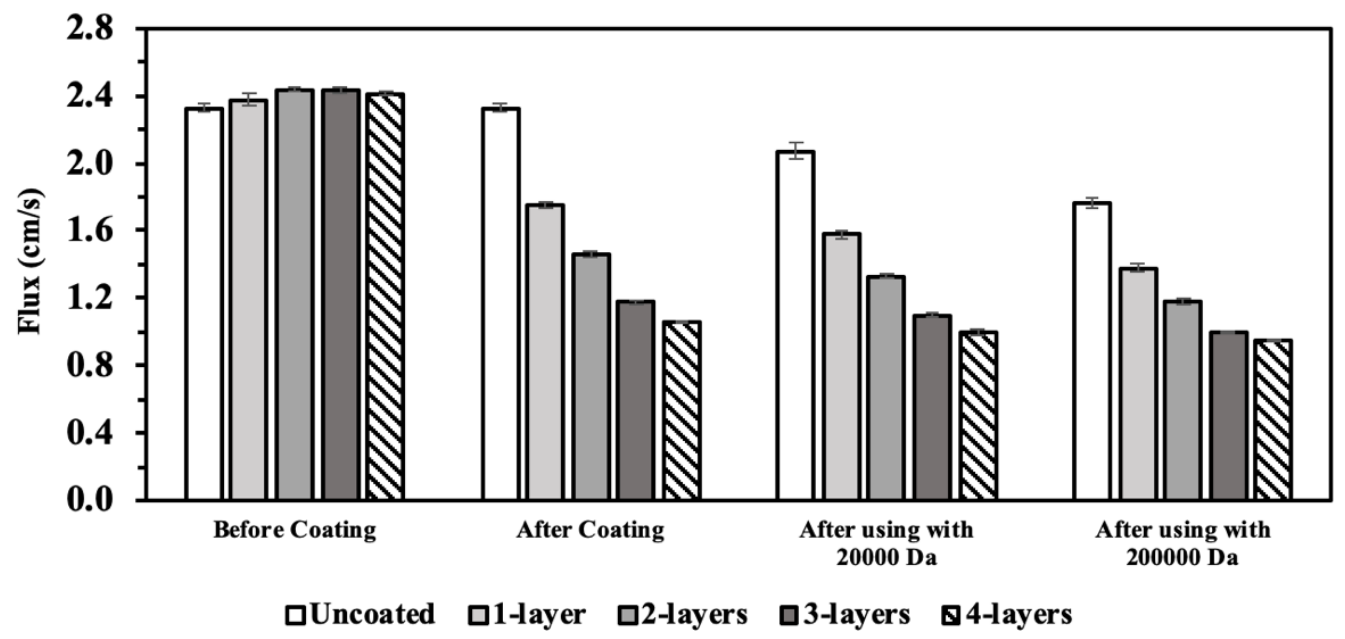

Fig. 4. 5 The relationship between flux and the number of coating layers. 


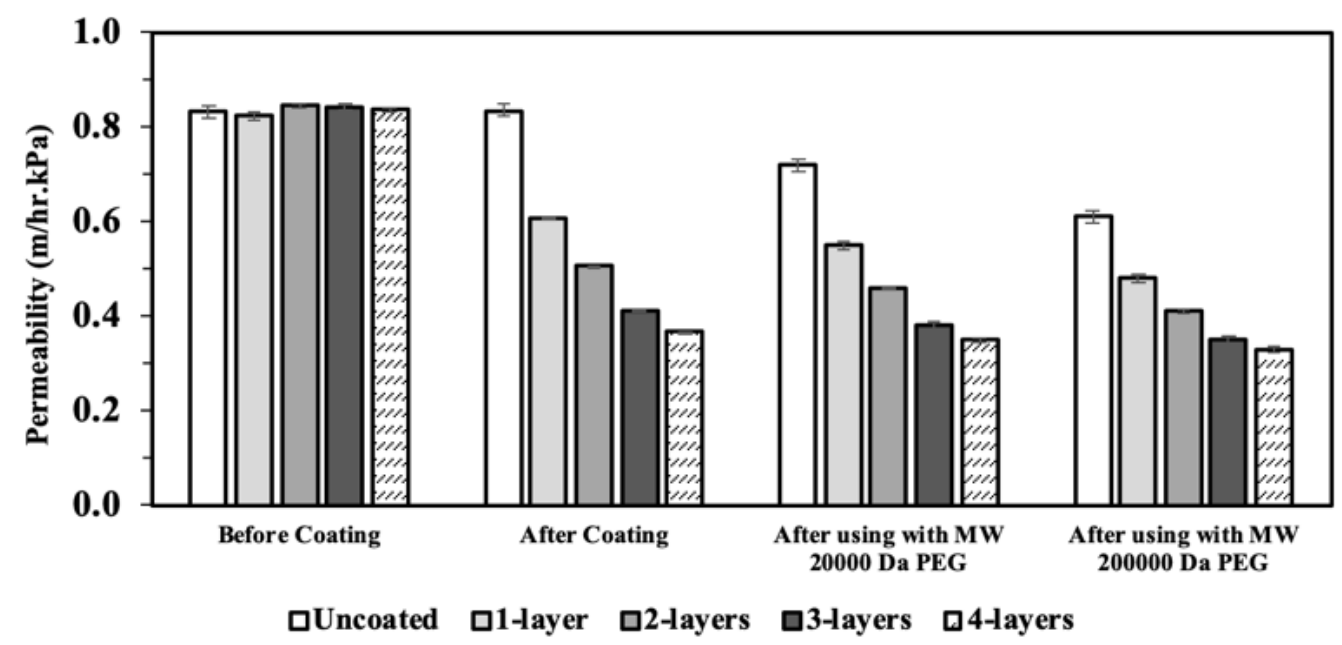

Fig. 4. 6 The relationship between permeability and the number of coating layers.

The flux measurements showed a continuous decrease with increasing the number of coated layers by $\mathrm{TiO}_{2}$ and $\mathrm{TiO}_{2} /$ Polyaniline. Those results could be interpreted that the coating process was achieved its goal by covering the surface of membranes and growing the active layer, as the SEM images showed that in Figures 3 and 4.

After using them in the fouling experiments with PEG (MW 20,000 and 200,000 Da), both flux and permeability were measured again after flushing all the membranes by using ultrapure water $(18.2 \mathrm{M} \Omega . \mathrm{cm})$ to solve the clogging problem on their surfaces. Higher recovery of flux and permeability was observed with 4 layers 95 and $96 \%$, subsequently. The new results of flux show slightly dropping in their values because of accumulating the PEG on the surface of membranes and inside the permeable paths. Therefore, PEG accumulation led to a decrease in the diameters of permeable pores on the surface and in the active layer resulting in a reduction of the flux through the membranes. The stuck PEG molecules on the inner surfaces of paths of pores.

Table 4.1 presents the decreasing ratios in flux before and after coating, and after using them with PEG (MW 20,000 and 200,000 Da) feed solutions. The coating process 
led to a decrease in the permeate flux continuously with increasing the number of coating layers.

Table 4. 1 Shows the flux decreasing ratios of all membranes

\begin{tabular}{|c|c|c|c|c|c|}
\hline $\begin{array}{c}\text { Membrane } \\
\text { situation }\end{array}$ & Non-coated & $\mathbf{1}$ & $\mathbf{2}$ & $\mathbf{3}$ & $\mathbf{4}$ \\
\hline clean & 0 & 0 & 0 & 0 & 0 \\
\hline $\begin{array}{c}\text { After coating } \\
\text { After fouling }\end{array}$ & 0 & 0.26 & 0.40 & 0.52 & 0.56 \\
\hline $\begin{array}{c}\text { experiments with } \\
\text { PEG 20 kDa }\end{array}$ & 0.11 & 0.11 & 0.09 & 0.07 & 0.05 \\
$\begin{array}{c}\text { After fouling } \\
\text { experiments with } \\
\text { PEG 200 kDa }\end{array}$ & 0.15 & 0.13 & 0.11 & 0.09 & 0.05 \\
\hline
\end{tabular}

Remarkably, flux decreasing ratios through the membranes decreased slightly with increasing the number of $\mathrm{TiO}_{2}$ and $\mathrm{TiO}_{2} /$ Polyaniline coating layers and after applying them for PEG removal. Those results give a good indication about improving and developing the membranes' performances through increasing the permeate flux as a result of increasing the PEG rejection, which helps to keep the pores in active layers clean.

\subsubsection{Fouling analysis}

To investigate the membrane fouling, Polyethylene glycol (PEG) was used in this study as a model of organic material. Figure 4.7a presents the TMP evolution of uncoated and coated membranes over time using PEG (MW 20,000 Da) as a feed solution. All the membranes were continuously operated until the pump reaches its maximum flow value.

Depending on Bain and Xue [154], we expect in this study that the surface of coated membranes has different kinds of functional groups, such as $\mathrm{C}=\mathrm{C}, \mathrm{C}=\mathrm{N}, \mathrm{C}-\mathrm{N}^{+}, \mathrm{N}-\mathrm{H}$. Therefore, the PEG molecules will be adsorbed onto the membrane surface that has $\mathrm{TiO}_{2}$ or $\mathrm{TiO}_{2} / \mathrm{PANI}$ by forming hydrogen bonds between $\mathrm{OH}^{-}$groups on $\mathrm{TiO}_{2}$ or $\mathrm{TiO}_{2} / \mathrm{PANI}$ 
and PEG oxygen atoms [155]. On the other hand, the PEG protons will form bonds nitrogen atoms on the surface of coated membranes [156].

Thus, TMP values of all membranes in this study showed a continuous increase at different rates because of accumulating PEG on the surface and inside the pores in active layers of membranes over time. Also, it can be observed and compared the effect of the number of coating layers on TMPs evolution during the fouling experiment. When the number of $\mathrm{TiO}_{2}$ and $\mathrm{TiO}_{2} /$ Polyaniline layers increased, the pores' diameters on the membranes surface decreased. As a result, PEG molecules will be rejected from passing through the membrane.

The TMP of the non-coated membrane evolved slower than the other membranes while the TMP of 4 layers membrane developed faster and became fouled during the first $10 \mathrm{~min}$. On the other hand, the fouling happened quickly with 3 and 4-layers during the first 15 minutes in comparison with others because of accumulating the PEG foulant on their surfaces faster than removing them by the crossflow shear forces and diffusion [157][158]. While the fouling evolved slower with (1 and 2) layers because of the pore diameters on their surfaces that their sizes are larger than the pore diameters size on the surfaces of 3 and 4 layers. Those large pore diameters let the PEG molecules pass through the membranes. The permeate flow was gradually decreasing until the end of the experiment because of the continuous accumulating of foulants on the top layer of membranes and blocking the permeable paths [159].

Figure 4.7b shows the relationship between TMP vs. time for uncoated and coated membranes by using PEG (MW 200,000 Da) as a feed solution. With using higher molecular weight of PEG, TMP readings of all the membranes increased quickly over time 
in comparison with the previous measurements with PEG (MW 20,000 Da). This increment belongs to the pores plugging by PEG molecules, which made the pores narrower; therefore, the values of permeability of all the membranes became lower after the fouling experiment, as mentioned previously in Section 3.1.1.
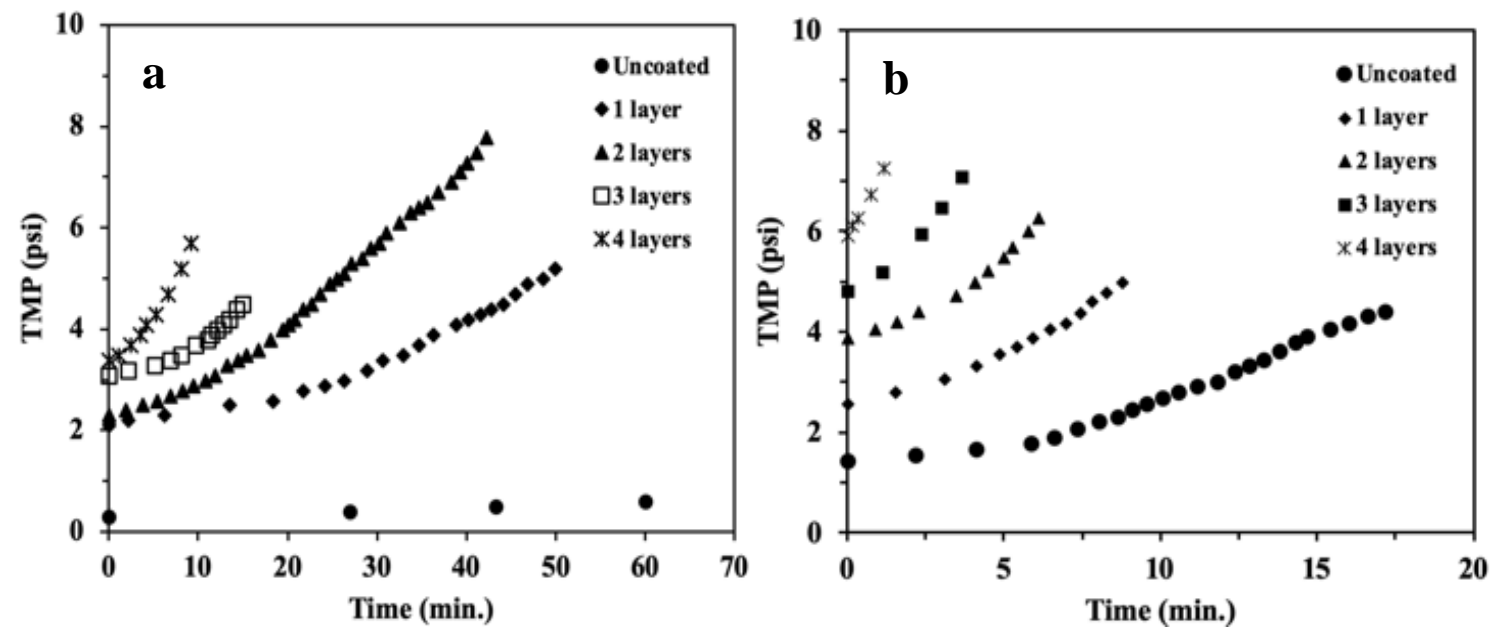

Fig. 4. 7 TMP evolution vs time using (a) PEG (MW 20 kDa) (b) PEG (MW 200 kDa).

After completing the fouling experiments with all the membranes, ultrapure water (18.2 M $2 . \mathrm{cm})$ was used to clean the membranes up from PEG accumulation by pumping the water in the reverse direction, as shown in Figure 4.8. The new TMPs showed decreasing in their values in comparison with the last values recorded at the end of the fouling experiments. Therefore, the new TMPs values were almost the same as the values of clean TMPs membranes before using them in the fouling experiments. 

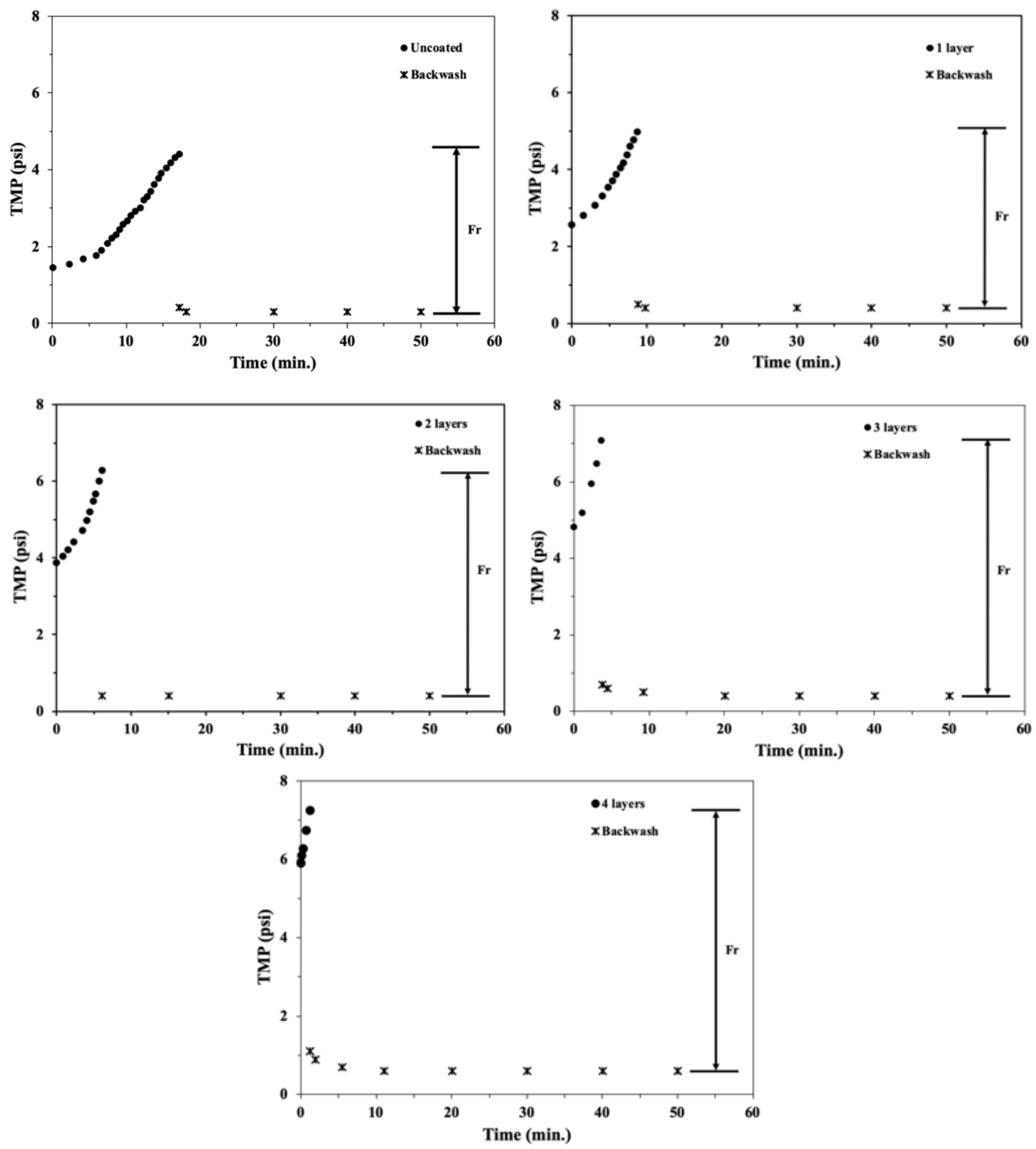

Fig. 4. 8 Comparison between the TMP of all the used membranes before and after using.

\subsubsection{Rejection Analysis}

The measurements of PEG (MW 20,000 Da) rejection of all the membranes during the fouling experiment at constant flux are presented in Figure 4.9. For constant flux fouling, the rejection of all membranes decreased quickly during the first minutes because 
of increasing TMP inside the system. As a result, the concentration of PEG in the permeate flow showed increasing due to evolving the TMP, which lets PEG pass out of the pores in the active and support layers, particularly with non-coated and 1 layer membranes.

On the other hand, the quick accumulation of PEG on the surfaces of membranes 2,3 , and 4 layers led to fill the small diameters of pores then resulting to prevent moving the molecules of PEG toward the permeate flow. Therefore, PEG concentrations decreased in permeate flow by increasing the number of coating layers.

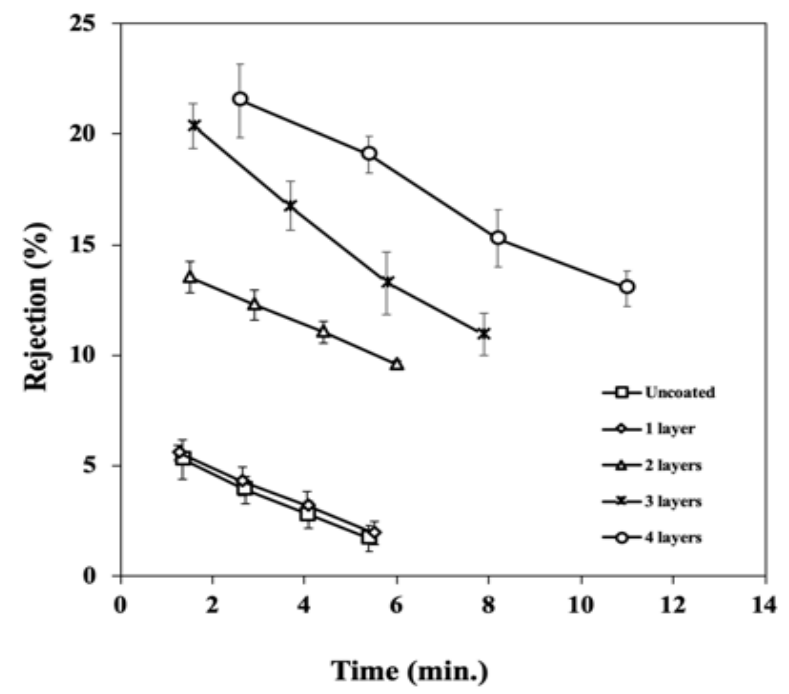

Fig. 4. 9 Rejection evolution vs time using PEG (MW 20,000 Da) at a constant flux $33 \mathrm{ml} / \mathrm{min}$.

Subsequently, the results show there are no significant differences between the rejection ratios of uncoated and 1 layer membranes. Those close values of rejection could be interpreted that the $\mathrm{TiO}_{2}$ nanoparticles in the 1 layer membrane didn't fill most of the pores in the support layer or cover the membranes surface completely, which led to permit the PEG particles from leaving the membrane toward the permeate flow. While the other coating layers showed increasing in the values of rejection because of filling the pores by $\mathrm{TiO}_{2}$ nanoparticles, also, it should be noted that the number of Polyaniline that used to 
increase the attachment among the $\mathrm{TiO}_{2}$ layers plays an important role with that. Finally, this study showed an increase in the sampling time for the PEG rejection test over time.

Figure 4.10 presents a comparison of the rejection ratios of PEG (MW 200,000 Da) for all the used membranes in this study. Because of using a higher molecular weight of PEG, the rejection values of membranes 3 and 4 layers decreased slower than the other membranes due to formed smaller pore diameters with increasing the number of coating layers and blocked most of the pores by accumulating PEG molecules. On the other hand, increase the TMP inside the system pushed PEG molecules out of the membranes towards the permeate flow.

The rejection values of 1 layer and 2 layers membranes decreased quickly with increasing the molecular weight of PEG. Those result indicates how the effect of increasing the molecular weight of PEG on the membranes' performances and how the number of $\mathrm{TiO}_{2}$ coating layers affect the rejection process.

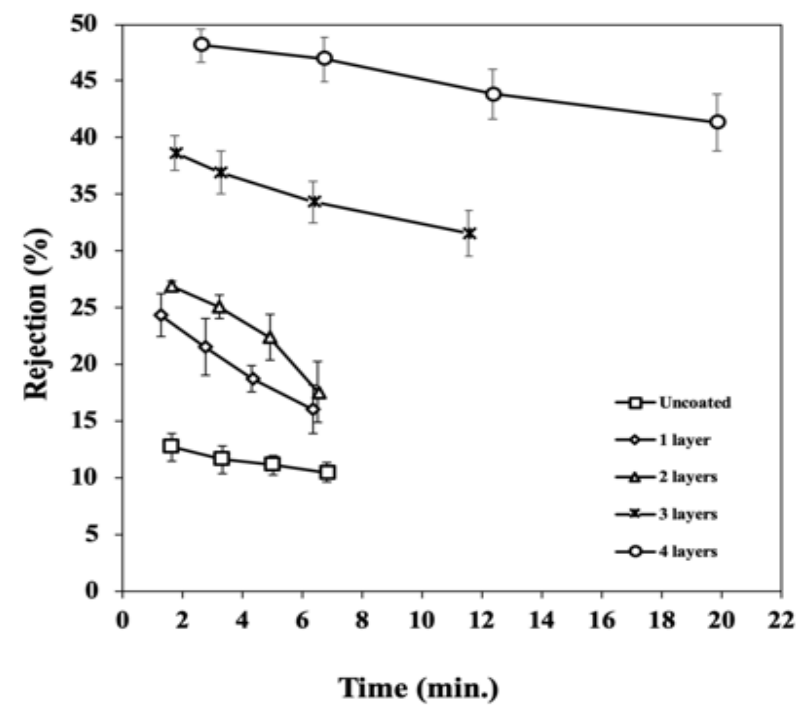

Fig. 4. 10 Rejection evolution vs time using PEG (MW 200,000 Da) at a constant flux $33 \mathrm{ml} / \mathrm{min}$. 


\subsection{Conclusion}

In this study, a group of tubular ceramic membranes were coated by multi-layers of $\mathrm{TiO}_{2} / \mathrm{PANI}$. Their characteristics were investigated using SEM analysis, flux, permeability, fouling, and rejection. Two different molecular weights (20,000Da and 200,000Da) of polyethylene glycol (PEG) were used to study the as a model of organic material. SEM images showed the pore diameters in the surface and active layer of coated membranes gradually decreased with increase the coating layers. Moreover, the values of flux and permeability also decreased when the number of coating layers increase. Therefore, those results confirmed that the coating process was successfully achieved in this work. Depending on the fouling results, TMP showed gradual increasing rates with increase the coating layers because of accumulating PEG molecules on the membrane surface and inside permeable paths. With using PEG (MW 200,000 Da), TMP evolved quickly with using 4 layers membrane because its surface was fouled by PEG molecules; whereas, it grew slower with the non-coated membrane.

Rejection results illustrated that PEG concentration in the permeate flow increased because of evolving the TMP that will enforce PEG molecules pass through the non-coated and coated membranes. On the other hand, the rejection ratios showed no significant difference between uncoated and 1-layer membranes comparison with other 2,3,4-layers. These results could be interpreted that the $\mathrm{TiO}_{2}$ nanoparticles did not completely cover the pores on the membrane's surface or fill permeable paths in the support layer. As a result, PEG particles will leave the membrane quickly with increase TMP. After completing the fouling and rejection experiments, all the membranes were cleaned using ultrapure water (18.2 M $\Omega . \mathrm{cm})$ by pumping it in the reverse direction. The new membranes TMP presented 
decrease and almost became the same as the values of TMPs before used them in fouling and rejection experiments. As a result, it could be use the membranes many times after clean them, and, particularly, the 4-layers showed a little change in its TMP values when it is clean and after cleaned. 


\section{Chapter 5: Enhanced Degradation of Sulfamethazine by using Advance Oxidation Processes (AOPs) Combined with Membrane Filtration.}

\subsection{Introduction}

Two-thirds of the human population around the world is affected by water scarcity for a month at least per year [160]. Existing good quality water resources may reach their limits rapidly in most parts of the world as a result of the continuous discharge of domestic and industrial waste in addition to their non-biodegradable compounds such as antibiotics [161]. Sulfamethazine (SMZ) is one kind of a wide range of antibiotics, and it belongs to pharmaceutical active compounds (PhACs). Because of its broad applications as a bacteriostatic agent, SMZ has become recently a widespread contaminant, and the conventional treatment processes are unable to remove it effectively [162]. For instance, coagulation and flocculation processes have been used to remove some kinds of pollutants in water and wastewater. Regardless, these technologies have some disadvantages such as generation toxic secondary by-products and unsatisfactory removal efficiency for some recalcitrant compounds (e.g., antibiotics, dyes, pesticides, pharmaceutical, etc.) [163], as mentioned in Table 5.1. Thus, improved treatment technologies, readily available and simple to operate, could support actions to increase widespread access to clean water [164]. Many treatment technologies such as adsorption [99], membrane filtration [100], and advanced oxidation processes [101] have been used to remove different types of contaminants, and SMZ is one of them. 
Table 5. 1. Uses and disadvantages of some water and wastewater technologies.

\begin{tabular}{|c|c|c|}
\hline $\begin{array}{c}\text { Water } \\
\text { technologies }\end{array}$ & Contaminate removed & Disadvantages \\
\hline $\begin{array}{l}\text { Biological } \\
\text { methods }\end{array}$ & $\begin{array}{l}\text { Using biological cultures (pure } \\
\text { or mixed) }\end{array}$ & $\begin{array}{l}\text { Need to generate optimal favorable environment, } \\
\text { requiring to manage and maintain the } \\
\text { microorganisms and/or physicochemical pre- } \\
\text { treatment, slow process (kinetics problems), low } \\
\text { dyes biodegradability, etc. }\end{array}$ \\
\hline $\begin{array}{l}\text { Coagulation and } \\
\text { flocculation }\end{array}$ & $\begin{array}{l}\text { Removing bacteria, dissolved } \\
\text { organic carbon, turbidity, some } \\
\text { chemical contaminants, and } \\
\text { heavy metals such as arsenic, } \\
\text { fluorides, phosphorus, etc. }\end{array}$ & $\begin{array}{l}\text { Non-reusable chemicals (aid chemicals, } \\
\text { coagulants, flocculants,) required, monitoring of } \\
\text { the effluent (pH), low arsenic removal, and } \\
\text { produced high sludge volume (cost, treatment, } \\
\text { management). }\end{array}$ \\
\hline $\begin{array}{l}\text { Chemical } \\
\text { precipitation }\end{array}$ & $\begin{array}{l}\text { To uptake the pollutants and } \\
\text { separate the products formed }\end{array}$ & $\begin{array}{l}\text { Ineffective in removing of the metal ions at low } \\
\text { concentrations, disposal and handling problems } \\
\text { (cost, treatment, management), High sludge } \\
\text { production, monitoring the effluent (pH) }\end{array}$ \\
\hline Ozone & $\begin{array}{l}\text { Effective in eliminating color, } \\
\text { iron, manganese, odor, and } \\
\text { tastes; Also, it is not affected } \\
\text { by } \mathrm{pH} \text { and temperature }\end{array}$ & $\begin{array}{l}\text { Chemicals needed, Oxidants production, transport, } \\
\text { and management, short half-life, influenced by the } \\
\text { kinds of oxidants }\end{array}$ \\
\hline
\end{tabular}

Membrane filtration technologies have been considered as a suitable solution to remove the low concentrations of contaminants and pathogens from water and wastewater to the allowable limits for drinking and discharging [165]. Because of providing barriers for contaminants separation, membranes' fouling is expected to increase during operation with time. The fouling is originated from accumulating the contaminants on the surface of membranes that lead to a decrease in the efficiency of the separation, shorter membrane lifespan [166], reduction of permeate flux [167], an increase of the transmembrane pressure (TMP), and amount and frequency of chemicals required for cleaning [168]. To minimize or reverse membrane fouling, understanding the mechanisms of fouling and cleaning are needed, but yet lacking. The fouling control and removal methods include; chemical, electrical, hydraulic, and physical cleaning. However, all of these methods generate undesired factors and challenges to the processes such as downtime, increased running costs, and damage to the membrane [169]. 
Recently, advanced oxidation processes (AOPs) have successfully combined with ceramic membrane filtration to overcome fouling issues and to degrade the contaminants in water [170][11]. Membrane filtration processes could be improved by coating the surface of membranes with photocatalytic materials such as titanium dioxide $\left(\mathrm{TiO}_{2}\right)$, iron oxide (IO), zinc oxide ( $\mathrm{ZnO})$, etc. Using metal oxide nanoparticles as a photocatalytic will prevent the accumulation of organic contaminants on the surface of membranes, so they will play a key role by degrading the pollutants to simple elements such as $\mathrm{CO}_{2}$ and $\mathrm{H}_{2} \mathrm{O}$ after illuminating them with UV-light. Therefore, metal oxide nanoparticles will contribute to solving the excessive fouling problems and, as a result, provide high flux for a long time without increasing TMP. On the other hand, this technique will lead to avoid using the chemicals for maintenance and cleaning to remove the secondary waste. This kind of technology is called "self-cleaning" that regenerates itself continuously without needing to use an external method for cleaning [166]. The oxidative degradation ability of the photocatalysts and the separation role of the porous membrane could work together in one unit to produce a superior hybrid membrane material [171].

Thus, this study aims to coat the tubular ceramic microfiltration membrane with $\mathrm{TiO}_{2}$ nanoparticles as hybrid separation/degradation media. The coated membrane will be installed in the module and surrounded by UV-LED strips as a source of radiation at 365 $\mathrm{nm}$. This system will be applied to evaluate the performance of the SMZ photodegradation process. $\mathrm{pH}$, ionic strength $\left(\mathrm{Cl}^{-}\right.$and $\left.\mathrm{NO}_{3}^{-}\right)$, humic acid, $\mathrm{SMZ}$ concentrations were considered in this work to study their presence effects on the membrane performance and SMZ removal. 


\subsection{Materials and methods}

\subsubsection{Chemicals}

All reagents were of analytical grade and used as purchased without additional purification. Heptane ( $\geq 99 \%)$ and Hydrochloric acid (38\% analytical grade) were obtained from Alfa Aesar (Tewksbury, MA, USA). Ammonium Persulfate ( $\geq 98 \%$ ), and titanium isopropoxide (99.9\%) were purchased from Sigma-Aldrich (St Louis, MO, USA). Aniline liquid was provided from Fisher Scientific (Pittsburgh, PA, USA). Sulfamethazine (HPLC Grade) were purchased from Sigma-Aldrich (St Louis, MO, USA). Calcium chloride $\left(\mathrm{CaCl}_{2}\right)$ (Isooctane, 99\%) were obtained from Fisher Scientific.

\subsubsection{Instruments}

Ultrapure water (18.2 M $\Omega . c m)$ (Thermo Scientific Barnstead ${ }^{\mathrm{TM}}$ E-pure ${ }^{\mathrm{TM}}$ ultrapure Water Purification System, Waltham, MA, USA) was used to prepare all the solutions and to clean all the parts of experimental system. A UV-LED flex strip was obtained from LEDlightsworld (ShenZhen, China) with a nominal power: $14.4 \mathrm{~W} / \mathrm{m}$ and main emission wavelength of $365 \mathrm{~nm}$.

\subsubsection{Membrane fabrication}

As mentioned in chapter 4, alumina porous ceramic tube was used as a support layer, and its dimensions are $15 \mathrm{~cm}$ long, inner diameter $3.15 \mathrm{~mm}$, and outer diameter 9.5 $\mathrm{mm}$, as shown in Figure 5.4(a,b). The membrane was cut to 3 pieces, $4 \mathrm{~cm}$ long each, and prepared for coating by $\mathrm{TiO}_{2}$. The procedure of coating was carried out in a consecutive pattern which can be described as follow: the piece of membrane was placed in $200 \mathrm{ml}$ heptane under a gentle stirring for 10 minutes, then $0.5 \mathrm{ml}$ of $0.5 \mathrm{M}$ of titanium isopropoxide was added to the solution. Then, the membrane was submerged 30 minutes 
afterword covered by Titania layer. Ultrapure nitrogen gas flow was applied to prevent any loss of the precursor due to the air moisture.
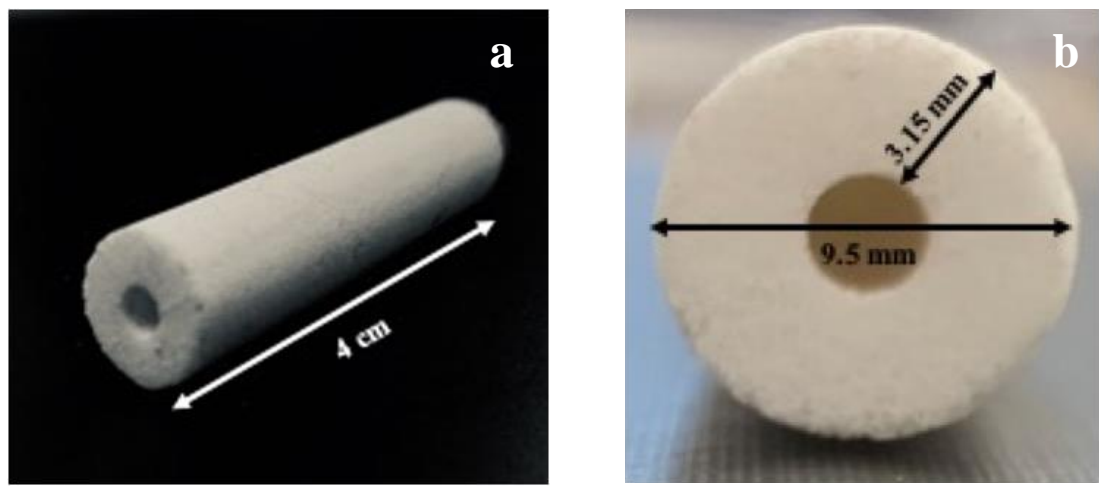

Figure 5. 1 Tubular ceramic supports: (a) side view (b) cross-sectional view.

\subsubsection{Experimental set-up.}

The experimental set up for filtration/degradation studies is shown in Figure 5.5. A 1L conical flask was used for the feed solution. A peristaltic pump, flowmeter with flow control valve to measure and control the values of inflow rate, and pressure gauge for following the changes up inside the experimental system. A custom made membrane module with tubular configuration was used to house the filters. UV-LED strip was attached on the inner edge of module around and over the membrane at a net distance of $0.82 \mathrm{~cm}$. This arrangement will ensure uniform irradiation throughout the membrane surface.

During SMZ degradation experiment, $10 \mathrm{~mL}$ samples from permeate flow, depending on flowrate, and $10 \mathrm{~mL}$ samples from the feed solution were taken every $10 \mathrm{~min}$. All the samples were filtered by $0.22 \mu$ m nylon syringe filters to quantify the concentration of sulfamethazine by HPLC. 

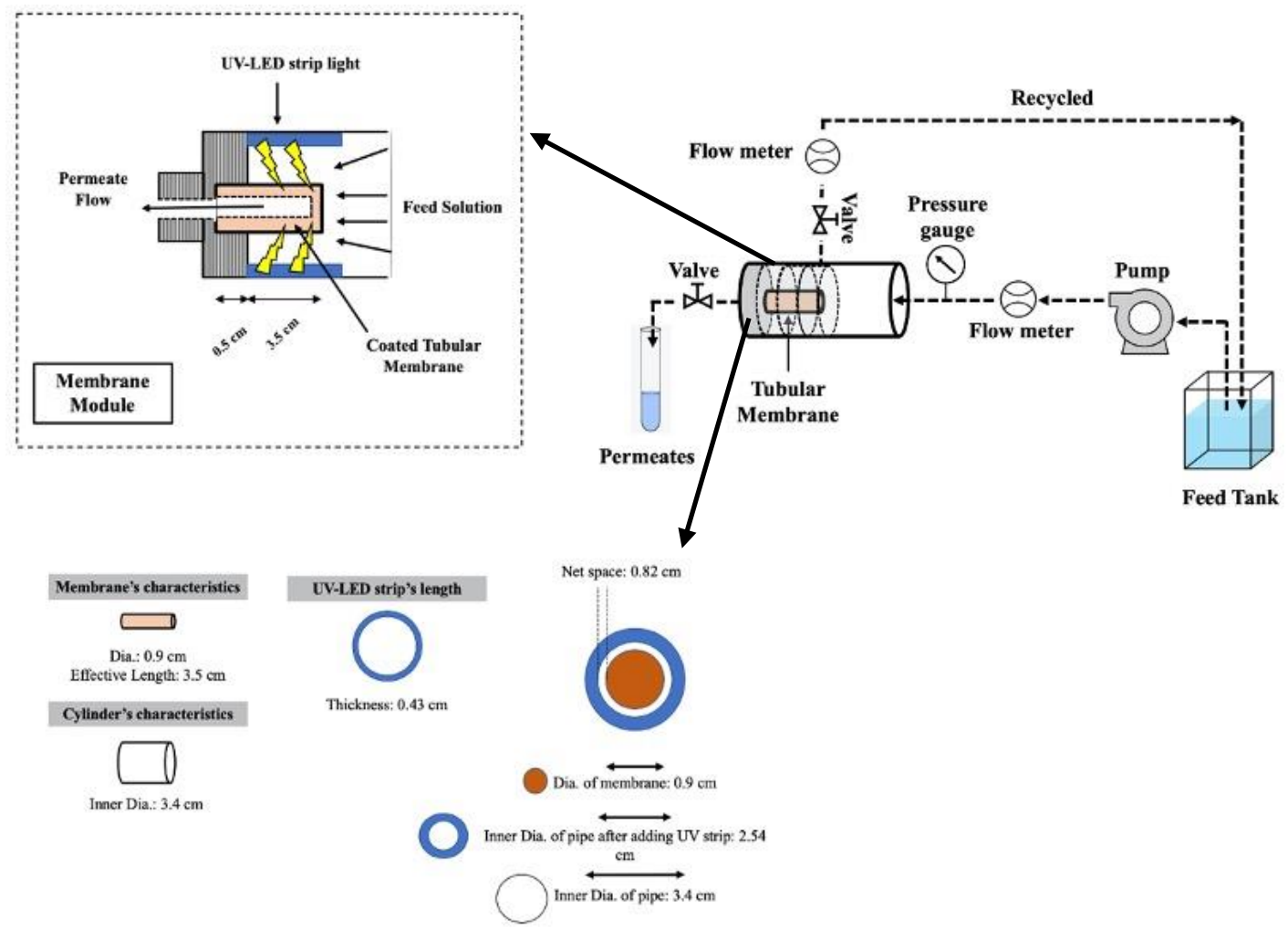

Figure. 5. 2 Schematic of experimental setup for integrated direct contact membrane filtration-UV photolysis treatment.

\subsection{Filtration/Reaction experiments:}

The membrane operation conditions were varied systematically to investigate the influencing factors such as the initial SMZ concentration, $\mathrm{pH}$, presence of NOM (humic acid), and ionic strength and to optimize the degradation conditions, as explained in the subsections below.

\subsubsection{Preparation of SMZ standard curve}

The calibration curve of SMZ was established by preparing different concentrations $(0,0.1,0.25,1,5,10,15$, and $20 \mathrm{ppm})$ solution were kept at $4{ }^{\circ} \mathrm{C}$ in the refrigerator. All SMZ samples were analyzed by HPLC within 24 hours after filtered with $0.22 \mu$ m nylon 
membrane filter. SMZ concentrations were quantified within 24 hours by High Performance Liquid Chromatography (HPLC) (LC- 2010A HT, Shimadzu, Japan) equipped with the $\mathrm{C} 18$ reversed-phase column (4.6 $\mathrm{mm} \times 100 \mathrm{~mm}$, Phenomenex, US) and a diode array detector (DAD) at the detection wavelength of $254 \mathrm{~nm}$. The column temperature was $40{ }^{\circ} \mathrm{C}$ and the injection volume was $20 \mu \mathrm{L}$. The flow rate of mobile phases used in this HPLC method was $0.5 \mathrm{~mL} / \mathrm{min}$, and mobile phases consisted of $0.1 \%$ phosphoric acid in water and $100 \%$ acetonitrile. The gradient used is described below at Table 5.2.

Table 5.2 The gradient conditions for HPLC method.
$\begin{array}{cc}\text { Time (min.) } & \frac{\text { Acetonitrile }}{2 \%} \\ 0-0.5 & 2 \%-80 \% \text { (Linear) } \\ 0.5-7 & 80 \%-98 \% \text { (Linear) } \\ 7-9 & 98 \%-2 \% \text { (Linear) } \\ 9-10 & 2 \% \\ 10-15 & \end{array}$

The $\mathrm{pH}$ values have direct influence on the charge of contaminants and membrane's surface. Therefore, three different $\mathrm{pH}$ values $(2,5,8)$ were selected depending on the acidbase diagram to study the effect of $\mathrm{pH}$ on the membrane efficiency to degrade and remove SMZ. For this purpose, the $\mathrm{pH}$ was adjusted to 2,5 and 8 , respectively, by adding $0.1 \mathrm{~N}$ $\mathrm{HCl}$ and $\mathrm{NaOH}$ to the $\mathrm{SMZ}$ solution.

\subsubsection{Effect of SMZ}

To evaluate the efficiency of catalyst-coated membrane for SMZ photocatalytic degradation, two feed initial concentrations, 5 and $10 \mathrm{ppm}$, were used at three different $\mathrm{pH}$ $(2,5,8)$. 


\subsubsection{Effect of presence of organic matter}

In this study, humic acid (HA) was selected as a model of natural organic matter (NOM) to study its effect on SMT degradation. A concentration of $1 \mathrm{ppm}$ of HA was used for this purpose.

\subsubsection{Effect of ionic strength}

Inorganic ions presence in water affect significantly SMZ degradation. The effect of inorganic ions such as, chloride $\left(\mathrm{Cl}^{-}\right)$and nitrate $\left(\mathrm{NO}_{3}^{-}\right)$ions, on SMZ photolysis were systematically examined. Different $\mathrm{NaNO}_{3}$ concentration $1,10,100 \mathrm{mM}$ and $10 \mathrm{ppm}$ of chloride were studied at 5ppm SMZ and pH5.

\subsection{Results and discussion}

\subsubsection{Effect of pH on $\mathrm{SMZ}$ removal}

The $\mathrm{pH}$ of the solution directly affects contaminants adsorption and degradation by governing the degree of dissociation of the functional groups on the membrane surface and changed the surface potential of the material. Before studying SMZ degradation by UVlight, dark control experiments were carried out to compare the SMZ removal on catalystcoated membrane under different conditions, as shown in Figure 5.3-6. Two different concentrations of SMZ 5ppm and 10ppm were used for this purpose as a feed solution at different $\mathrm{pH}$ values $(2,5,8)$.

In the absence of UV light, the experiments of SMZ removal showed no remarkable change in its concentration at $\mathrm{pH} 5$ in both permeate flow and feed solution. Those results confirmed that SMZ adsorption process on the membrane surface is not significant without using UV-light. On the other hand, the large size of pores also plays an important role to 
let SMZ molecules pass through the membrane's active and support layers without significantly capturing them.
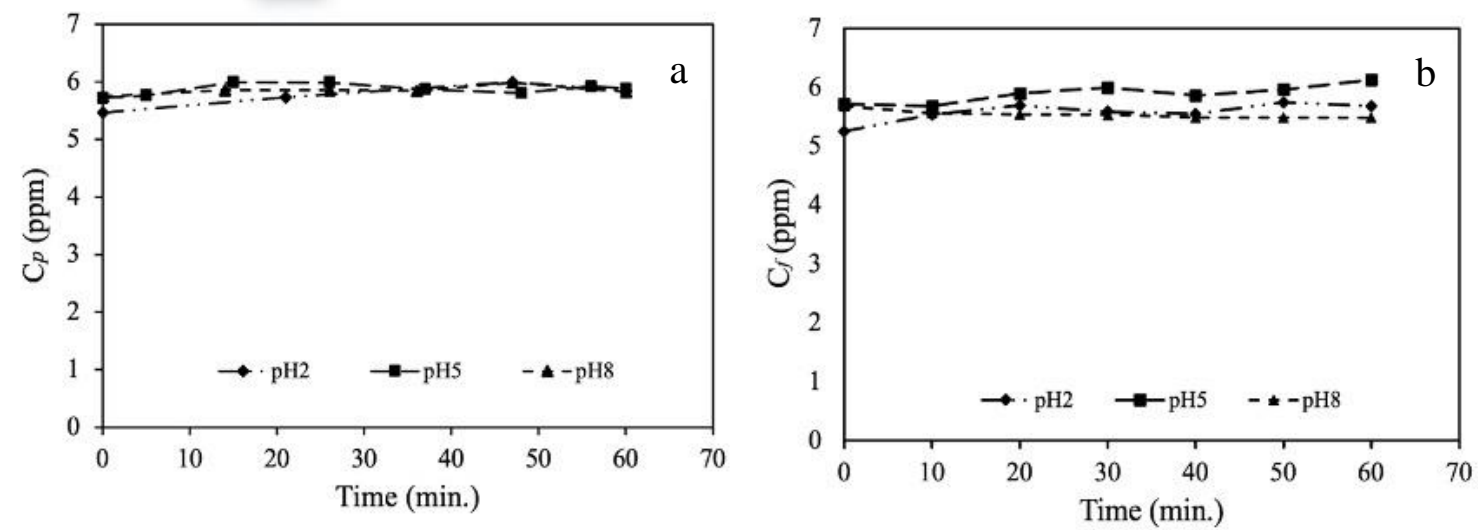

Figure 5.3 Influence of $\mathrm{pH}$ on the removal of SMZ, 5ppm initial [SMZ] in the absence of UV light: (a) permeate (b) feed.
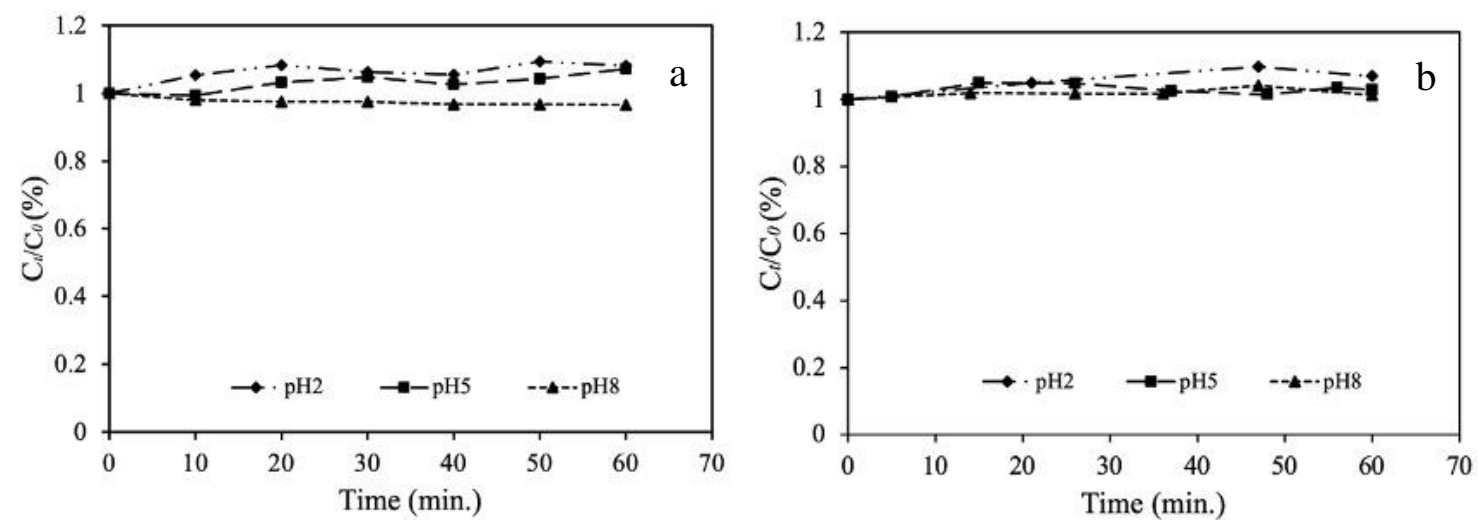

Figure 5.4 Percentage removal $\left(\mathrm{C} / \mathrm{C}_{\mathrm{o}}\right)$ vs time in the absence of UV light (5ppm initial [SMZ]):

(a) permeate (b) feed.
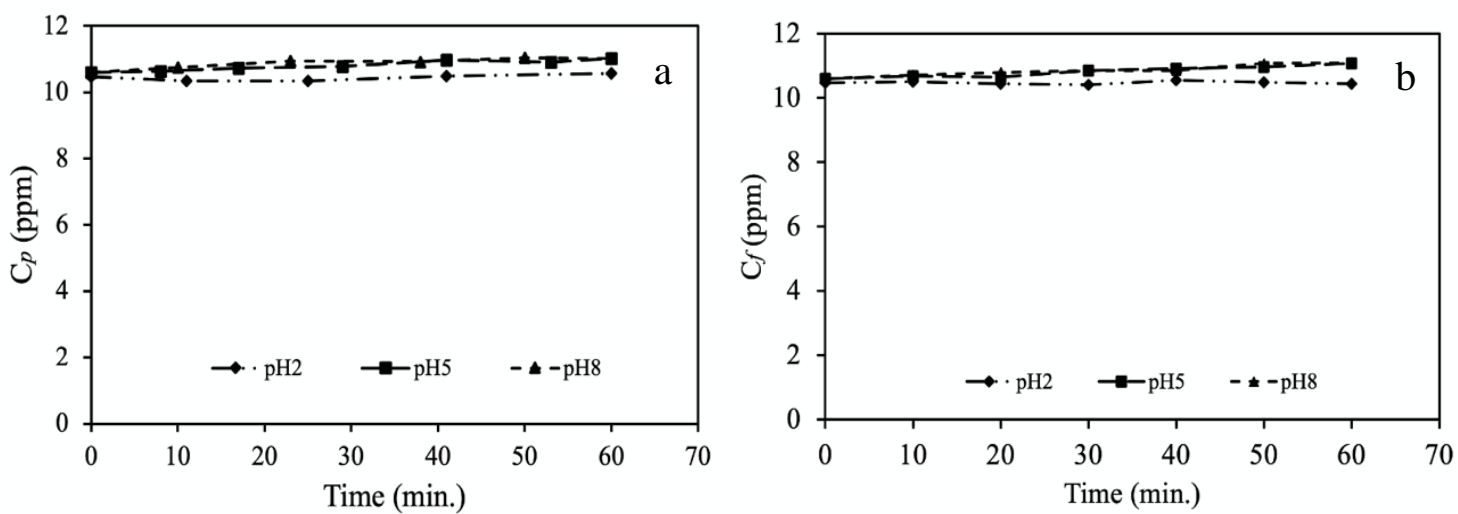

Figure 5.5 Influence of $\mathrm{pH}$ on the removal of SMZ, $10 \mathrm{ppm}$ initial [SMZ] in the absence of UV light: (a) permeate (b) feed. 

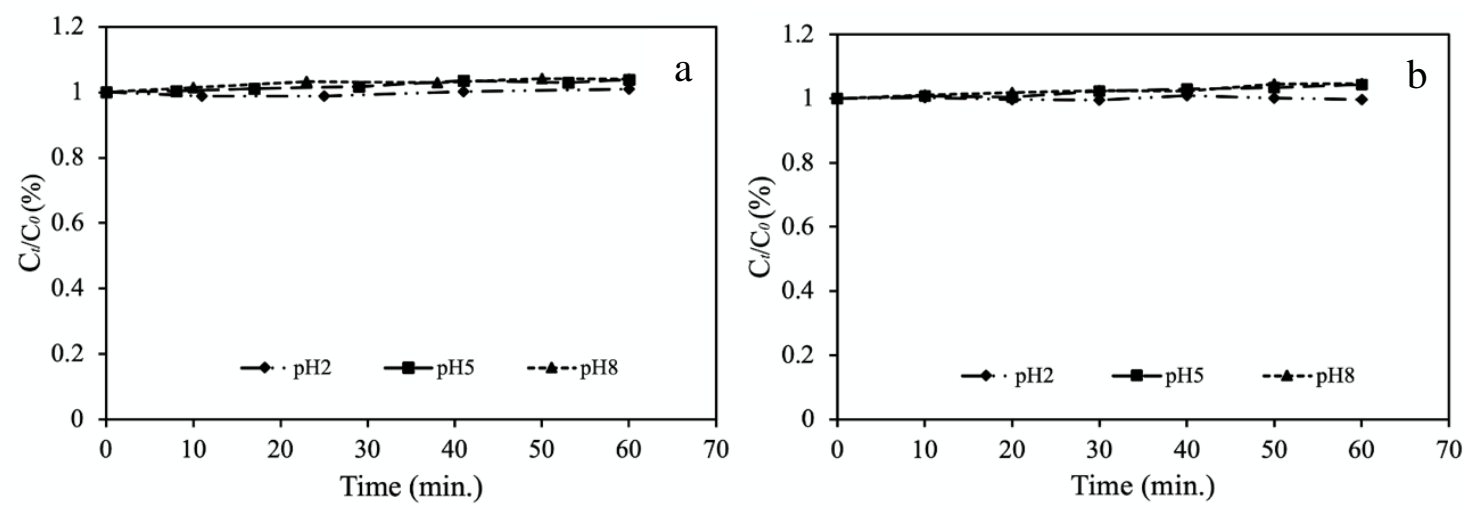

Figure 5.6 Percentage removal $\left(\mathrm{C} / \mathrm{C}_{\mathrm{o}}\right)$ vs time in the absence of UV light (10 ppm initial [SMZ]):

(a) permeate (b) feed.

Moreover, the system that used in this study is a continuous flow, and the SMZ molecules maybe did not get enough time to be adsorbed by active sites on the surface of membrane. The results agree with many researchers and studies that previously mentioned the stability of SMZ concentration in the absence of UV-light [166][167]. The other values of $\mathrm{pH}, 2$ and 8, almost showed same results of SMZ removal with $\mathrm{pH}$. Therefore, altering the $\mathrm{pH}$ solution had no effect on SMZ adsorption. Those results confirm that electrostatic force was not main role between $\mathrm{TiO}_{2}$ particles and $\mathrm{SMZ}$ molecules.

Under UV light, the influence of $\mathrm{pH}$ solution $(2,5,8)$ on the degradation of $5 \mathrm{ppm}$ SMZ as an initial concentration was investigated, as illustrate in figures 5.7 and 5.8. SMZ degradation showed increase when the $\mathrm{pH}$ of solution became more acidic. This result can be interpreted when $\mathrm{TiO}_{2}$ is illuminated by UV-light, an electron will migrate from the valence band toward conduction band to produce electron $\left(\mathrm{e}_{\mathrm{cb}}{ }^{-}\right)$in the conduction band and hole $\left(\mathrm{h}_{\mathrm{vb}}{ }^{+}\right)$. As a result, the electron will interact with the oxygen molecules and produce superoxide $\left(\mathrm{O}_{2}{ }^{-*}\right)$ that will interact with the vicinity $\mathrm{SMZ}$ molecules.

Because the system used in this study is continuous flow reactor, the concentration of dissolved oxygen was available without decreasing in comparison with batch reactor. 
Moreover, the holes will interact with the water molecules and produce hydroxyl radicals $\left(\mathrm{OH}^{-*}\right)$ that will also interact with SMZ molecules and mineralize it completely releasing concurrently the oxidative products of $\mathrm{H}_{2} \mathrm{O}$ and $\mathrm{CO}_{2}$.

In addition, $\mathrm{TiO}_{2}$ will produce $\mathrm{H}_{2} \mathrm{O}_{2}$ in the aerated aqueous solution through reduction of oxygen molecular by exciting electron to the conduction band. Also, $\mathrm{H}_{2} \mathrm{O}_{2}$ will be formed by recombination of hydroxyl radicals on the $\mathrm{TiO}_{2}$ surface. This process is considered the only pathway for $\mathrm{H}_{2} \mathrm{O}_{2}$ production when the dissolved oxygen is available in systems. $\mathrm{H}_{2} \mathrm{O}_{2}$ will be continuously produced, specially, in the acidic solution because of the proton availability that will react with superoxide $\left(\mathrm{O}_{2}{ }^{-}\right)$and produce Hydroperoxy radical $\left(\mathrm{HO}_{2}{ }^{\circ}\right)$. As a result, the molecules of hydroperoxy radical $\left(\mathrm{HO}_{2}{ }^{*}\right)$ will react with each other and produce $\mathrm{H}_{2} \mathrm{O}_{2}$ in the solution [174].

The results, shown in figures 7 and 8, illustrated there is no increment in SMZ degradation after $20 \mathrm{~min}$., and the photochemical reaction reached to equilibrium situation. Those results could be explained that the oxygen content inside the system was almost exerted by the photoreaction, and, as a result, $\mathrm{O}_{2}{ }^{\circ}$ that responsible about producing $\mathrm{H}_{2} \mathrm{O}_{2}$ was also decrease. Therefore, SMZ degradation rate decreased inside the experimental setup [175].

At $\mathrm{pH}$ 5, the results showed degradation in SMZ molecules but less than in $\mathrm{pH} 2$. Those results can be explained in terms of $\mathrm{PZC}$ of $\mathrm{TiO}_{2}$. The particles of $\mathrm{TiO}_{2}$ will carry positive charge on the surface of membrane when the solution $\mathrm{pH}$ is lower than PZC (6.5). As a result, the surface of the membrane will be charged in positively because the surface of $\mathrm{TiO}_{2}$ is protonated $\left(\mathrm{TiO}_{2} \mathrm{H}^{+}\right)$. On the other hand, $\mathrm{SMZ}$ molecules will exist in neutral 
form $\left(\mathrm{SMZ}^{0}\right)$, at $\mathrm{pH} \geq 2.65$ and $\mathrm{pH} \leq 7.42$, and zwitterion $\left(\mathrm{SMZ}^{ \pm}\right)$[176]. Thus, positively charge of $\mathrm{TiO}_{2}$ will adsorb $\mathrm{SMZ}$ through the polarized group $-\mathrm{SO}_{2} \mathrm{~N}-$ of $\mathrm{SMZ}$.

SMZ degradation at $\mathrm{pH} 8$ showed decrease in comparison with other $\mathrm{pHs}$ because both $\mathrm{SMZ}$ molecules and $\mathrm{TiO}_{2}$ are in negative charged. In this case, $\mathrm{SMZ}$ molecules would be more difficult to react with $\mathrm{TiO}_{2}$ because the force of electrostatic repulsive will be large under neutral and basic conditions. As a result, the efficiency of SMZ degradation and reaction rate will decrease when the $\mathrm{pH}>6.5$.
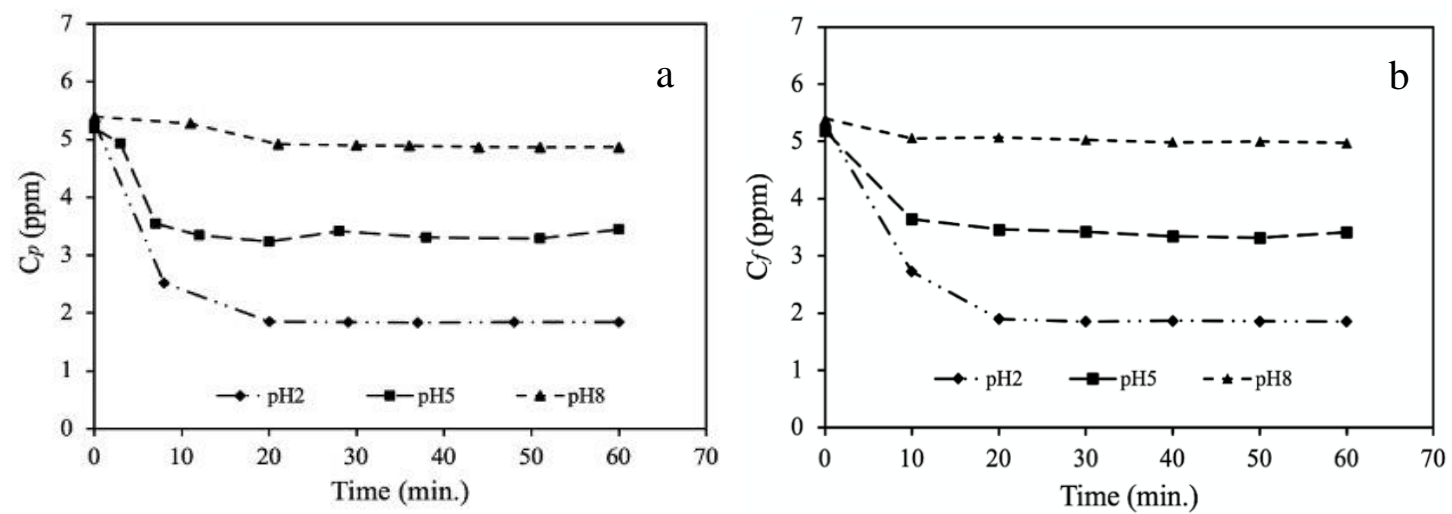

Figure 5.7 Influence of $\mathrm{pH}$ on the removal of SMZ, 5ppm initial [SMZ] under UV light (a) permeate (b) feed.
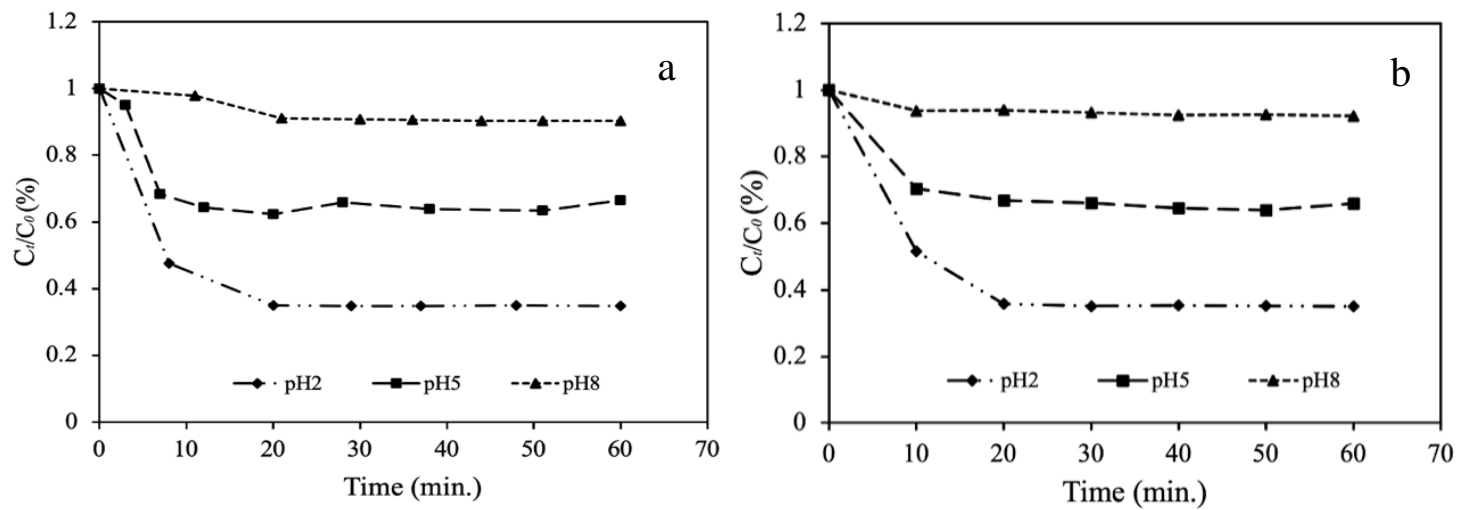

Figure 5.8 Percentage removal $\left(\mathrm{C} / \mathrm{C}_{\mathrm{o}}\right)$ vs time in the absence of UV light (5 ppm initial [SMZ]):

(a) permeate (b) feed.

\subsubsection{Effect of SMZ concentration}

Two concentrations of SMZ, 5ppm and $10 \mathrm{ppm}$, were studied under different $\mathrm{pH}$ values 2,5,8, as illustrated in figure 5.9 and 5.10. The concentrations of SMZ 5ppm and 
10ppm showed decrease in permeate flow and feed solution together after 8min. and 20min., respectively, under illumination. On the other hand, degradation ratios $\mathrm{C}_{\mathrm{C}} \mathrm{C}_{\mathrm{o}}$ of SMZ shows increase in both concentrations in the permeate flow and the feed solution when $\mathrm{pH}$ decreases. However, the removal efficiency of 10ppm SMZ concentration decreased when $\mathrm{pH}$ values increased $65 \%$ at $\mathrm{pH} 2,37 \%$ at $\mathrm{pH} 5$, and $10 \%$ with $\mathrm{pH} 8$ after $1 \mathrm{hr}$ of photodegradation reaction. In same trend, the removal efficiency of 5ppm SMZ decreased $62 \%$ at $\mathrm{pH} 2,30 \%$ at $\mathrm{pH} 5$, and $2 \%$ at $\mathrm{pH} 8$ after $1 \mathrm{hr}$. As noticed, the removal efficiency of SMZ slightly decreased after increase SMZ concentration with all pH values. The results revealed decrease in the membrane efficiency when the SMZ concentration increase because the active layer was unable to handle with the excess amount of SMZ. Therefore, SMZ molecules remained in the permeate flow without degrading. To keep the efficiency of membrane, it may be needed to increase the active sites on the membrane surface to be able dealing with excess amount of SMZ.
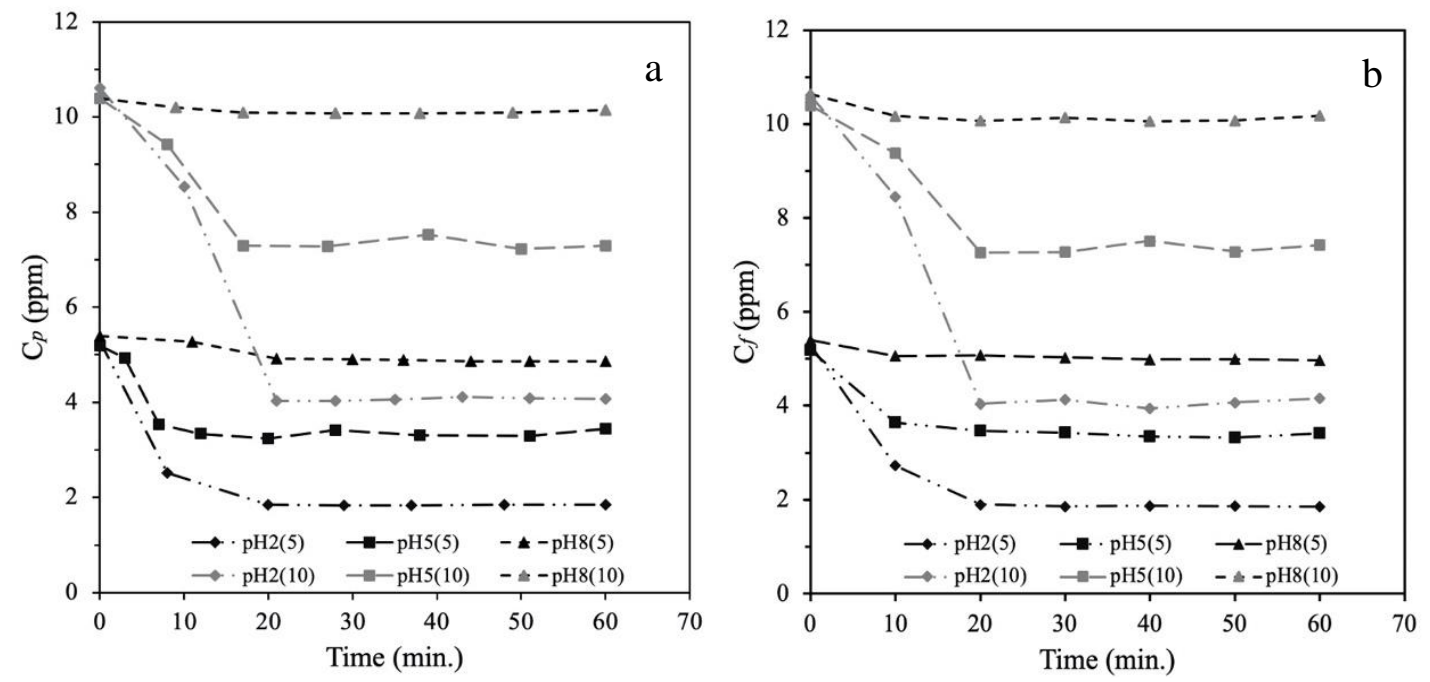

Figure 5.9 Influence of the $\mathrm{pH}$ on the removal of SMZ, 5ppm and 10ppm initial [SMZ] under of UV light (a) permeate (b) feed. 

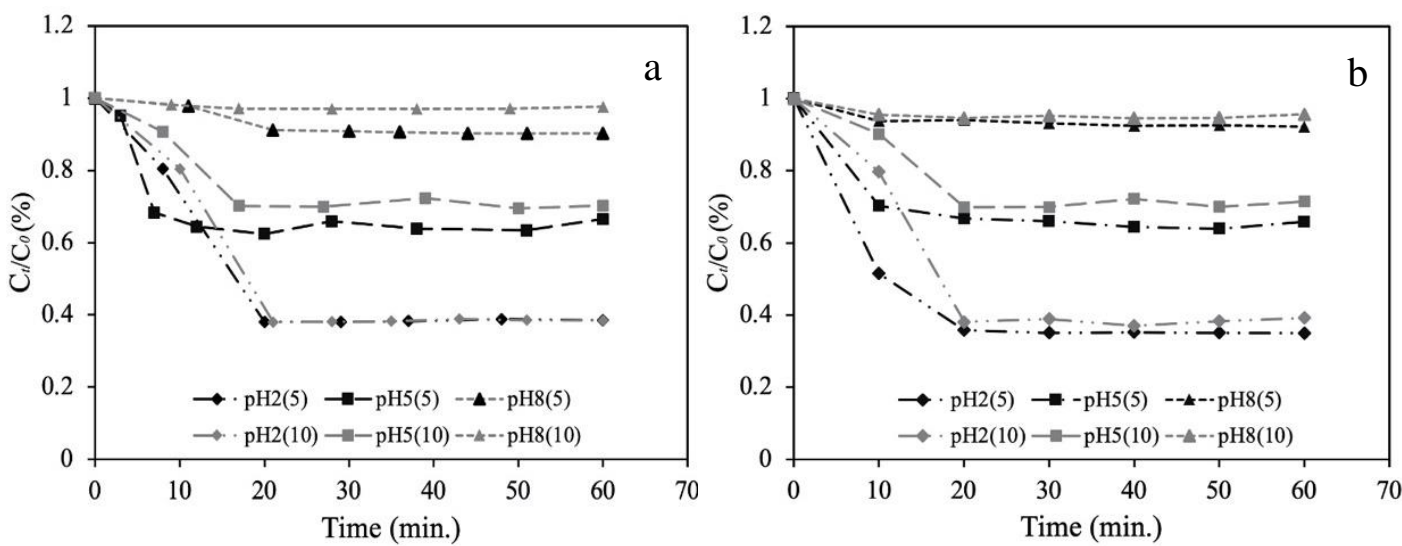

Fig. 5.10 Percentage removal $\left(\mathrm{C} / \mathrm{C}_{\mathrm{o}}\right)$ vs time in the absence of UV light (5ppm and 10ppm initial [SMZ]):

(a) permeate (b) feed.

\subsubsection{Effect of HA presence on SMZ degradation}

To study the effect of presence HA on the removal of SMZ in the water, dark control experiments were carried out first. The used feed solution in this experiment includes 1ppm HA and 5ppm SMZ, at pH 2,5,8. The results showed that SMZ removal by the coated membrane was not significant in both permeate flow and feed solution at the three $\mathrm{pH}$ values tested, as depicted in Figure 5.11 and 12. In comparison with Figure 5.3, the results showed that added HA to the solutions did not improve the ability of the membrane to remove SMZ molecules.
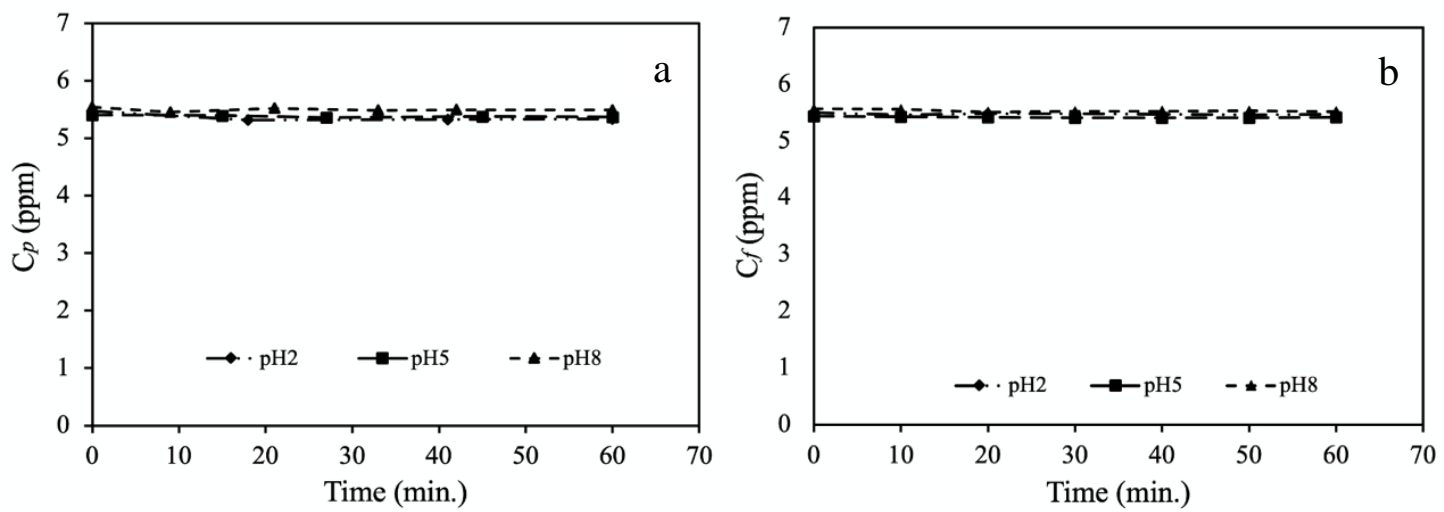

Fig. 5.11 Influence of $\mathrm{pH}$ on the removal of SMZ, 1ppm HA and 5ppm [SMZ], in the absence of UV light (a) permeate (b) feed. 

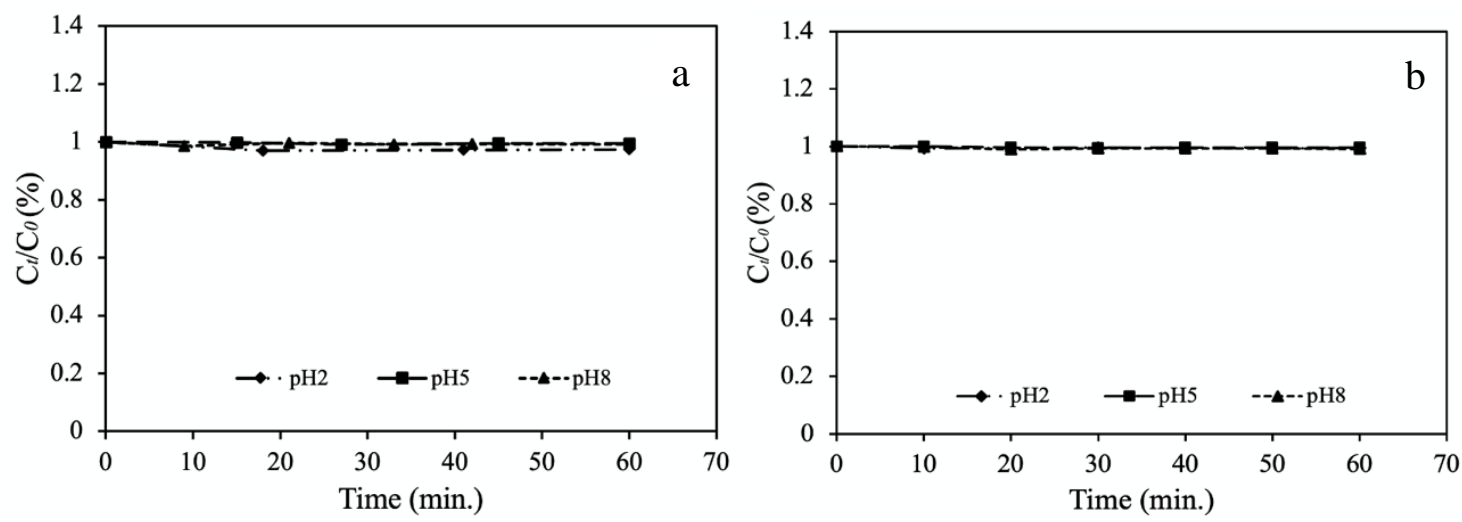

Fig. 5.12 Percentage removal $\left(\mathrm{C} / \mathrm{C}_{\mathrm{o}}\right)$ vs time in the absence of UV light (1ppm HA and 5ppm [SMZ]):

(a) permeate (b) feed.

Figures 5.13 and 5.14 illustrate the effect of the absence and presence of HA on the SMZ degradation at $\mathrm{pH} 2,5,8$. At $\mathrm{pH}$ 2, the results showed that there is a significant enhancement in the SMZ degradation by decreasing the required time to degrade the same concentration of SMZ in clean water.
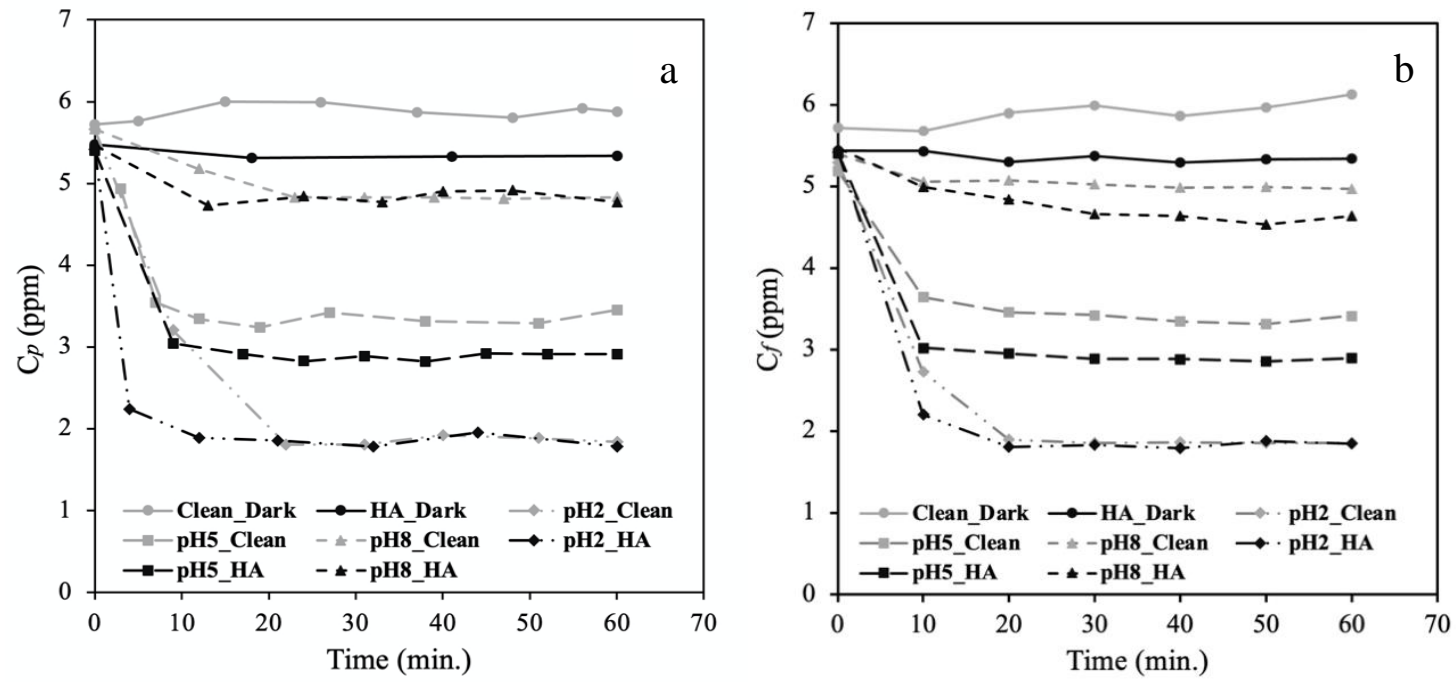

Fig. 5.13 The influence of the pH solution on 1ppm HA and 5ppm [SMZ] vs time under of UV light (a) permeate (b) feed. 

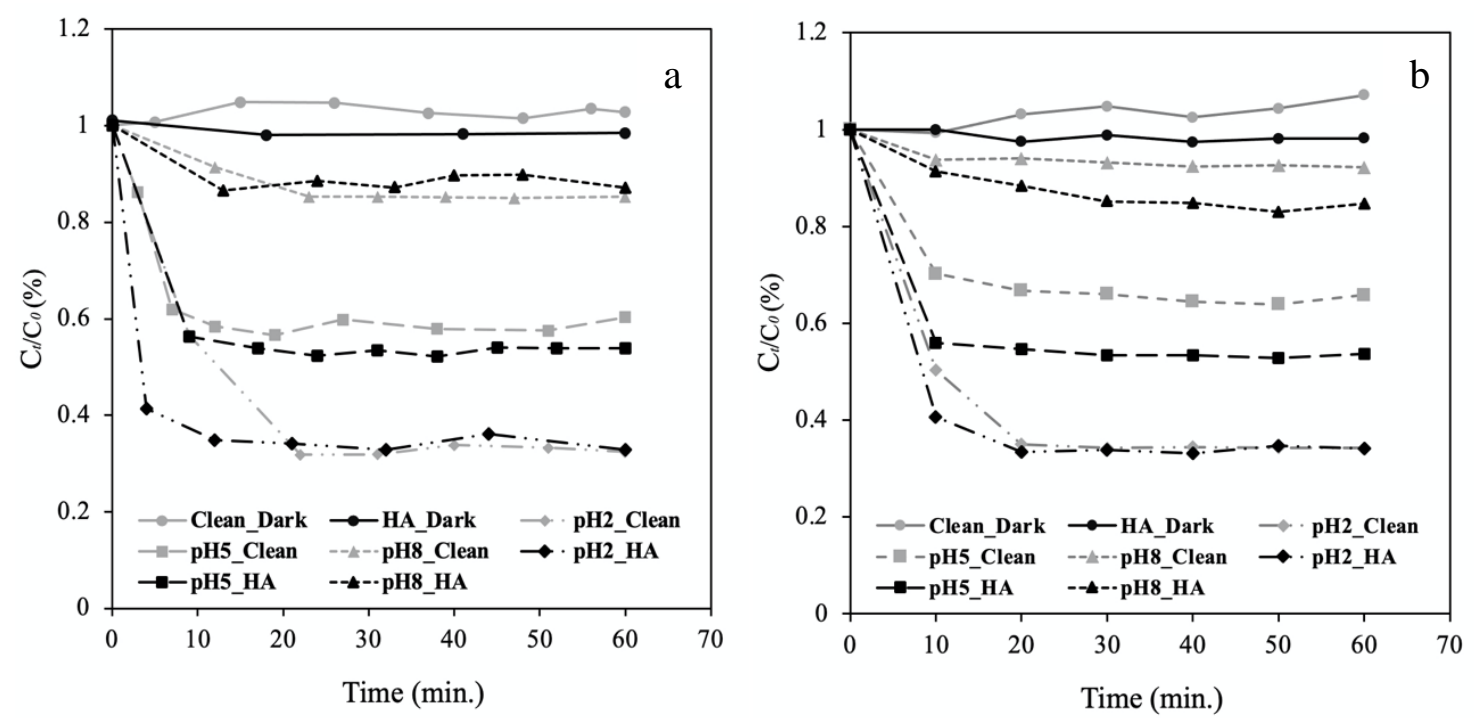

Fig. 5.14 The normalized 1ppm HA and 5ppm [SMZ] plotted vs time under of UV light (a) permeate (b) feed.

SMZ degradation showed increase at $\mathrm{pH} 5$ in the presence of $\mathrm{HA}$, and this increment became stable until the experiment completed. On the other hand, SMZ degradation at $\mathrm{pH} 8$ exhibited a simple increase at the beginning of experiment then became unworthy. These increments in the SMZ degradation rates could be attributed to the existence of dissolved organic matter (DOM), that has a pronounced effect on photochemical based water treatment processes. Biomass after decomposed it is considered as a major source of producing DOM which is composed of large carbon-based structures with large number of light absorbing chromophores. DOM will lead to an excited state (DOM*) upon light absorption Equation 5.1. DOM* can undergo electron or energy transfer pathways with molecular oxygen to produce ${ }^{1} \mathrm{O}_{2}$ (single oxygen) or $\mathrm{O}_{2}{ }^{\bullet-}$ Equation 5.2. These reactive oxygen species (ROS) will initiate SMZ degradation Equation 5.3. Dissolved organic matter will sensitize $\mathrm{TiO}_{2}$ too Equation 5.4 which leads to charge carries with the potential to start processes of degradation Equation 5.5 [177]. 


$$
\begin{aligned}
& \mathrm{DOM}+\mathrm{h} v \rightarrow \mathrm{DOM}^{*} \\
& \mathrm{DOM}^{*}+\mathrm{O}_{2} \rightarrow{ }^{1} \mathrm{O}_{2}\left(\mathrm{O}_{2}{ }^{\bullet-}\right) \\
& { }^{1} \mathrm{O}_{2}\left(\mathrm{O}_{2}{ }^{\bullet-}\right)+\mathrm{SMZ} \rightarrow \mathrm{SMZ}_{(\mathrm{OX})} \\
& \mathrm{DOM}^{*}+\mathrm{TiO}_{2} \rightarrow \mathrm{TiO}_{2}{ }^{*} \\
& \mathrm{TiO}_{2}{ }^{*} \rightarrow \mathrm{e}_{\mathrm{cb}}{ }^{-}+\mathrm{h}_{v b}{ }^{+} \rightarrow \mathrm{ROS}+\mathrm{SMZ} \rightarrow \mathrm{SMZ}_{(\mathrm{OX})}
\end{aligned}
$$

\subsubsection{Effect of ionic strength on the SMZ degradation}

To study the effect of adding IS on SMZ degradation, three different concentrations of ionic strength $\left(1,10,100 \mathrm{mM}\right.$ of $\left.\mathrm{NaNO}_{3}\right)$ were prepared as feed solutions after adjusting their $\mathrm{pH}$ solution at 5 with the absence of UV light. The results showed that SMZ adsorption on the membrane surface was low with all IS values in both permeate flow and feed solution, as illustrated in figures 5.15 and 5.16. The results confirmed that the SMZ adsorption was negligible in the next SMZ photodegradation experiments by using IS solutions.
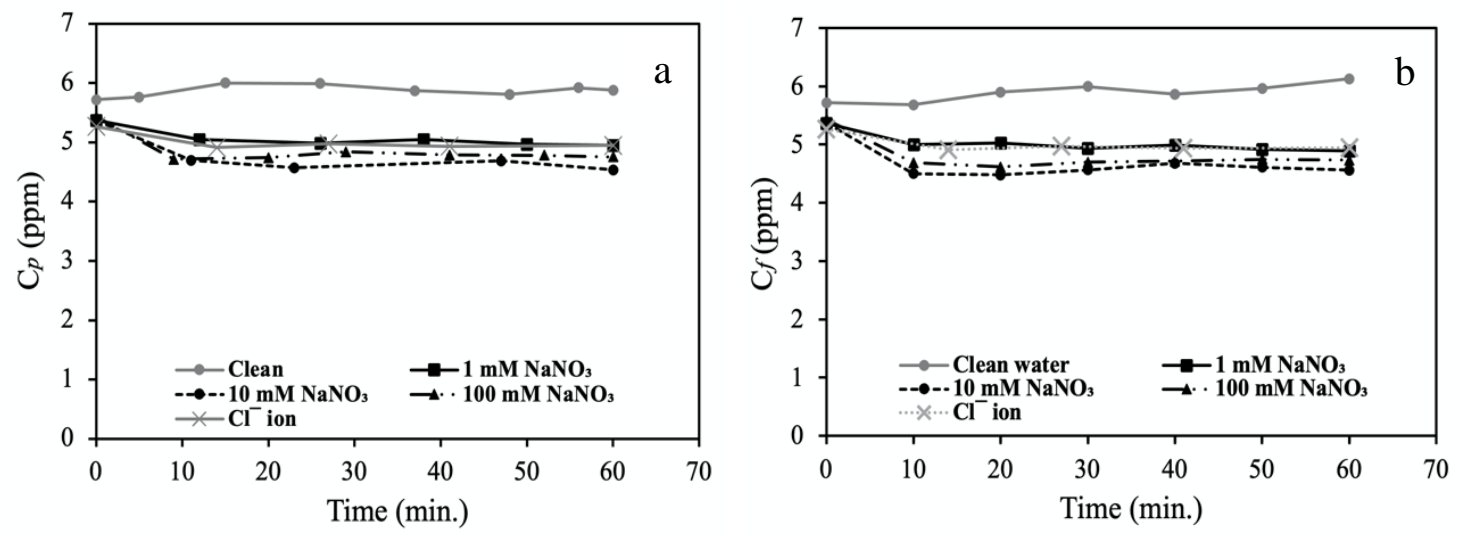

Fig. 5.15 The influence of different levels of $\mathrm{NaNO}_{3} 1,10,100 \mathrm{mM}$ and $\mathrm{NaCl}^{-} 10 \mathrm{mM}$ on an initial 5ppm [SMZ] solution at pH5 vs time at the absence of UV light (a) permeate (b) feed. 

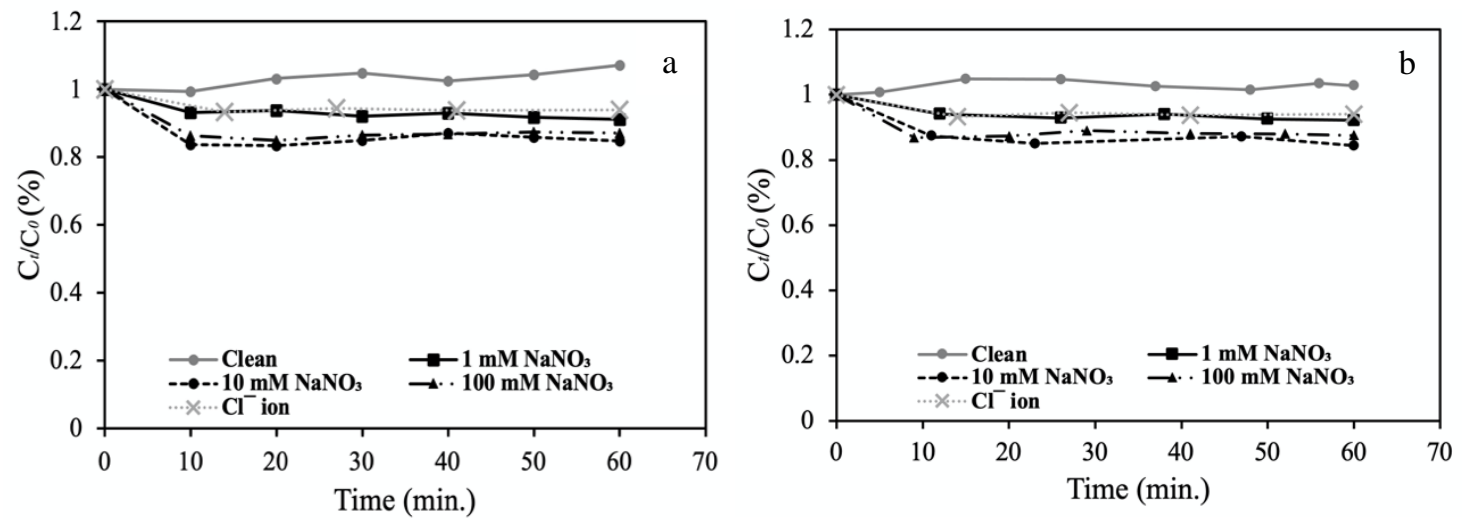

Fig. 5.16 Percentage removal $\left(\mathrm{C} / \mathrm{C}_{0}\right)$ vs time in the absence of UV light (different levels of $\mathrm{NaNO}_{3} 1,10,100 \mathrm{mM}$ and $\mathrm{NaCl}^{-} 10 \mathrm{mM}$ on an initial 5ppm [SMZ] solution at pH5): (a) permeate (b) feed.

Notably, the results showed a significant increase SMZ degraded with increase nitrate ions within 1,10,100 $\mathrm{mM}$ after $1 \mathrm{hr}$ under UV-light, as shown in figures 5.17 and 5.18. After 8 min., SMZ had been decomposed and removed around 73, 95, 97\%, respectively, of its initial amount. It indicates that SMZ was converted after $1 \mathrm{hr}$. This result attributed to a favorable electrostatic interaction between $\mathrm{TiO}_{2}$ particles and $\mathrm{SMZ}$ when the value of $\mathrm{pH}$ is 5 [178]. Consistent with our observation, Hao et al. mentioned that promotes of effect of presence nitrate ion on UV degradation sulphonamide compounds [1]. On the other hands, nitrate ions will adsorb the excess UV light when its concentration increases that will be led to competition for the number of photons available [180]. Therefore, SMZ degradation didn't enhanced proportionately when the nitrate ion concentration increased.

Because of its presence in significant concentration in water bodies over a varied concentration range of $0.1-500 \mathrm{ppm}[181]$, chloride $\left(\mathrm{Cl}^{-}\right)$ion was studied in this work to investigate its effect on the SMZ degradation and the membrane performance. Therefore, 10ppm of $\mathrm{Cl}^{-}$was added to 5ppm SMZ solution at $\mathrm{pH} 5$ in the absence and under UV light. 

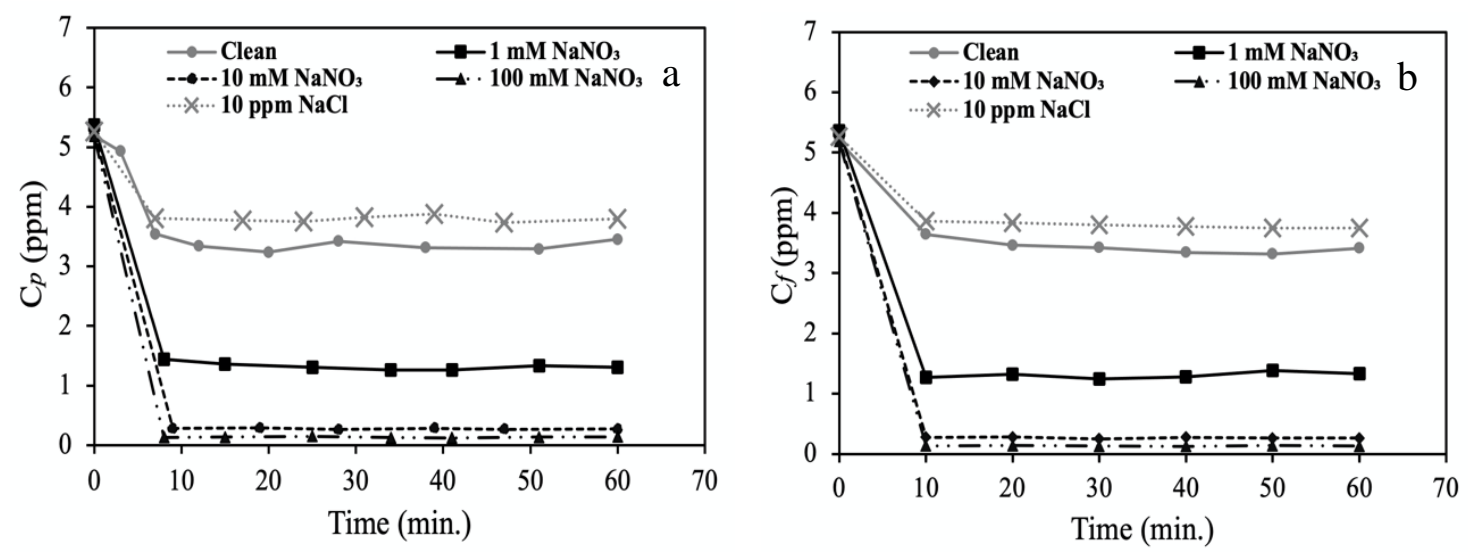

Fig. 5.17 The influence of $\mathrm{NaNO}_{3} 1,10,100 \mathrm{mM}$ on an initial 5ppm [SMZ] solution at pH5 vs time under of UV-light (a) permeate flow (b) feed.
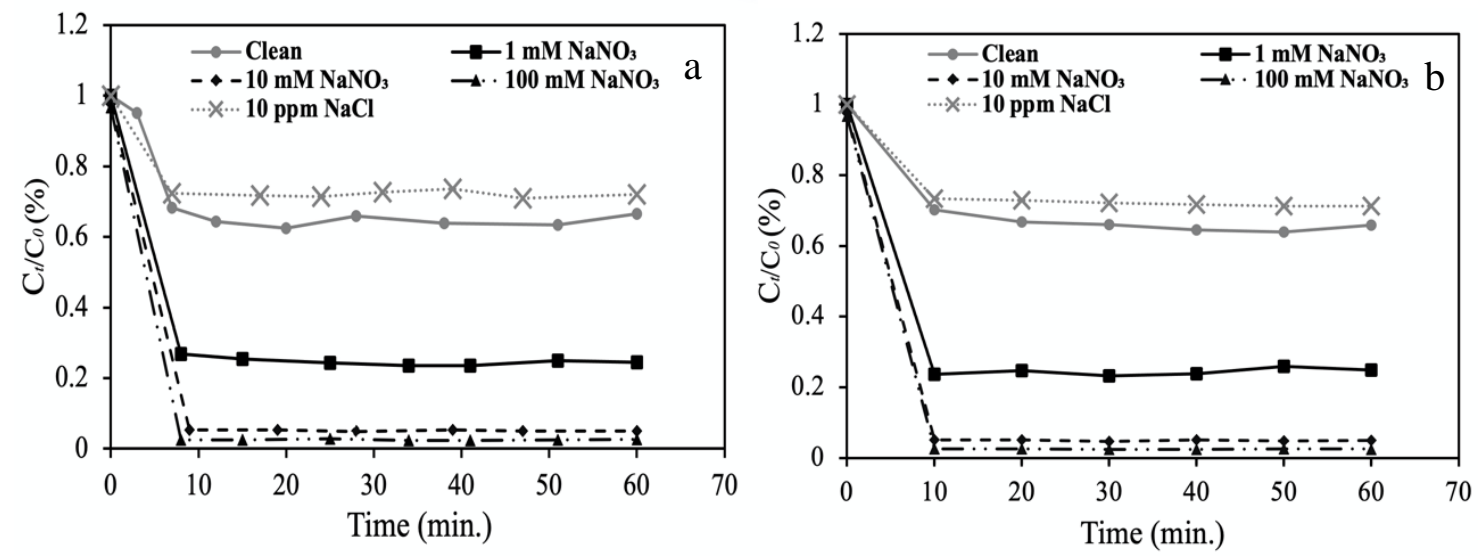

Fig. 5.18 The normalized of $\mathrm{NaNO}_{3} 1,10,100 \mathrm{mM}$ on an initial 5ppm [SMZ] solution at pH5 vs time under of UV-light (a) permeate (b) feed.

In the absence of UV light, SMZ removal efficiency showed not significant decrease after $1 \mathrm{hr}$., as shown in Figures 5.17 and 5.18. This result belongs to the affinity of $\mathrm{Cl}^{-}$ions to be adsorbed by the positive active sites on the membrane surface, so the membrane surface will be neutral to SMZ molecules. Thus, $\mathrm{Cl}^{-}$will lead to make the adsorption of $\mathrm{SMZ}$ molecules by $\mathrm{TiO}_{2}$ particles slower by decreasing the electrostatic interaction force between the membrane surface and SMZ molecules. Therefore, SMZ adsorption will be not important role in the following SMZ photodegradation experiments. 
Under UV light, the results showed decrease slightly SMZ concentration in comparison with clean water, as shown in figures 5.21 and 5.22. The reduction of SMZ degradation in the presence of $\mathrm{Cl}^{-}$ion could be interpretated to the competition between $\mathrm{SMZ}$ and $\mathrm{Cl}^{-}$ions for $\mathrm{UV}$ light. In addition, $\mathrm{Cl}^{-}$ion presence may generate some radicals such as, $\mathrm{Cl}^{\bullet}$, that may inhibit the degradation of SMZ [182]. Zhuang et al. mentioned that a slightly reduction of SMZ removal efficiency in the presence of $2 \mathrm{mM} \mathrm{Cl}^{-}$[183].

\subsubsection{Fouling and TMP evolution during membrane operation}

Figures 5.19a-d shows the TMP profiles with absence UV light under different values of $\mathrm{pH}, \mathrm{SMZ}, \mathrm{HA}$, and IS, respectively, as feed solutions and during 1 hour of filtration. The results showed slight differences between the beginning and final of TMP. Those results confirmed that the membrane surface without illumining $\mathrm{TiO}_{2}$ particles will let the SMZ pass the system without degradation or accumulation, as shown in figures 5.36, 5.11 and 12, and 5.15 and 16. On the other hand, HPLC results confirmed that SMZ passed the system without changing in its concentration. After illumination the surface of membrane by UV-LED light, figures 5.20(a-d) show that no significant differences between the TMP with or without illumination the membrane surface by UV-LED light. The fouling didn't change with using different values of $\mathrm{pH}, \mathrm{SMZ}, \mathrm{HA}$, and IS as feed solutions. Those results shows that the large pore size on the membrane surface will led to delay accumulation of SMZ and HA in absence of UV-LED light. Therefore, the surface of membranes stayed clean without significant fouling during the filtration processes [169]. Same situation happened with presence of UV-LED light. TMP didn't change significantly even with degradation of SMZ on the membrane surface after 1 hour of filtration. 

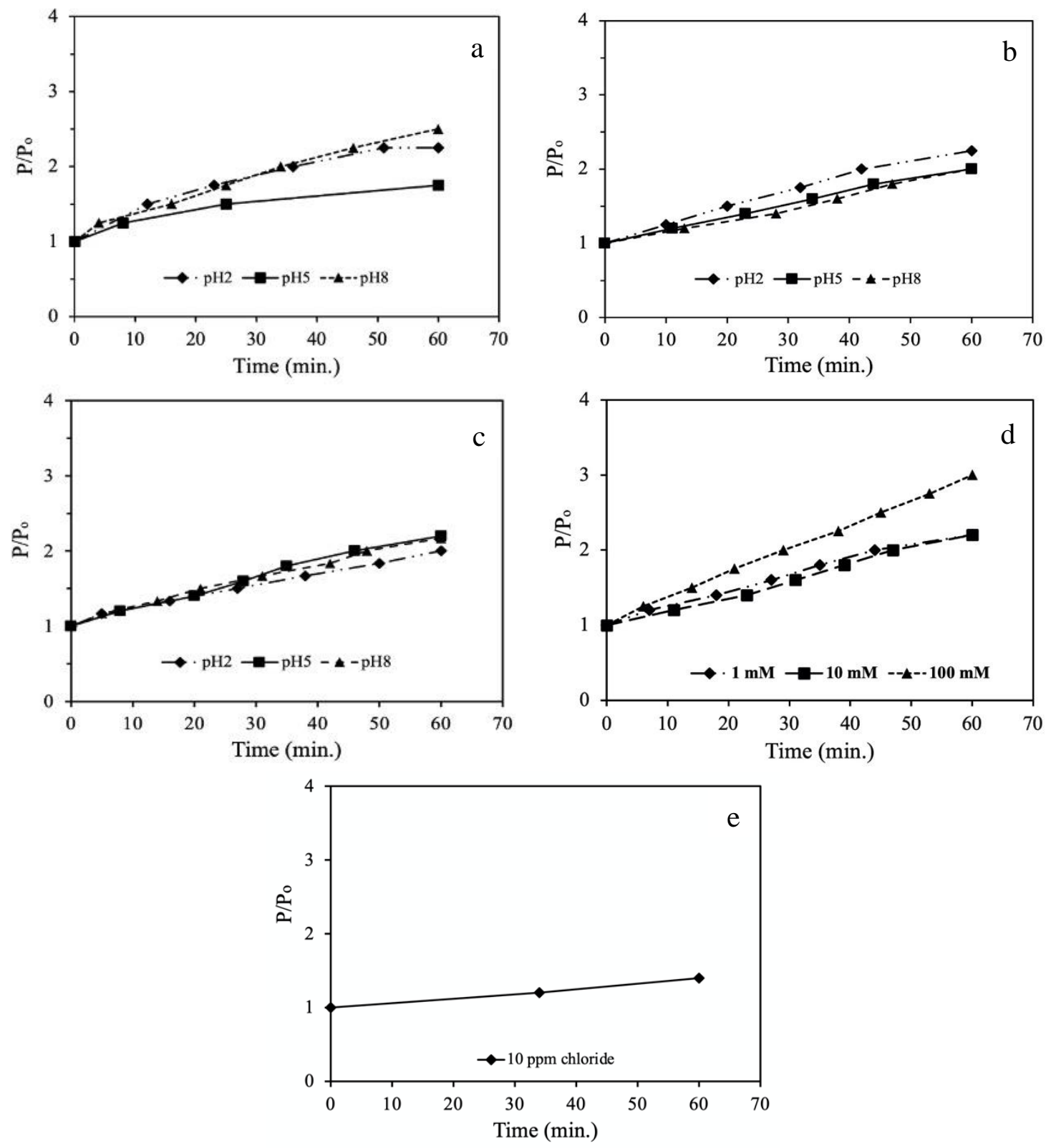

Figure 5.19 Normalized pressure-time profiles vs time at absence of UV light (a) 5ppm [SMZ] (b) 10ppm [SMZ]

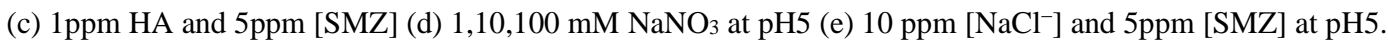



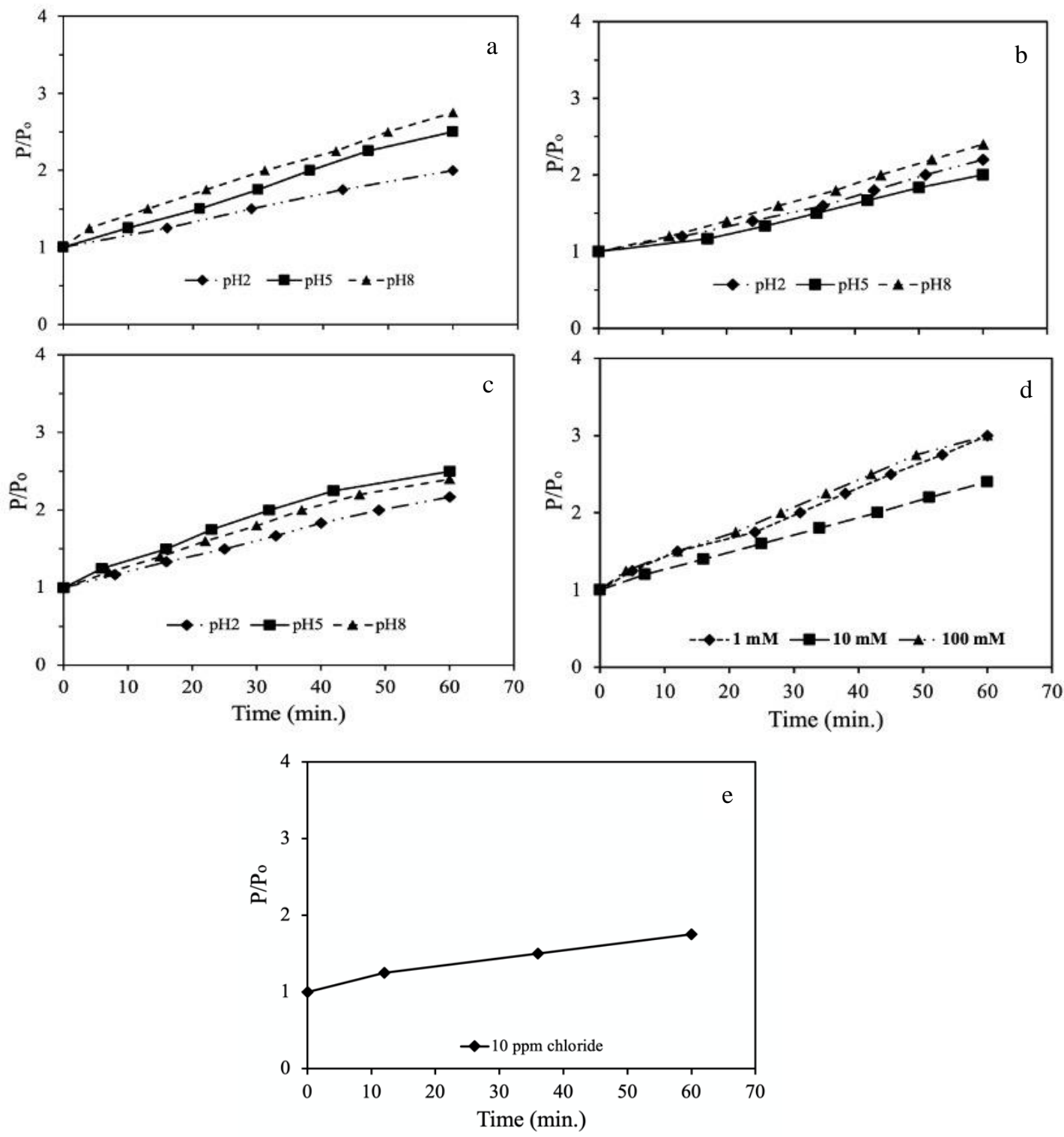

Figure 5.20 Normalized pressure-time profiles vs time under UV light (a) 5ppm [SMZ] (b) 10ppm [SMZ] (c) 1ppm HA and 5ppm [SMZ] (d) 1,10,100 mM NaNO 3 at pH5 (e) $10 \mathrm{ppm}\left[\mathrm{NaCl}^{-}\right]$and 5ppm [SMZ] at pH5. 


\subsection{Conclusion}

A novel technique that includes two processes: filtration and advanced oxidation was used to examine the kinetic of photocatalytic degradation of SMZ on the supported $\mathrm{TiO}_{2}$ ceramic tubular membrane. In the absence and presence of UV-light. A continues flow reactor was performed to compare the SMZ degradation under different conditions. In this study, two SMZ concentrations (5 ppm and $10 \mathrm{ppm}$ ) were examined their degradation under different $\mathrm{pH} \mathrm{2,5}$, and 8 values in the absence and presence of UV-light. The results showed that the SMZ removal was no significant in the absence of UV-light. Under UV-light, the system significantly removed the SMZ from the solution at $\mathrm{pH} 2$ after $1 \mathrm{hr}$. On the other hand, the presence of HA was investigated its effect on the degradation of $5 \mathrm{ppm}$ [SMZ] at $\mathrm{pH}$ 2,5, and 8 as an initial solution. The degradation efficiency of SMZ was noteworthy improved in the presence of HA with all $\mathrm{pH}$ values by decreasing the required time to degrade $\mathrm{SMZ}$ in clean water. $\mathrm{NaNO}_{3}{ }^{-}(1,10,100 \mathrm{mM})$ and $\mathrm{NaCl}^{-}(10 \mathrm{ppm})$ ions were also studied their effects on the degradation of $5 \mathrm{ppm} \mathrm{SMZ} \mathrm{at} \mathrm{pH} \mathrm{5.} \mathrm{The} \mathrm{rate} \mathrm{of}$ $\mathrm{SMZ}$ degradation was faster in the presence of $\mathrm{NO}_{3}{ }^{-}$comparison with clean water, and this rate decreased roughly with increase of $\mathrm{NO}_{3}{ }^{-}$. This decrease is interpreted that $\mathrm{NO}_{3}{ }^{-}$ion will adsorb the excess UV light and led to competition for the number of photons available. Otherwise, SMZ degradation decreased in the presence of $\mathrm{Cl}^{-}$ion because of the competition between $\mathrm{SMZ}$ and $\mathrm{Cl}^{-}$ions for $\mathrm{UV}$ light. In addition, $\mathrm{Cl}^{-}$ion will generate some radicals such as, $\mathrm{Cl}^{\bullet}$, which may inhibit the degradation of SMZ [182]. TMP of this system was monitored, and the results showed there is no significant increase with SMZ degradation. As a result, this system offers a suitable treatment to remove SMZ from water. 


\section{Chapter 6: Conclusion and Future work}

\subsection{Conclusion.}

The application of metal oxides to water treatment processes was investigated in order to address current challenges in drinking water quality. A new group of iron/graphene oxides composite materials (IOGO) with composition varying form $5 \%$ to $25 \% \mathrm{GO}$ in weight were fabricated and characterized. XRD analysis showed that iron oxide was while SEM images confirmed that IO particles distributed uniformly on the GO sheets. The material was evaluated as adsorbent for $\mathrm{As}(\mathrm{V})$ removal from water. As(V) removal from water. The adsorption capacity increased with GO content, which also the led to increase the BET surface area. IOGO25 showed the highest efficiency for As(V) adsorption removal of all composites. As(V) adsorption kinetics was well fit with a pseudo-second order kinetic model; a correlation between GO content and faster kinetics was observed. The surface complexation was proposed as the main mechanism for $\mathrm{As}(\mathrm{V})$ adsorption. The IOGO composites were able to remove $\mathrm{As}(\mathrm{V})$ contamination below the recommended MCL for drinking water. The incorporation of GO resulted in a more efficient material, with higher adsorption capacity than hematite and faster adsorption kinetics.

In a seond approach, a group of tubular alumina ceramic membranes were coated by multi-layers of $\mathrm{TiO}_{2}$. SEM images showed that pore diameters gradually decreased in both surface and active layer of the coated membranes with the increase the number of coating layers. The results of flux and permeability confirmed that the coating process was successful, indicted by a decrease in their values. Polyethylene glycol (PEG) (MW 20 kDa and $200 \mathrm{kDa}$ ) were used as a model organic compound to study the fouling and the rejection 
evolution of the membranes. Transmembrane pressure (TMP) showed gradual increase rates with increasing number of coating layers. On the other hand, TMP evolved quickly with 4 layers membrane using PEG (MW $200 \mathrm{kDa}$ ). Rejection experiements showed that PEG concentration in the permeate flow increased because evolving TMP. After a water rinse, the membrane TMP decreases to practically the same as before being used in fouling and rejection experiments, which suggests a very low level of irreversible fouling.

The $\mathrm{TiO}_{2}$ coated membranes were tested in filtration and reaction (advanced oxidation) process for the degradation of sulfamethazine (SMZ). The membrane was tested in the absence and presence of UV-light at continues flow reactor mode. Two initial SMZ concentrations (5 ppm and $10 \mathrm{ppm}$ ), three $\mathrm{pH}$ levels $(2,5$, and 8), presence of humic acid (HA $5 \mathrm{ppm}$ ), and ionic strength (10 ppm $\mathrm{NaCl}$ and $1,10,100 \mathrm{mM}$ of $\mathrm{NaNO}^{-}$), were examined to study their effect on SMZ removal and degradation. In the absence of UVlight, the results showed that SMZ was not removed by the membrane with the all parameters studied. Under UV-light, the system was able to remove $67 \%$ of SMZ from the solution at $\mathrm{pH}$ 2. The presence of HA led to an improvement of SMZ degradation at all $\mathrm{pH}$ values, as well as the presence of $\mathrm{NO}_{3}{ }^{-}$. However, $\mathrm{SMZ}$ degradation decreased in the presence of $\mathrm{Cl}^{-}$ion because of the competition between $\mathrm{SMZ}$ and $\mathrm{Cl}$ - ions for $\mathrm{UV}$ light. The studied system offers a suitable treatment for SMZ degradation from water.

\subsection{Future work}

The works have stimulated us to make the following suggestions for future work. 


\subsubsection{Investigating the performance of the coated tubular ceramic membranes by multilayers of $\mathrm{TiO}_{2}$ for removal a group of antibiotics contaminants.}

After the successful coating process of the tubular ceramic membranes, their efficiency of those membranes will be examined to remove of three antibiotics most frequently identified in the aquatic environment such as, sulfamethazine, oxytetracycline, tetracycline. Also, the effect of presence of organic and inorganic compounds on antibiotics removal will be studied.

\subsubsection{Degradation Mechanisms Analysis of Photocatalytic}

The major intermediates formed during sulfamethazine photocatalytic degradation and their analogues will be detected or deduced by analyzing the taken samples from the influent and permeate flow using HPLC/MS/MS. Also, this study will investigate their degradation behaviors.

\subsubsection{Flow rates of inflow and retentate}

The effects of using different flow rates of inflow and retentate will be investigated on the degradation process of SMT. The operating flow rates will be adjusted by hand operation using the flow control valves installed in the flowmeters and the valve in the permeate flow line.

\subsubsection{Time of illumination by UV-light}

To study the effect of illumination time on photodegradation efficiency of SMZ, the efficiency of photodegradation at different time periods will be carried out by turning the UV-light at different time $(20,30,40,60 \mathrm{~min})$ and $\mathrm{pH}(2,5,8)$. 


\section{Reference:}

[1] D. Altieri, "The effects of overpopulation on water resources and water security," Dep. Eng. Swart. Coll. Available Fubini Swart. Edu ENVS2danEssay4 Html, 2016.

[2] N. Ngwuluka, N. Ochekpe, and P. Odumosu, "An assessment of pharmaceutical waste management in some Nigerian pharmaceutical industries," Afr. J. Biotechnol., vol. 10, pp. 11259-11264, Sep. 2011.

[3] T. Dey, Nanotechnology for Water Purification. Universal-Publishers, 2012.

[4] "1 in 3 people globally do not have access to safe drinking water - UNICEF, WHO." https://www.unicef.org/press-releases/1-3-people-globally-do-not-have-access-safedrinking-water-unicef-who (accessed Oct. 05, 2019).

[5] M. T. Amin, A. A. Alazba, and U. Manzoor, "A review of removal of pollutants from water/wastewater using different types of nanomaterials," Adv. Mater. Sci. Eng., vol. 2014, 2014.

[6] M. Kamali, K. M. Persson, M. E. Costa, and I. Capela, "Sustainability criteria for assessing nanotechnology applicability in industrial wastewater treatment: Current status and future outlook," Environ. Int., vol. 125, pp. 261-276, 2019.

[7] M. T. Amin, A. A. Alazba, and U. Manzoor, "A review of removal of pollutants from water/wastewater using different types of nanomaterials," Adv. Mater. Sci. Eng., vol. 2014, 2014.

[8] A. Kraus, K. Jainae, F. Unob, and N. Sukpirom, "Synthesis of MPTS-modified cobalt ferrite nanoparticles and their adsorption properties in relation to Au (III)," J. Colloid Interface Sci., vol. 338, no. 2, pp. 359-365, 2009. 
[9] A. K. M. Hussain, "Application of advanced adsorption processes for dissolved organic matter and heavy metal removal from water sources," $\mathrm{PhD}$ Thesis, University of Missouri-Columbia, 2015.

[10] N. Vieno, T. Tuhkanen, and L. Kronberg, "Removal of pharmaceuticals in drinking water treatment: effect of chemical coagulation," Environ. Technol., vol. 27, no. 2, pp. 183-192, 2006.

[11] I. Gehrke, A. Geiser, and A. Somborn-Schulz, "Innovations in nanotechnology for water treatment," Nanotechnol. Sci. Appl., vol. 8, p. 1, 2015.

[12] R. J. Narayan, P. N. Kumta, C. Sfeir, D.-H. Lee, D. Choi, and D. Olton, "Nanostructured ceramics in medical devices: applications and prospects," Jom, vol. 56, no. 10, p. 38, 2004.

[13] A. Lagashetty and A. M. Bhavikatti, "Nanotechnology-an overview," 2009.

[14] I. El Saliby, H. Shon, J. Kandasamy, and S. Vigneswaran, "Nanotechnology for water and wastewater treatment: in brief," Water Wastewater Treat. Technol. Encycl. Life Support Syst. EOLSS, 2009.

[15] E. Zekić, Ž. Vuković, and I. Halkijević, "Application of nanotechnology in wastewater treatment," Graldjevinar, vol. 70, no. 04., pp. 315-323, 2018.

[16] M. Taran, M. Safaei, N. Karimi, and A. Almasi, "Benefits and Application of Nanotechnology in Environmental Science: an Overview.”

[17] S. Bayda, M. Adeel, T. Tuccinardi, M. Cordani, and F. Rizzolio, "The history of nanoscience and nanotechnology: From chemical-physical applications to nanomedicine," Molecules, vol. 25, no. 1, p. 112, 2020. 
[18] F. Sanchez and K. Sobolev, "Nanotechnology in concrete-a review," Constr. Build. Mater., vol. 24, no. 11, pp. 2060-2071, 2010.

[19] X. Qu, P. J. Alvarez, and Q. Li, "Applications of nanotechnology in water and wastewater treatment," Water Res., vol. 47, no. 12, pp. 3931-3946, 2013.

[20] D. V. Singh et al., "Wonders of Nanotechnology for Remediation of Polluted Aquatic Environs," in Fresh Water Pollution Dynamics and Remediation, Springer, 2020, pp. 319-339.

[21] S. Chaturvedi, P. N. Dave, and N. K. Shah, "Applications of nano-catalyst in new era," J. Saudi Chem. Soc., vol. 16, no. 3, pp. 307-325, 2012.

[22] S. Kanchi, "Nanotechnology for water treatment," J Env. Anal Chem, vol. 1, no. 2, pp. 1-3, 2014.

[23] D. Mohan and C. U. Pittman Jr, "Arsenic removal from water/wastewater using adsorbents-a critical review," J. Hazard. Mater., vol. 142, no. 1-2, pp. 1-53, 2007.

[24] J. Theron, J. A. Walker, and T. E. Cloete, "Nanotechnology and water treatment: applications and emerging opportunities," Crit. Rev. Microbiol., vol. 34, no. 1, pp. 43-69, 2008.

[25] A. M. Awad et al., "Adsorption of organic pollutants by nanomaterial-based adsorbents: An overview," J. Mol. Liq., p. 112335, 2020.

[26] M. M. Benjamin and D. F. Lawler, Water quality engineering: Physical/chemical treatment processes. John Wiley \& Sons, 2013.

[27] A. K. M. Hussain, "Application of advanced adsorption processes for dissolved organic matter and heavy metal removal from water sources," $\mathrm{PhD}$ Thesis, University of Missouri-Columbia, 2015. 
[28] Y. Jeong, "The adsorption of arsenic (V) by iron (Fe2O3) and aluminum (A12O3) oxides," 2005.

[29] S. Z. N. Ahmad, W. N. W. Salleh, A. F. Ismail, N. Yusof, M. Z. M. Yusop, and F. Aziz, "Adsorptive removal of heavy metal ions using graphene-based nanomaterials: Toxicity, roles of functional groups and mechanisms," Chemosphere, vol. 248, p. 126008, 2020.

[30] Y. Zhang, W. Peng, L. Xia, and S. Song, "Adsorption of Cd(II) at the Interface of water and graphene oxide prepared from flaky graphite and amorphous graphite," $J$. Environ. Chem. Eng., vol. 5, no. 4, pp. 4157-4164, Aug. 2017, doi: 10.1016/j.jece.2017.08.004.

[31] Y. B. Onundi, A. A. Mamun, M. F. Al Khatib, and Y. M. Ahmed, "Adsorption of copper, nickel and lead ions from synthetic semiconductor industrial wastewater by palm shell activated carbon," Int. J. Environ. Sci. Technol., vol. 7, no. 4, pp. 751-758, 2010.

[32] Y. Subbareddy et al., "A facile approach of adsorption of acid blue 9 on aluminium silicate-coated fuller's earth-equilibrium and kinetics studies," Surf. Interfaces, p. 100503, 2020.

[33] S. P. Ghaleh, E. Khodapanah, and S. A. Tabatabaei-Nezhad, "Comprehensive monolayer two-parameter isotherm and kinetic studies of thiamine adsorption on clay minerals: Experimental and modeling approaches,” J. Mol. Liq., p. 112942, 2020.

[34] N. Jiang, R. Shang, S. G. Heijman, and L. C. Rietveld, "Adsorption of triclosan, trichlorophenol and phenol by high-silica zeolites: Adsorption efficiencies and mechanisms," Sep. Purif. Technol., vol. 235, p. 116152, 2020. 
[35] K. Balasubramani, N. Sivarajasekar, and M. Naushad, "Effective adsorption of antidiabetic pharmaceutical (metformin) from aqueous medium using graphene oxide nanoparticles: Equilibrium and statistical modelling," J. Mol. Liq., vol. 301, p. 112426, 2020.

[36] H. Su, Z. Ye, and N. Hmidi, "High-performance iron oxide-graphene oxide nanocomposite adsorbents for arsenic removal," Colloids Surf. Physicochem. Eng. Asp., vol. 522, pp. 161-172, 2017.

[37] F. Yu, J. Ma, and D. Bi, "Enhanced adsorptive removal of selected pharmaceutical antibiotics from aqueous solution by activated graphene," Environ. Sci. Pollut. Res., vol. 22, no. 6, pp. 4715-4724, Mar. 2015, doi: 10.1007/s11356-014-3723-9.

[38] S. Eigler and A. Hirsch, "Chemistry with Graphene and Graphene OxideChallenges for Synthetic Chemists," Angew. Chem. Int. Ed., vol. 53, no. 30, pp. 77207738, 2014, doi: 10.1002/anie.201402780.

[39] A. Bianco et al., "All in the graphene family - A recommended nomenclature for twodimensional carbon materials," Carbon, vol. 65, pp. 1-6, Dec. 2013, doi: 10.1016/j.carbon.2013.08.038.

[40] J. Wang et al., "Exploration of the adsorption performance and mechanism of zeolitic imidazolate framework-8@graphene oxide for $\mathrm{Pb}(\mathrm{II})$ and 1-naphthylamine from aqueous solution,” J. Colloid Interface Sci., vol. 542, pp. 410-420, Apr. 2019, doi: 10.1016/j.jcis.2019.02.039.

[41] G. Ersan, O. G. Apul, F. Perreault, and T. Karanfil, "Adsorption of organic contaminants by graphene nanosheets: A review," Water Res., vol. 126, pp. 385-398, Dec. 2017, doi: 10.1016/j.watres.2017.08.010. 
[42] N. M. Mahmoodi, M. Oveisi, and E. Asadi, "Synthesis of NENU metal-organic framework-graphene oxide nanocomposites and their pollutant removal ability from water using ultrasound," J. Clean. Prod., vol. 211, pp. 198-212, Feb. 2019, doi: 10.1016/j.jclepro.2018.11.136.

[43] J. Wang et al., "Exploration of the adsorption performance and mechanism of zeolitic imidazolate framework-8@graphene oxide for $\mathrm{Pb}$ (II) and 1-naphthylamine from aqueous solution,” J. Colloid Interface Sci., vol. 542, pp. 410-420, Apr. 2019, doi: 10.1016/j.jcis.2019.02.039.

[44] L. Li, Z. Shi, H. Zhu, W. Hong, F. Xie, and K. Sun, "Adsorption of azo dyes from aqueous solution by the hybrid MOFs/GO," Water Sci. Technol., vol. 73, no. 7, pp. 1728-1737, Apr. 2016, doi: 10.2166/wst.2016.009.

[45] K. Soleimani, A. D. Tehrani, and M. Adeli, "Bioconjugated graphene oxide hydrogel as an effective adsorbent for cationic dyes removal," Ecotoxicol. Environ. Saf., vol. 147, pp. 34-42, Jan. 2018, doi: 10.1016/j.ecoenv.2017.08.021.

[46] J. Li et al., "Removal of $\mathrm{Cu}$ (II) and fulvic acid by graphene oxide nanosheets decorated with Fe3O4 nanoparticles," ACS Appl. Mater. Interfaces, vol. 4, no. 9, pp. 4991-5000, 2012.

[47] C. N. R. Rao, U. Maitra, and H. Matte, "Synthesis, characterization, and selected properties of graphene," Graphene Synth. Prop. Phenom., 2012.

[48] L. Jothinathan and J. Hu, "Kinetic evaluation of graphene oxide based heterogenous catalytic ozonation for the removal of ibuprofen," Water Res., vol. 134, pp. 63-73, 2018. 
[49] N. M. Mahmoodi, M. Oveisi, and E. Asadi, "Synthesis of NENU metal-organic framework-graphene oxide nanocomposites and their pollutant removal ability from water using ultrasound," J. Clean. Prod., vol. 211, pp. 198-212, 2019.

[50] H. Wang, C. Wang, S. Liu, L. Chen, and S. Yang, "Superhydrophobic and superoleophilic graphene aerogel for adsorption of oil pollutants from water," $R S C$ Adv., vol. 9, no. 15, pp. 8569-8574, 2019.

[51] M. Sarno, M. Casa, C. Cirillo, and P. Ciambelli, "Complete removal of persistent pesticide using reduced graphene oxide- silver nanocomposite," Chem. Eng. Trans., vol. 60, pp. 151-156, 2017.

[52] P. Chen et al., "Insights into the synergetic mechanism of a combined visRGO/TiO2/peroxodisulfate system for the degradation of PPCPs: Kinetics, environmental factors and products," Chemosphere, vol. 216, pp. 341-351, 2019.

[53] M. S. Samuel, Sk. S. Shah, J. Bhattacharya, K. Subramaniam, and N. D. Pradeep Singh, "Adsorption of $\mathrm{Pb}(\mathrm{II})$ from aqueous solution using a magnetic chitosan/graphene oxide composite and its toxicity studies," Int. J. Biol. Macromol., vol. 115, pp. 1142-1150, Aug. 2018, doi: 10.1016/j.ijbiomac.2018.04.185.

[54] W. J. Stark, P. R. Stoessel, W. Wohlleben, and A. Hafner, "Industrial applications of nanoparticles," Chem. Soc. Rev., vol. 44, no. 16, pp. 5793-5805, 2015.

[55] S. Singh, V. Kumar, R. Romero, K. Sharma, and J. Singh, "Applications of Nanoparticles in Wastewater Treatment," in Nanobiotechnology in Bioformulations, Springer, 2019, pp. 395-418. 
[56] K. R. Kunduru, M. Nazarkovsky, S. Farah, R. P. Pawar, A. Basu, and A. J. Domb, "Nanotechnology for water purification: applications of nanotechnology methods in wastewater treatment," in Water Purification, Elsevier, 2017, pp. 33-74.

[57] N. Ilankoon, "Use of iron oxide magnetic nanosorbents for Cr (VI) removal from aqueous solutions: A review,” J. Eng. Res. Appl., vol. 4, no. 10, pp. 55-63, 2014.

[58] K. E. Engates, Characterization, sorption, and exhaustion of metal oxide nanoparticles as metal adsorbents. The University of Texas at San Antonio, 2010.

[59] H. J. Shipley, K. E. Engates, and V. A. Grover, "Removal of Pb (II), Cd (II), Cu (II), and $\mathrm{Zn}$ (II) by hematite nanoparticles: effect of sorbent concentration, $\mathrm{pH}$, temperature, and exhaustion," Environ. Sci. Pollut. Res., vol. 20, no. 3, pp. 1727$1736,2013$.

[60] A. Fakhri and S. Adami, "Adsorption and thermodynamic study of Cephalosporins antibiotics from aqueous solution onto $\mathrm{MgO}$ nanoparticles," J. Taiwan Inst. Chem. Eng., vol. 45, no. 3, pp. 1001-1006, 2014.

[61] H. Park, N. V. Myung, H. Jung, and H. Choi, "As (V) remediation using electrochemically synthesized maghemite nanoparticles," J. Nanoparticle Res., vol. 11, no. 8, p. $1981,2009$.

[62] Y. Huang, A. N. Fulton, and A. A. Keller, "Optimization of porous structure of superparamagnetic nanoparticle adsorbents for higher and faster removal of emerging organic contaminants and PAHs," Environ. Sci. Water Res. Technol., vol. 2, no. 3, pp. 521-528, 2016.

[63] M. Mulder, Basic principles of membrane technology. Springer Science \& Business Media, 2012. 
[64] D. V. Quang et al., "Effective water disinfection using silver nanoparticle containing silica beads,” Appl. Surf. Sci., vol. 266, pp. 280-287, 2013.

[65] A. Lee, J. W. Elam, and S. B. Darling, "Membrane materials for water purification: design, development, and application," Environ. Sci. Water Res. Technol., vol. 2, no. 1, pp. 17-42, 2016.

[66] F. Senusi, M. Shahadat, S. Ismail, and S. A. Hamid, "Recent advancement in membrane technology for water purification," in Modern Age Environmental Problems and their Remediation, Springer, 2018, pp. 147-167.

[67] D. M. Warsinger et al., "A review of polymeric membranes and processes for potable water reuse," Prog. Polym. Sci., vol. 81, pp. 209-237, 2018.

[68] C. Feng, K. C. Khulbe, T. Matsuura, S. Tabe, and A. F. Ismail, "Preparation and characterization of electro-spun nanofiber membranes and their possible applications in water treatment," Sep. Purif. Technol., vol. 102, pp. 118-135, 2013.

[69] P. Geng and G. Chen, “Antifouling ceramic membrane electrode modified by Magnéli Ti4O7 for electro-microfiltration of humic acid," Sep. Purif. Technol., vol. 185, pp. $61-71,2017$.

[70] M. Wegmann, B. Michen, and T. Graule, "Nanostructured surface modification of microporous ceramics for efficient virus filtration," J. Eur. Ceram. Soc., vol. 28, no. 8, pp. 1603-1612, 2008.

[71] S. P. Suriyaraj, A. Bhattacharyya, and R. Selvakumar, "Hybrid Al 2 O 3/bio-TiO 2 nanocomposite impregnated thermoplastic polyurethane (TPU) nanofibrous membrane for fluoride removal from aqueous solutions," $R S C A d v$. , vol. 5, no. 34, pp. 26905-26912, 2015. 
[72] P. Lens, J. Virkutyte, V. Jegatheesan, and S. Al-Abed, Nanotechnology for water and wastewater treatment. Iwa Publishing, 2013.

[73] "Nanotechnology for Water Remediation Jiban Saikia,... - Google Scholar." https://scholar.google.com/scholar?hl=en\&as_sdt=0\%2C26\&q=Nanotechnology+fo $\mathrm{r}+$ Water+Remediation+Jiban+Saikia\%2C+Abhijit+Gogoi\%2C+and+Sukanya+Baru ah\&btnG= (accessed May 09, 2020).

[74] Z. Zhang, C.-C. Wang, R. Zakaria, and J. Y. Ying, "Role of particle size in nanocrystalline TiO2-based photocatalysts," J. Phys. Chem. B, vol. 102, no. 52, pp. 10871-10878, 1998.

[75] V. Keuter and I. Gehrke, "Development of Multibarrier Systems Consisting of NanoEnhanced Membranes and UV-LEDs for Water Purification Applications," Procedia Eng., no. 44, pp. 544-545, 2012.

[76] A. Mezni et al., "Facile synthesis of highly thermally stable TiO 2 photocatalysts," New J. Chem., vol. 41, no. 12, pp. 5021-5027, 2017.

[77] S.-Y. Lee and S.-J. Park, "TiO2 photocatalyst for water treatment applications," J. Ind. Eng. Chem., vol. 19, no. 6, pp. 1761-1769, 2013.

[78] Q. Xiang, J. Yu, and P. K. Wong, "Quantitative characterization of hydroxyl radicals produced by various photocatalysts," J. Colloid Interface Sci., vol. 357, no. 1, pp. 163-167, 2011.

[79] W. T. Frankenberger Jr, Environmental chemistry of arsenic. CRC Press, 2001.

[80] J. F. Ferguson and J. Gavis, "A review of the arsenic cycle in natural waters," Water Res., vol. 6, no. 11, pp. 1259-1274, 1972. 
[81] K. N. Ghimire, K. Inoue, H. Yamaguchi, K. Makino, and T. Miyajima, “Adsorptive separation of arsenate and arsenite anions from aqueous medium by using orange waste," Water Res., vol. 37, no. 20, pp. 4945-4953, 2003.

[82] Y. Jeong, "The adsorption of arsenic (V) by iron (Fe2O3) and aluminum (A12O3) oxides," 2005.

[83] J. G. Hering, P.-Y. Chen, J. A. Wilkie, M. Elimelech, and S. Liang, “Arsenic removal by ferric chloride," J.-Am. Water Works Assoc., vol. 88, no. 4, pp. 155-167, 1996.

[84] T. Yuan, J. Yong Hu, S. L. Ong, Q. F. Luo, and W. Jun Ng, “Arsenic removal from household drinking water by adsorption," J. Environ. Sci. Health Part A, vol. 37, no. 9, pp. 1721-1736, 2002.

[85] P. L. Smedley and D. G. Kinniburgh, "A review of the source, behaviour and distribution of arsenic in natural waters," Appl. Geochem., vol. 17, no. 5, pp. 517568, May 2002, doi: 10.1016/S0883-2927(02)00018-5.

[86] D. K. Nordstrom, Worldwide occurrences of arsenic in ground water. American Association for the Advancement of Science, 2002.

[87] M.-J. Kim, J. Nriagu, and S. Haack, “Arsenic species and chemistry in groundwater of southeast Michigan,” Environ. Pollut., vol. 120, no. 2, pp. 379-390, 2002.

[88] S. R. Hinkle and D. J. Polette, Arsenic in ground water of the Willamette Basin, Oregon, vol. 98. US Department of the Interior, US Geological Survey, 1999.

[89] I. A. for R. on Cancer, “Arsenic, metals, fibres, and dusts. Volume 100 C. A review of human carcinogens," IARC Monogr. Eval. Carcinog. Risks Hum. Lyon FR Int. Agency Res. Cancer Arsen. Arsen. Compd., pp. 41-94, 2012. 
[90] A. H. Welch, D. B. Westjohn, D. R. Helsel, and R. B. Wanty, "Arsenic in ground water of the United States: Occurence and geochemistry," Ground Water, vol. 38, no. 4, p. 589, 2000.

[91] A. H. Smith, P. A. Lopipero, M. N. Bates, and C. M. Steinmaus, Arsenic epidemiology and drinking water standards. American Association for the Advancement of Science, 2002.

[92] A. K. Sarmah, M. T. Meyer, and A. B. Boxall, "A global perspective on the use, sales, exposure pathways, occurrence, fate and effects of veterinary antibiotics (VAs) in the environment," Chemosphere, vol. 65, no. 5, pp. 725-759, 2006.

[93] "Pharmaceuticals, Hormones, and Other Organic Wastewater Contaminants in U.S. Streams, 1999-2000: A National Reconnaissance | Environmental Science \& Technology.” https://pubs.acs.org/doi/10.1021/es011055j (accessed Jan. 22, 2021).

[94] R. Hirsch, T. Ternes, K. Haberer, and K.-L. Kratz, "Occurrence of antibiotics in the aquatic environment," Sci. Total Environ., vol. 225, no. 1, pp. 109-118, Jan. 1999, doi: 10.1016/S0048-9697(98)00337-4.

[95] J. Wang, T. Zhou, J. Mao, and X. Wu, "Comparative study of sulfamethazine degradation in visible light induced photo-Fenton and photo-Fenton-like systems," $J$. Environ. Chem. Eng., vol. 3, no. 4, pp. 2393-2400, 2015.

[96] C.-C. Lin and M.-S. Wu, "Feasibility of using UV/H2O2 process to degrade sulfamethazine in aqueous solutions in a large photoreactor," J. Photochem. Photobiol. Chem., vol. 367, pp. 446-451, 2018. 
[97] N. Wang et al., "Enhanced photocatalytic degradation of sulfamethazine by Bi-doped $\mathrm{TiO} 2$ nano-composites supported by powdered activated carbon under visible light irradiation," Sep. Purif. Technol., vol. 211, pp. 673-683, 2019.

[98] M. G. Alalm, A. Tawfik, and S. Ookawara, "Comparison of solar TiO2 photocatalysis and solar photo-Fenton for treatment of pesticides industry wastewater: operational conditions, kinetics, and costs," J. Water Process Eng., vol. 8, pp. 55-63, 2015.

[99] Z. Qiang, X. Bao, and W. Ben, "MCM-48 modified magnetic mesoporous nanocomposite as an attractive adsorbent for the removal of sulfamethazine from water," Water Res., vol. 47, no. 12, pp. 4107-4114, 2013.

[100] M. Taheran, S. K. Brar, M. Verma, R. Y. Surampalli, T. C. Zhang, and J. R. Valéro, "Membrane processes for removal of pharmaceutically active compounds (PhACs) from water and wastewaters," Sci. Total Environ., vol. 547, pp. 60-77, 2016.

[101] J. Wang and L. Chu, "Irradiation treatment of pharmaceutical and personal care products (PPCPs) in water and wastewater: an overview," Radiat. Phys. Chem., vol. 125, pp. 56-64, 2016.

[102] G. Ungureanu, S. Santos, R. Boaventura, and C. Botelho, "Arsenic and antimony in water and wastewater: overview of removal techniques with special reference to latest advances in adsorption," J. Environ. Manage., vol. 151, pp. 326-342, 2015.

[103] T. S. Choong, T. G. Chuah, Y. Robiah, F. G. Koay, and I. Azni, “Arsenic toxicity, health hazards and removal techniques from water: an overview," Desalination, vol. 217, no. 1-3, pp. 139-166, 2007. 
[104] H. Su, Z. Ye, and N. Hmidi, "High-performance iron oxide-graphene oxide nanocomposite adsorbents for arsenic removal," Colloids Surf. Physicochem. Eng. Asp., vol. 522, pp. 161-172, 2017.

[105] J. A. Cotruvo, “2017 WHO Guidelines for Drinking Water Quality: First Addendum to the Fourth Edition," J.-Am. Water Works Assoc., vol. 109, no. 7, pp. 44-51, 2017.

[106] R. Zakhar, J. Derco, and F. Čacho, "An overview of main arsenic removal technologies," Acta Chim. Slovaca, vol. 11, no. 2, pp. 107-113, 2018.

[107] S. Lata and S. R. Samadder, "Removal of arsenic from water using nano adsorbents and challenges: a review," J. Environ. Manage., vol. 166, pp. 387-406, 2016.

[108] D. Mohan and C. U. Pittman Jr, "Arsenic removal from water/wastewater using adsorbents-a critical review," J. Hazard. Mater., vol. 142, no. 1-2, pp. 1-53, 2007.

[109] P. Sabbatini, F. Yrazu, F. Rossi, G. Thern, A. Marajofsky, and M. F. de Cortalezzi, "Fabrication and characterization of iron oxide ceramic membranes for arsenic removal," Water Res., vol. 44, no. 19, pp. 5702-5712, 2010.

[110] T. M. McCoy, P. Brown, J. Eastoe, and R. F. Tabor, "Noncovalent magnetic control and reversible recovery of graphene oxide using iron oxide and magnetic surfactants," ACS Appl. Mater. Interfaces, vol. 7, no. 3, pp. 2124-2133, 2015.

[111] R. Zacharia, H. Ulbricht, and T. Hertel, "Interlayer cohesive energy of graphite from thermal desorption of polyaromatic hydrocarbons," Phys. Rev. B, vol. 69, no. 15, p. 155406, 2004.

[112] J. Li et al., "Reduced aggregation and cytotoxicity of amyloid peptides by graphene oxide/gold nanocomposites prepared by pulsed laser ablation in water," Small, vol. 10, no. 21, pp. 4386-4394, 2014. 
[113] I. Ahmad et al., "Graphene oxide-iron oxide nanocomposite as an inhibitor of A $\beta 42$ amyloid peptide aggregation," Colloids Surf. B Biointerfaces, vol. 159, pp. 540-545, 2017.

[114] S. Yean et al., "Effect of magnetite particle size on adsorption and desorption of arsenite and arsenate," J. Mater. Res., vol. 20, no. 12, pp. 3255-3264, 2005.

[115] S. C. Tang and I. M. Lo, "Magnetic nanoparticles: essential factors for sustainable environmental applications," Water Res., vol. 47, no. 8, pp. 2613-2632, 2013.

[116] U. Schwertmann and R. M. Cornell, Iron oxides in the laboratory. John Wiley \& Sons, 2008.

[117] M. Storms, Surface interactions between nanoscale iron and organic material: potential uses in water treatment process units. University of Missouri-Columbia, 2015.

[118] J. Chen, B. Yao, C. Li, and G. Shi, “An improved Hummers method for eco-friendly synthesis of graphene oxide," Carbon, vol. 64, pp. 225-229, 2013.

[119] N. S. Abdullah, S. S. Sharifuddin, and M. Hussin, "Study on Adsorption of Mercury from Aqueous Solution on Activated Carbons Prepared from Palm Kernel Shell," in Key Engineering Materials, 2018, vol. 783, pp. 109-114.

[120] M. Li, C. Liu, Y. Xie, H. Cao, H. Zhao, and Y. Zhang, "The evolution of surface charge on graphene oxide during the reduction and its application in electroanalysis," Carbon, vol. 66, pp. 302-311, 2014.

[121] D. C. Marcano et al., "Improved synthesis of graphene oxide," ACS Nano, vol. 4, no. 8, pp. 4806-4814, 2010. 
[122] F. T. Johra, J.-W. Lee, and W.-G. Jung, "Facile and safe graphene preparation on solution based platform," J. Ind. Eng. Chem., vol. 20, no. 5, pp. 2883-2887, 2014.

[123] M. Li, C. Liu, Y. Xie, H. Cao, H. Zhao, and Y. Zhang, "The evolution of surface charge on graphene oxide during the reduction and its application in electroanalysis," Carbon, vol. 66, pp. 302-311, 2014.

[124] E. Repo, M. Mäkinen, S. Rengaraj, G. Natarajan, A. Bhatnagar, and M. Sillanpää, "Lepidocrocite and its heat-treated forms as effective arsenic adsorbents in aqueous medium," Chem. Eng. J., vol. 180, pp. 159-169, 2012.

[125] P. Lian, X. Zhu, S. Liang, Z. Li, W. Yang, and H. Wang, "Large reversible capacity of high quality graphene sheets as an anode material for lithium-ion batteries," Electrochimica Acta, vol. 55, no. 12, pp. 3909-3914, 2010.

[126] R. M. Cornell and U. Schwertmann, The iron oxides: structure, properties, reactions, occurrences and uses. John Wiley \& Sons, 2003.

[127] Z. Wang, D. Xu, Y. Huang, Z. Wu, L. Wang, and X. Zhang, "Facile, mild and fast thermal-decomposition reduction of graphene oxide in air and its application in highperformance lithium batteries," Chem. Commun., vol. 48, no. 7, pp. 976-978, 2012.

[128] H. Su, Z. Ye, and N. Hmidi, "High-performance iron oxide-graphene oxide nanocomposite adsorbents for arsenic removal," Colloids Surf. Physicochem. Eng. Asp., vol. 522, pp. 161-172, 2017.

[129] S. Stankovich et al., "Synthesis of graphene-based nanosheets via chemical reduction of exfoliated graphite oxide," carbon, vol. 45, no. 7, pp. 1558-1565, 2007.

[130] A. Lassoued, M. S. Lassoued, B. Dkhil, S. Ammar, and A. Gadri, "Synthesis, photoluminescence and Magnetic properties of iron oxide ( $\alpha$-Fe2O3) nanoparticles 
through precipitation or hydrothermal methods," Phys. E Low-Dimens. Syst. Nanostructures, vol. 101, pp. 212-219, 2018.

[131] V. Rebuttini, "Functional iron oxide-based hybrid nanostructures," 2014.

[132] Y. Zhang et al., "What factors control the mechanical properties of poly (dimethylsiloxane) reinforced with nanosheets of 3-aminopropyltriethoxysilane modified graphene oxide?," Polymer, vol. 54, no. 14, pp. 3605-3611, 2013.

[133] M. Baikousi et al., "Synthesis and characterization of $\gamma$-Fe2O3/carbon hybrids and their application in removal of hexavalent chromium ions from aqueous solutions," Langmuir, vol. 28, no. 8, pp. 3918-3930, 2012.

[134] F. Yu, S. Sun, J. Ma, and S. Han, "Enhanced removal performance of arsenate and arsenite by magnetic graphene oxide with high iron oxide loading," Phys. Chem. Chem. Phys., vol. 17, no. 6, pp. 4388-4397, 2015.

[135] A. Sharma, N. Verma, A. Sharma, D. Deva, and N. Sankararamakrishnan, "Iron doped phenolic resin based activated carbon micro and nanoparticles by milling: Synthesis, characterization and application in arsenic removal," Chem. Eng. Sci., vol. 65, no. 11, pp. 3591-3601, Jun. 2010, doi: 10.1016/j.ces.2010.02.052.

[136] W. Tang, Q. Li, S. Gao, and J. K. Shang, “Arsenic (III, V) removal from aqueous solution by ultrafine $\alpha$-Fe2O3 nanoparticles synthesized from solvent thermal method," J. Hazard. Mater., vol. 192, no. 1, pp. 131-138, 2011.

[137] S. Lin, D. Lu, and Z. Liu, "Removal of arsenic contaminants with magnetic $\gamma$-Fe2O3 nanoparticles," Chem. Eng. J., vol. 211, pp. 46-52, 2012. 
[138] L. M. Tung et al., "Superparamagnetic Iron Oxide@ Carbon Core-Shell Nanoparticles as Advanced Adsorbent for Efficient Removal of As (V) Ions From Wastewater," IEEE Trans. Magn., vol. 54, no. 6, pp. 1-6, 2018.

[139] Y. S. Ho and G. McKay, "The kinetics of sorption of divalent metal ions onto sphagnum moss peat," Water Res., vol. 34, no. 3, pp. 735-742, Feb. 2000, doi: 10.1016/S0043-1354(99)00232-8.

[140] M. Gallegos-Garcia, K. Ramírez-Muñiz, and S. Song, “Arsenic removal from water by adsorption using iron oxide minerals as adsorbents: a review," Miner. Process. Extr. Metall. Rev., vol. 33, no. 5, pp. 301-315, 2012.

[141] P. S. Goh, W. J. Lau, M. H. D. Othman, and A. F. Ismail, "Membrane fouling in desalination and its mitigation strategies," Desalination, vol. 425, pp. 130-155, 2018.

[142] H. Ravishankar, J. Christy, and V. Jegatheesan, "Graphene oxide (GO)-Blended polysulfone (PSf) ultrafiltration membranes for lead ion rejection," Membranes, vol. 8, no. 3, p. 77, 2018.

[143] C. Liyanage and K. Yamada, "Impact of population growth on the water quality of natural water bodies," Sustainability, vol. 9, no. 8, p. 1405, 2017.

[144] S. Azizi, I. Kamika, and M. Tekere, "Evaluation of heavy metal removal from wastewater in a modified packed bed biofilm reactor," PloS One, vol. 11, no. 5, p. e0155462, 2016.

[145] C. F. Couto, L. C. Lange, and M. C. S. Amaral, "A critical review on membrane separation processes applied to remove pharmaceutically active compounds from water and wastewater," J. Water Process Eng., vol. 26, pp. 156-175, 2018. 
[146] T. A. Kurniawan, G. Y. Chan, W.-H. Lo, and S. Babel, "Physico-chemical treatment techniques for wastewater laden with heavy metals," Chem. Eng. J., vol. 118, no. 12, pp. 83-98, 2006.

[147] H. J. Kim, H. R. Pant, J. H. Kim, N. J. Choi, and C. S. Kim, "Fabrication of multifunctional TiO2-fly ash/polyurethane nanocomposite membrane via electrospinning," Ceram. Int., vol. 40, no. 2, pp. 3023-3029, 2014.

[148] Y. Wang, R. Ou, Q. Ge, H. Wang, and T. Xu, "Preparation of polyethersulfone/carbon nanotube substrate for high-performance forward osmosis membrane," Desalination, vol. 330, pp. 70-78, 2013.

[149] X. Song, Z. Liu, and D. D. Sun, “Energy recovery from concentrated seawater brine by thin-film nanofiber composite pressure retarded osmosis membranes with high power density,” Energy Environ. Sci., vol. 6, no. 4, pp. 1199-1210, 2013.

[150] S. Yang et al., "Polypropylene membrane surface modification by RAFT grafting polymerization and $\mathrm{TiO} 2$ photocatalysts immobilization for phenol decomposition in a photocatalytic membrane reactor," Sep. Purif. Technol., vol. 83, pp. 157-165, 2011.

[151] H. Zhang et al., "Mineralization-inspired preparation of composite membranes with polyethyleneimine-nanoparticle hybrid active layer for solvent resistant nanofiltration," J. Membr. Sci., vol. 470, pp. 70-79, 2014.

[152] M. R. Esfahani et al., "Nanocomposite membranes for water separation and purification: Fabrication, modification, and applications," Sep. Purif. Technol., 2018.

[153] G. Wu et al., "Titanium dioxide-supported non-precious metal oxygen reduction electrocatalyst," Chem. Commun., vol. 46, no. 40, pp. 7489-7491, 2010. 
[154] C. Bian and G. Xue, "Nanocomposites based on rutile-TiO2 and polyaniline," Mater. Lett., vol. 61, no. 6, pp. 1299-1302, 2007.

[155] S. Rahim, M. S. Ghamsari, and S. Radiman, "Surface modification of titanium oxide nanocrystals with PEG," Sci. Iran., vol. 19, no. 3, pp. 948-953, 2012.

[156] Z. A. Boeva and V. G. Sergeyev, "Polyaniline: Synthesis, properties, and application,” Polym. Sci. Ser. C, vol. 56, no. 1, pp. 144-153, 2014.

[157] Z. Cai, C. Wee, and M. M. Benjamin, "Fouling mechanisms in low-pressure membrane filtration in the presence of an adsorbent cake layer," J. Membr. Sci., vol. 433, pp. 32-38, 2013.

[158] G. Gésan, G. Daufin, U. Merin, J.-P. Labbé, and A. Quémerais, "Fouling during constant flux crossflow microfiltration of pretreated whey. Influence of transmembrane pressure gradient," J. Membr. Sci., vol. 80, no. 1, pp. 131-145, 1993.

[159] D. J. Miller, S. Kasemset, D. R. Paul, and B. D. Freeman, "Comparison of membrane fouling at constant flux and constant transmembrane pressure conditions," J. Membr. Sci., vol. 454, pp. 505-515, 2014.

[160] T. Distefano and S. Kelly, "Are we in deep water? Water scarcity and its limits to economic growth," Ecol. Econ., vol. 142, pp. 130-147, 2017.

[161] S. Kaniou, K. Pitarakis, I. Barlagianni, and I. Poulios, "Photocatalytic oxidation of sulfamethazine," Chemosphere, vol. 60, no. 3, pp. 372-380, 2005.

[162] Z. Wan, J. Hu, and J. Wang, "Removal of sulfamethazine antibiotics using CeFegraphene nanocomposite as catalyst by Fenton-like process," J. Environ. Manage., vol. 182, pp. 284-291, Nov. 2016, doi: 10.1016/j.jenvman.2016.07.088. 
[163] K. Alamelu and J. Ali, "TiO2-Pt composite photocatalyst for photodegradation and chemical reduction of recalcitrant organic pollutants," J. Environ. Chem. Eng., vol. 6, no. 5, pp. 5720-5731, 2018.

[164] L. T. Nyamutswa, B. Zhu, D. Navaratna, S. Collins, and M. C. Duke, "Proof of Concept for Light Conducting Membrane Substrate for UV-Activated Photocatalysis as an Alternative to Chemical Cleaning," Membranes, vol. 8, no. 4, p. 122, 2018.

[165] H. Vatankhah, C. C. Murray, J. W. Brannum, J. Vanneste, and C. Bellona, "Effect of pre-ozonation on nanofiltration membrane fouling during water reuse applications," Sep. Purif. Technol., vol. 205, pp. 203-211, 2018.

[166] Z. Geng et al., "Self-cleaning anti-fouling hybrid ultrafiltration membranes via side chain grafting of poly (aryl ether sulfone) and titanium dioxide," J. Membr. Sci., vol. 529, pp. 1-10, 2017.

[167] R. Zhu et al., "Mechanism of humic acid fouling in a photocatalytic membrane system,” J. Membr. Sci., vol. 563, pp. 531-540, 2018.

[168] L. De Angelis and M. M. F. de Cortalezzi, "Ceramic membrane filtration of organic compounds: Effect of concentration, $\mathrm{pH}$, and mixtures interactions on fouling," Sep. Purif. Technol., vol. 118, pp. 762-775, 2013.

[169] L. T. Nyamutswa, B. Zhu, S. F. Collins, D. Navaratna, and M. C. Duke, "Light conducting photocatalytic membrane for chemical-free fouling control in water treatment," J. Membr. Sci., p. 118018, 2020.

[170] M. Hussain, "Ferroxane derived ceramic composite material as catalysts for heterogenous Fenton reactions for dyes and pharmaceutical removal in water," $\mathrm{PhD}$ Thesis, University of Missouri-Columbia, 2016. 
[171] S. Leong, A. Razmjou, K. Wang, K. Hapgood, X. Zhang, and H. Wang, "TiO2 based photocatalytic membranes: a review," J. Membr. Sci., vol. 472, pp. 167-184, 2014.

[172] S. Kaniou, K. Pitarakis, I. Barlagianni, and I. Poulios, "Photocatalytic oxidation of sulfamethazine," Chemosphere, vol. 60, no. 3, pp. 372-380, 2005.

[173] C. Zhou et al., "Visible-light-driven photocatalytic degradation of sulfamethazine by surface engineering of carbon nitride: Properties, degradation pathway and mechanisms," J. Hazard. Mater., vol. 380, p. 120815, 2019.

[174] M. Diantoro, A. Kusumaatmaja, and K. Triyana, "Study on photocatalytic properties of $\mathrm{TiO} 2$ nanoparticle in various $\mathrm{pH}$ condition," in Journal of Physics: Conference Series, 2018, vol. 1011, no. 1, p. 012069.

[175] C. Zhao, M. Pelaez, D. D. Dionysiou, S. C. Pillai, J. A. Byrne, and K. E. O'Shea, "UV and visible light activated $\mathrm{TiO} 2$ photocatalysis of 6-hydroxymethyl uracil, a model compound for the potent cyanotoxin cylindrospermopsin," Catal. Today, vol. 224, pp. 70-76, 2014.

[176] D. Friedmann, C. Mendive, and D. Bahnemann, "TiO2 for water treatment: Parameters affecting the kinetics and mechanisms of photocatalysis," Appl. Catal. B Environ., vol. 99, no. 3, pp. 398-406, Sep. 2010, doi: 10.1016/j.apcatb.2010.05.014.

[177] C. Zhao, M. Pelaez, D. D. Dionysiou, S. C. Pillai, J. A. Byrne, and K. E. O'Shea, "UV and visible light activated $\mathrm{TiO} 2$ photocatalysis of 6-hydroxymethyl uracil, a model compound for the potent cyanotoxin cylindrospermopsin," Catal. Today, vol. 224, pp. 70-76, 2014. 
[178] T.-W. Tzeng et al., "Photolysis and photocatalytic decomposition of sulfamethazine antibiotics in an aqueous solution with TiO 2," Rsc Adv., vol. 6, no. 73, pp. 6930169310, 2016.

[179] Z. Hao, C. Guo, J. Lv, Y. Zhang, Y. Zhang, and J. Xu, "Kinetic and mechanistic study of sulfadimidine photodegradation under simulated sunlight irradiation," Environ. Sci. Eur., vol. 31, no. 1, p. 40, Dec. 2019, doi: 10.1186/s12302-019-0223-z.

[180] N. Zhang, G. Liu, H. Liu, Y. Wang, Z. He, and G. Wang, "Diclofenac photodegradation under simulated sunlight: Effect of different forms of nitrogen and Kinetics," J. Hazard. Mater., vol. 192, no. 1, pp. 411-418, Aug. 2011, doi: 10.1016/j.jhazmat.2011.05.038.

[181] Y. Li, X. Qiao, Y. Zhang, C. Zhou, H. Xie, and J. Chen, "Effects of halide ions on photodegradation of sulfonamide antibiotics: formation of halogenated intermediates," Water Res., vol. 102, pp. 405-412, 2016.

[182] R. Luo et al., "Singlet oxygen-dominated non-radical oxidation process for efficient degradation of bisphenol A under high salinity condition," Water Res., vol. 148, pp. 416-424, 2019.

[183] X. Zhuang et al., "Enhanced Sulfamerazine Removal via Adsorption-Photocatalysis Using Bi2O3-TiO2/PAC Ternary Nanoparticles,” Water, vol. 12, no. 8, p. 2273, 2020. 


\section{VITA}

Mohammed M. Numaan was born on January $1^{\text {st }}, 1984$ in Tikrit, Iraq. From 20012005, he completed his bachelor's degree in civil engineering at Tikrit University. He got his master's degree in Civil and Environmental Eng./water quality management at Tikrit University in 2008. He has been working as a faculty member in Environmental Eng. Dept., and he published many articles in his field. In January 2016, he was sent by the Iraqi Ministery of Higher education to complete his Ph.D from the University of MissouriColumbia/Civil and Environmental Eng. dept. He received his Ph.D degree in water

treatment on May 2021. He will start to find new solutions for contaminants removal from water. 